\title{
Satellite Power System (SPS) Mapping of Exclusion Areas For Rectenna Sites
}

October 1978

Prepared for:

U.S. Department of Energy

Office of Energy Research

Satellite Power System Project Office

Under Contract No. EG-77-C-01-4024

\section{DOE/NASA}

Satellite Power System

Concept Development and

Evaluation Program 


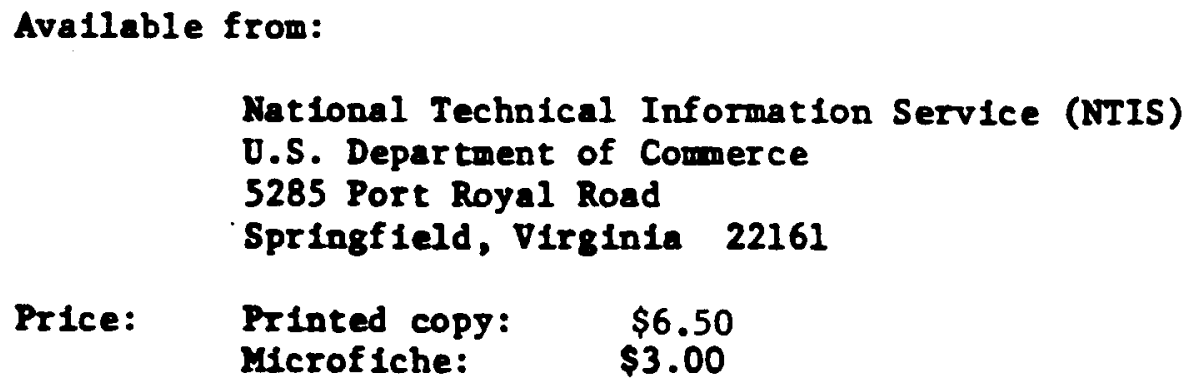




\section{Satellite Power System (SPS) Mapping of Exclusion Areas For Rectenna Sites}

October 1978

Prepared by:

James B. Blackburn, Jr.

Bill A. Bavinger

PRC Energy Analysis Company

McLean, Virginia 22102

Prepared for:

U.S. Department of Energy

Office of Energy Research

Satellite Power System Project Office

Washington, D.C. 20545

Under Contract No. EG-77-C-01-4024

\section{DOE/NASA}

Satellite Power System

Concept Development and

Evaluation Program 


\section{NOTICE}

This report was prepared as an account of work sponsored by the United States Government. Neither the United States nor the United States Department of Energy, nor any of their employees, makes any warranty, express or implied, or assumes any legal liability or responsibility for the accuracy, completeness, or usefulness of any information, apparatus, product, or process disclosed, or represents that its use would not infringe privately owned rights. Reference herein to any specific commercial product, process, or service by trade name, mark, manufacturer, or otherwise, does not necessarily constitute or imply its endorsement, recommendation, or favoring by the United States Government or any agency thereof. The views and opinions of authors expressed herein do not necessarily state or reflect those of the United States Government or any egency thereof. 


\section{Acknowledgements}

Project Staff

James B. Blackburn, Jr. - Principal Investigator School of Architecture

Bill A. Bavinger - Co-Principal Investigator School of Architecture

Arthur A. Few - Co-Principal Investigator -

Space Physics Department

Peter G. Rowe - School of Architecture

J. V. Leeds - Electrical Engineering Department

Research Assistants

Abdullah Al-Homomeidy - School of Architecture

Francis Essien - School of Architecture

John Gaulden - School of Architecture

Emilio Giralt - School of Architecture

Kevin Newman - School of Architecture

Sara Procianoy - School of Architecture

Mottaz Salama - School of Architecture

Perry Winston - School of Architecture

Laboratory Assistants

Jabir Al-Hilali - School of Architecture

Tim Barry - School of Architecture

Owen Richards - School of Architecture

William Turner - School of Architecture

Michael Welsh - School of Architecture

Secretarial

Christina Salas - Space Physics Department

Special Acknowledgements

Special acknowledgement is extended to Allan D. Kotin, Economic Consultant, Los Angeles, California, with whom we worked in developing many aspects of this report. His work is reported in a separate document on Resource Requirements For the Satellite Power System. Thanks are also extended to Wayne Smith and John Freeman of the Rice University Space Solar Power Research Program. Also, a special thanks to Joan Neagli, of Neagli's Secretarial Service for typing this report.

The authors wish to acknowledge the following people for the time taken to review the draft of this paper and prepare written comments on it:

$T$. Stephen Cheston of the Georgetown University Graduate School, Paul E. Custer of the National Science Foundation and Dr. James W. Moyer of Southern California Edison Co. 


\section{Executive Summary}

This report sets forth the results of a study by Rice University to determine those areas of the United States that were not available as potential sites for receiving antennas that are an integral part of the Satellite Power System (SPS) concept. Under the current SPS program, 60 satellite-rectenna pairs would be developed. Each pair would produce 5 gigawatts of power and the rectenna would require the dedication of approximately 50,000 acres of land per site. Therefore, 60 sites of 50,000 acres each, totalling approximately 3 million acres, will be required.

This study's approach to finding where, or even if, 60 such sites existed was to determine those areas of the United States where the rectenna could not be sited. 36 variables with the potential to exclude the rectenna were mapped and coded into the Rice University Computer System. Some of these variables absolutely exclude a rectenna from locating within the area of its spatial influence, and other variables potentially exclude the rectenna. These maps of variables were assembled from existing data and were mapped on a grid system of the United States. Each grid square was $26 \mathrm{~km}$ on a side.

The analysis of the information was completed by utilizing overlay or sieve analysis. Under this approach, variables were laid over other variables and the composite of this union of variables would represent areas where the rectenna could not be located. This report shows, in Section IV, 11 summary maps that indicate the land areas excluded as rectenna sites under various combinations of variables. The areas in "white" are not excluded as sites and are considered as "eligible" areas. It is important to note that the only interpretation to be given to these eligible areas is that they were not ruled out as sites. The areas should be studied in more detail to determine where rectennas could be located within these subset areas.

These various summary maps go from being less rectrictive to being more restrictive with respect to sites. Under Summary Map 1, approximately $50 \%$ of the United States was excluded as potential sites, with Summary Map 8 excluding 73\% of the United States and with Summary Map 9 excluding $83 \%$. Each summary map is accompanied by a detailed statistical analysis which describes the "eligible" areas on a state by state basis with respect to other variables not directly utilized in the creation of the summary maps.

Due to the complex nature of siting studies such as this, the Rice University team feels that this report is certainly not definitive with respect to siting. However, the methodology utilized appears appropriate to the problem of siting. Future work will be required prior to definitive sites being identified, and a major attempt should be made to coordinate additional work with existing Federal governmental data management systems. 


\section{TABLE OF CONTENTS}

Page

I. Introduction ................ 1

II. Methodology ............. 5

A. Mapping of Variables .............. 5

B. Analysis of Data .............. 11

1. Data Encoding Storage Access and Display ...... 12

2. Data Analysis.............. 15

III. Discussion of The Variables. . . . . . . . . . . 17

A. Land and Water................ 17

B. Federal Lands ................. . . . 19

1. National Recreation Areas. . . . . . . . . . . 19

2. Indian Reservations. ............. 21

3. Military Reservations. . . . . . . . . . . . . 22

4. Other Federal Lands. . . . . . . . . . . . . 22

C. National Forests . . . . . . . . . . . . . 23

D. Population ..................... 25

1. Standard Metropolitan Statistical Areas. . . . . . . 27

2. Population Density Greater Than 50 Persons

per Square Mile............. 29

3. Adjusted Population Distribution ......... 30

E. Wetlands ............... . . 31

1. Marshes. . . . . . . . . . . . . . . . . 33

2. Wetlands .................. 33

F. Topography Unacceptable. . . . . . . . . . . 33

G. South Slopes................. 36

H. Navigable Waterways. . . . . . . . . . . . . 38

I. Interstate Highways. . . . . . . . . . . . . . 38

J. Endangered Species Habitats. . . . . . . . . . . . 41

K. "Prime Agricultural Lands" . . . . . . . . . . . . 43

L. Flyways of Migratory Waterfowl . . . . . . . . . 47

M. Seismic Hazards. . . . . . . . . . . . . . . . . . . . . 49

N. 40 Degree Latitude ............... . 51

0 . Winds Greater Than 50 Knots. . . . . . . . . . . . 53

P. Number of Days With Hail . . . . . . . . . . . . . 55

Q. Number of Days With Thunderstorms. . . . . . . . 55

R. Sheet Rainfall .............. 58

S. Acid Rain................ . . 53

T. States...................... 61

U. Conclusion .................... 61

IV. Analysis of The Data ............ 63

Summary Map 1. . . . . . . . . . . . . . . 66

Summary Map 2. . . . . . . . . . . . . . . . . . . . . 69

Summary Map 3. .................. . . 72

Summary Map 4................. . . 75 
TABLE OF CONTENTS - (continued)

IV. Analysis of The Data - (continued)

Summary Map 5 .................. . . 78

Summary Map 6 . . . . . . . . . . . . . . . . 81

Summary Map 7 . . . . . . . . . . . . . . 84

Surmary Map 8 . . . . . . . . . . . . . . . . . 87

Summary Map 9 . . . . . . . . . . . . . . 99 90

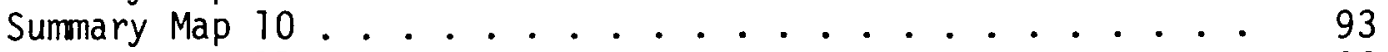

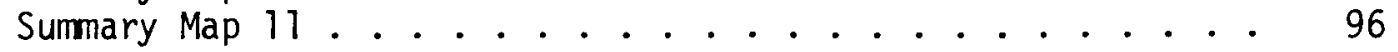

V. Conclusions and Suggestions For Future Work. . . . . . . 99

Appendix A............... 103

Appendix B . . . . . . . . . . . . 107

References .................... 111 
MAPPING OF EXCLUSION AREAS FOR RECTENNA SITES

I. INTRODUCTION

In determining the overall feasibility of the Satellite Power System (SPS), many important issues must be analyzed in great detail. One major area of inquiry concerns where the receiving antennas for microwaves beamed from space can be located within the continental United States. As set forth in the reference design, these receiving antennas will require sites of approximately 50,000 acres each, with 60 such sites being required across the United States. These 60 sites, therefore, would require the dedication of approximately 3,000,000 acres of land for the receiving antennas exclusive of land required for transmission facilities, access roads and other activities related to the land use.

The major purpose of this research effort was to determine where, or even if, 60 such sites existed. The approach utilized in this study was one of excluding land areas from consideration rather than seeking sites which had desirable characteristics. In oicher words, certain land areas cannot be considered as being eligible for rectenna sites since they already are dedicated land areas (as with existing cities and urban areas) or because of certain environmentally related characteristics that preclude other uses. If this set of variables can be determined and mapped, the land areas that were not mapped would emerge as "eligible" areas because no critical (or exclusion) variables were present in these areas.

In conjunction with Allan Kotin, a set of important locational variables was compiled. These variables are included in the white paper on Resources by Allan Kotin, and an extensive list of references and a review of pertinent literature is also included in the Kotin Report.

Even though the Kotin Report contains an extensive review of 
pertinent aspects of the Satellice Powe: System and the Recterna, a short summary of certain characteristics is needed to place this locational work in a system context. Uncer the SPS, a large sate?lite in gensynchronous orbit at the equator beams microwaves to a receiving antenna on the earth's surface. The satellite and rectenna are sized for 5 gigawatts D.C. power output. The satellite consists of a flat solar array with a transmitting antenna ( $1 \mathrm{~km}$ diameter) on one end. The receiving antenna is elliptical $\mathrm{n}$ shape and is $13 \mathrm{~km}$ on tne north-south axis and $9 \mathrm{~km}$ on the east-west axis. This design is based upon a reference latitude of approximately 34 degrees north. The satellite's position in geosynchronous orbit means that the circular microwave beam will project an ellipse on the earth's surface anywhere but at the equator. Therefore, the north-south dimension of the rectenna will increase as a site moves north from the 34 degrees north reference position.

The receiving antenna is composed of a large number of 10 meter $x$ 10 meter receiving panels. These panels are elevated in certain designs and are on the land surface in other designs. These panels, whether on the land surface or elevated, will cover approximately 25,000 acres. The power density at the center of the rectenna will be approximately 23 milliwatts per square centimeter with the power density diminishing to 1 milliwatt per square centimeter at the edge of the rectenna. Although the United States standard for microwave exposure is $10 \mathrm{~mW} / \mathrm{cm}^{2}$, standards in other countries such as the Soviet Union are much more restrictive. For this reason, the reference site in the Kotin study and in this Rice University study contains a $2 \mathrm{~km}$ buffer zone surrounding the rectenna. This makes the configuration of the site a $17 \mathrm{~km} \times 13 \mathrm{~km}$ ellipse. The use of a $2 \mathrm{~km}$ buffer zone lowers the microwave power density to $0.1 \mathrm{~mW} / \mathrm{cm}^{2}$ at the edge of the buffer. This level is 10 times higher than the Russian standard for non-occupational exposure. The current implementation plan calls for 60 such satellite/rectenna 
pairs to be constructed. Construction will commence in 1996 with the first system operating by the year 2000. From the year 2000 to the year 2030, two satellite/rectenna pairs will become operational each year, totalling 60 pairs. The total land area estimated to be required for the 60 rectennas (with a $2 \mathrm{~km}$ buffer zone) is approximately $13,300 \mathrm{~km}^{2}$ (over 5100 square miles), slightly less than $0.2 \%$ of the total land area of the continental United States.

Therefore, the following factors are important from the perspective of seeking 60 sites. First, some 55,000 acres will be required for each rectenna. Of this, approximately $50 \%$ will be cleared, with the remaining $50 \%$ being left uncleared but with restricted access due to microwave levels. Second, microwaves levels will be measureable beyond the rectenna with the buffer zone, and such levels may interfere with radio and other types of communications and navigation equipment. The extent of this radio frequency interference is not known, but the rectenna and the microwave beam per se are considered as a problem from a radio communications standpoint in this siting study. Third, the possibility of riultiple use beneath the receiving antenna has been raised, but this siting study assumes that the land area directly beneath the receiving antenna will be lost from functional, if not physical, standpoint. In this study, no attempt was made to quantify additional 1 and areas required for access roads, construction buildings and transmission lines.

In the sections which follow, the siting methodology is discussed first. Then, a detailed description and analysis of the data used will be presented. Section IV presents the results of certain analytical efforts and Section $V$ lists our conclusions and suggestions for future work. 


\section{METHODOLOGY}

The methodology utilized in this analysis consisted of three distinct steps. The first step involved the compilation and mapping of 36 data items. The second step involved the encoding of these 36 variables into Rice University's computer system. At this stage, the 48 states were also coded and entered as data items. The third step involved sequentially overlaying variables to produce "synthesis" maps, representing compilations across specified variables. In this manner, a declining number of eligible areas were identified in each map. Further the impacts of the addition of certain new variables can be viewed directly. For each of these synthesis maps, a tabular surmary was compiled which offered additional information concerning the grid cells that emerge as "eligible"

\section{A. MAPPING OF VARIABLES}

As mentioned earlier, the Rice University team worked with Allan Kotin in determining a list of important locational variables. Once these variables were identified, the mapping exercise was initiated. Those variables that are mapped and discussed subsequently in this paper are:

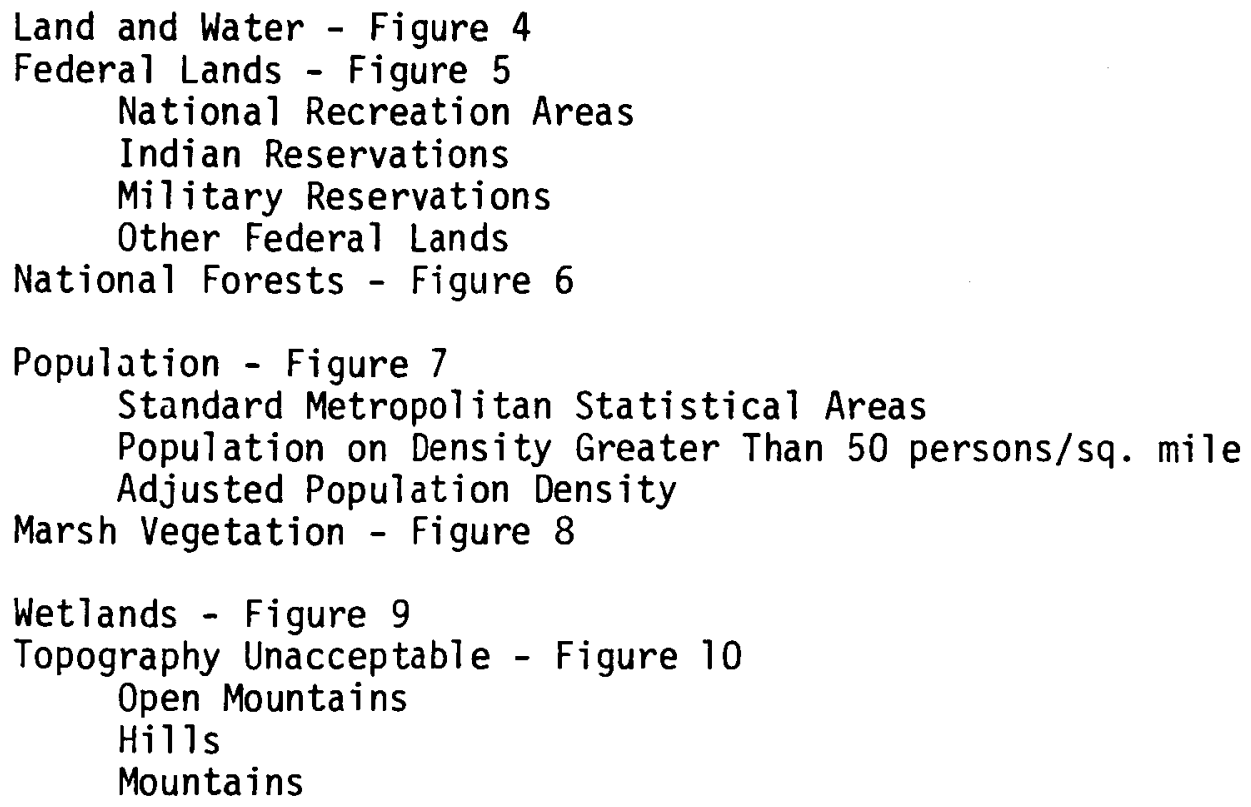


Topography Unacceptable, South Slopes - Figure 11

Open Mountains

Hills

Mountains

Navigable Waterways - Figure 12

Interstate Lighways - Figure 13

Endangered Species' Habitats - Figure 14

Land In Cultivation - Figure 15

Irrigated Land

cropland

Land Suitable for Cultivation - Figure 16

Greater Then $67 \%$ suitab?e

$50 \%$ to $67 \%$ suitable

Flyways of Migratory Waterfowl - Figure 17

Seismic Hazards - Figure 18

Major Damage Potential

Moderate Damage Potential

40 Degree Latitude - Figure 19

Windstorms - Figure 20

$2 \%$ Probability of Winds Greater than 50 Knots

$1 \%$ Probability of Winds Greater than 50 knots

Hail - Figure 21

Thunderstorms - Figure 22

Sheet Rainfall - Figure 23

Acid Rainfall - Figure 24

$\mathrm{PH}$ Between 4.0 and 5.0

$\mathrm{PH}$ Less than 4.0

Once the data was gathered for each of the above variables, the information was entered onto a map of the United States that was

divided into grid cells. These grid cells were used for coding purposes, and the translation of the information to this form was essential to the completion of the project.

Prior to entering the information on the gridded map of the United States, a decision was made concerning the size of the grid cell. The size of the grid cell represents a compromise between the time and resources available for the task and the desire to obtain as much spatial resolution as possible. The result was the choice of a grid square approximately $26 \mathrm{~km}$ or 16.2 miles on a side. The total land area within the grid square is approximately 170,000 acres.

In Figure 1 , the relationship of the rectenna site to the grid square can be seen. The rectenna occupies approximately $30 \%$ of a single grid square. While it is arguable that a greater resolution 


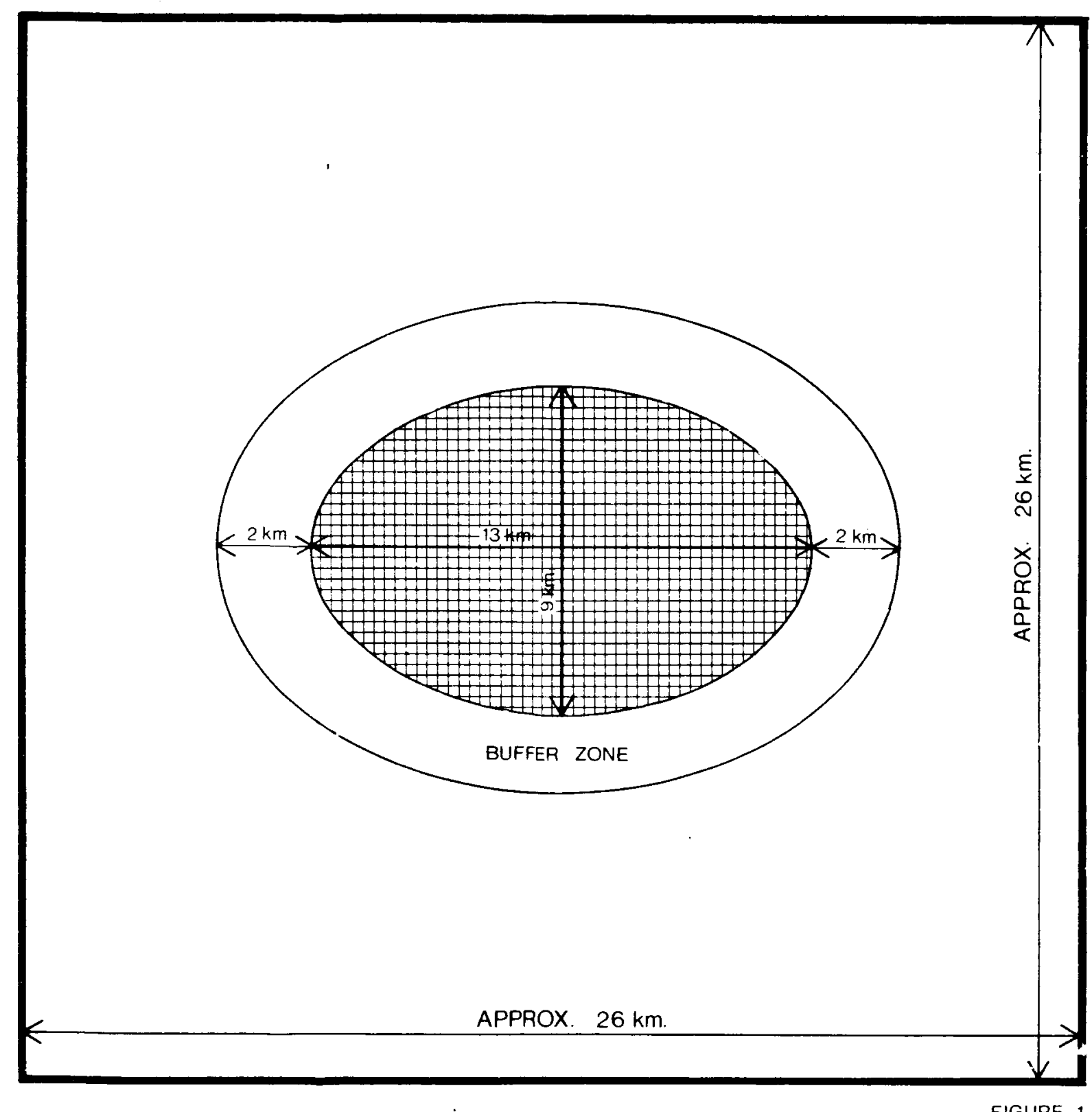

RELATIONSHIP OF RECEIVING ANTENNA TO GRID SQUARE 


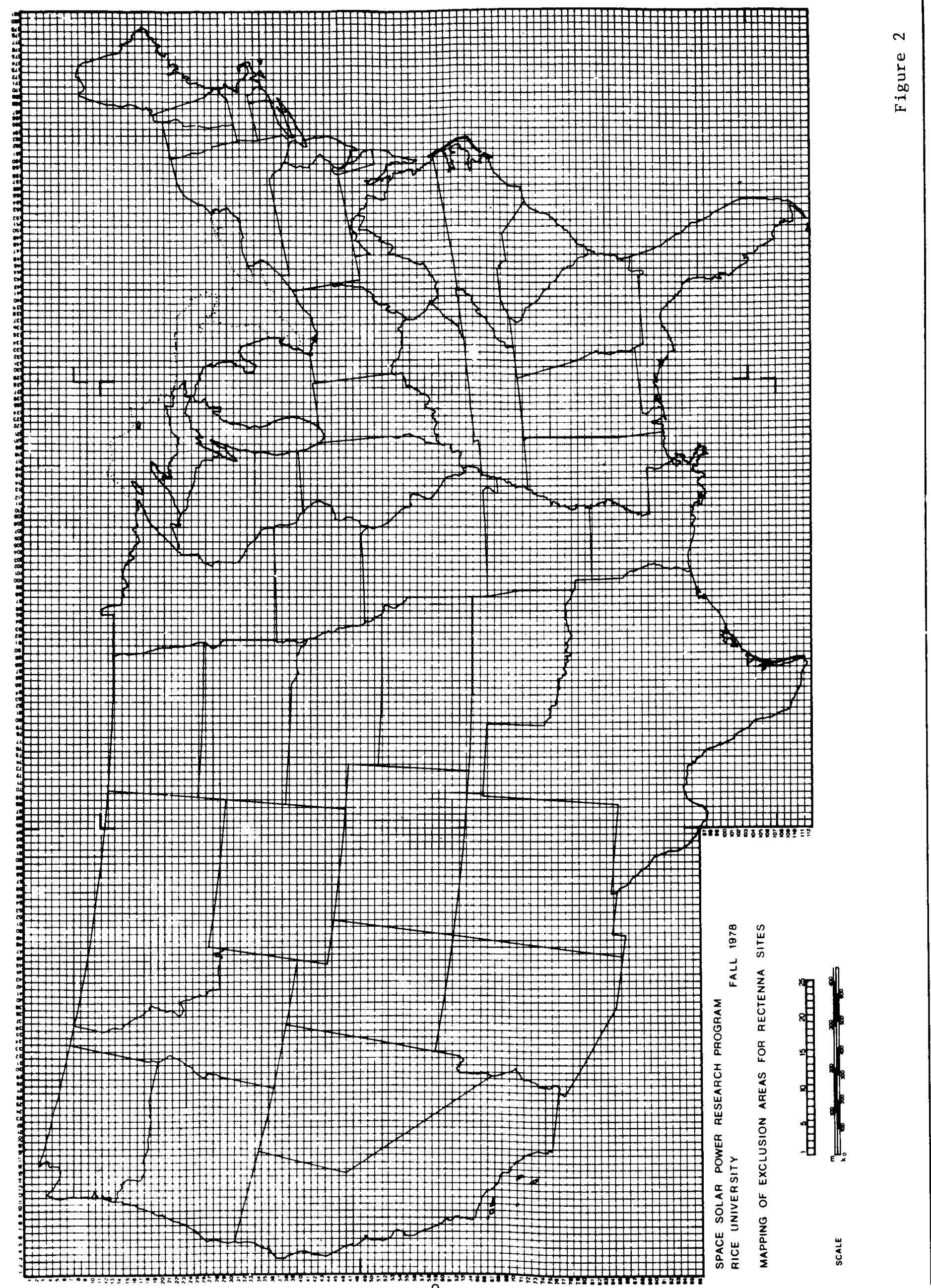


would have been aesirable, it is the opinion of the Rice University research team that this resolution is sufficient to be meaningful froin a locatiorial standpoint. Therefore, all of the maps of these variables will be presented in a $26 \mathrm{~km}$ grid cell format. Figure 2 shows the gridded map of the United States.

The mapping of the information at the grid cell level required a determination of the presence or absence of the variable from grid cells across the United States. Certain variables were coded as being present if any portion of the variable was indicated as being present within the grid cell whereas other variables were mapped as being present only if approximately $50 \%$ or more of the cell contained the variable. The discussion in Section III offers an explanation of the coding procedure on a variable by variable basis.

Due to time constraints and/or data limitations, certain variables considered to be important from a locational standpoint were not mapped in this study. Those variables of concern that were not treated include:

Local or State Owned Land (State and Local Parks)

Poor Soils

High Groundwater Table

Highways Other Than Interstate Highways

Airports and Air Approach Corridors

Major Air Corridors

Railroads

Dust Storm Areas

Wildlife Habitats (Other Than Designated Endangered Species) Very Poor Air Quality

Near Major/Numerous RF Sources

As will be explained in Section III, "Discussion of the Data", many of these variables are represented to some degree through other variables that were mapped. For instance, the mapping of Standard Metropolitan Statistical Areas should include much of the land area that is dedicated to major airports and major air approach corridors, and would include major/numerous RF sources. Nonetheless, it is important to note that the above variables were not mapped independently. 


\section{B. ANALYSIS OF THE DATA}

The analysis of the date consisted of two different yet complementary procedures. The first procedure concerned the decision on a variable by variable basis that (1) the variable was an absolute exclusion variable or (2) the variable was a potential exclusion variable. Due to the preliminary stage of the reference design, the analysis of the importance of most variables was from the perspective of the dedication of land areas for other uses. Generally, those variables that represented land uses that could not be preempted by the rectenna were identified as absolute exclusion variables. The remaining variables were treated as potential exclusion variables.

Further, there are two types of potential exclusion variables. These are (1) variables that represent an environmental or resource constraint that may not be addressed through design modifications and (2) those variables that exhibit the capacity to exclude the reference system but that can be addressed through design modifications. At this time, it is difficult to speculate upon which of the non-design related potential exclusion variables will emerge as critical locational criteria. For example, many variables in this category are identified because of unique legal/institutional problems associated with their use (i.e., the use of Indian lands for sites) and others are identified due to the uncertainty of the microwave effects (i.e., the effects upon migratary waterfowl). Due to the disparity between such variables, the analytical approach is designed with an ability to aggregate and disaggregate the variables.

The variables indicated as being design :ariables appear easier to assess. In many respects, these variables will cause design modifications if the rectenna is to be located in areas where these variables occur. In turn, addressing these variables will require additional dollars to be expended and modifications in the cost expectations relative to the rectenna will result. Therefore, these variables appear 
more applicable in the context of understanding the full costs of building the rectenna. These environmental variations were not addressed in the reference system explicitly, although they are implicitly addressed in the range of costs to be expected (lowest cust and highest cost per satellite and rectenna pair).

Additionally, certain of the variables mapped in this study are potential inclusion variables. In other words, there are aspects of these variables that may make location within their spatial dominion desirable. For example, "other federal lands" (excluding national forests) would be potentially good sites since $25 \%$ or more of the mapped area is under federal control. These other federal lands are relatively inexpensive; controversial regarding the aggregation of a 50,000 acre contiguous parcel may be less than would be the case where private property would have to acquired for the entirety of the site.

Therefore, there are many nuances of the information presented in Section III. For this reason, a major attempt was made in this study to fully document the approach and assumptions so that additional variables can be considered and the impact of individual variables can be traced. In other words, a critical element of this approach is to determine those variables that "drive" the locational decision. A further result may be the identification of options that have not been considered heretofore.

1. Data Encoding, Storage, Access and Display:

Prior to analysis per se, the data utilized for analytical purposes was entered into the Rice Architecture Geographic Information System (RAGIS). The basic elements of RAGIS are shown in Figure 3 . One of the central features of the information system is the use of a nost language to support and control its operations. The computer language Speakeasy (developed at Argonne National Laboratory, see Cohen and Pieper, 1977) was used since it stresses the use of English syntax, conversational inpui-output modes and on-line interactions. Speakeasy is an extensible language that comes with broad general 


\section{RAGIS \\ SYSTEM DIAGRAM}

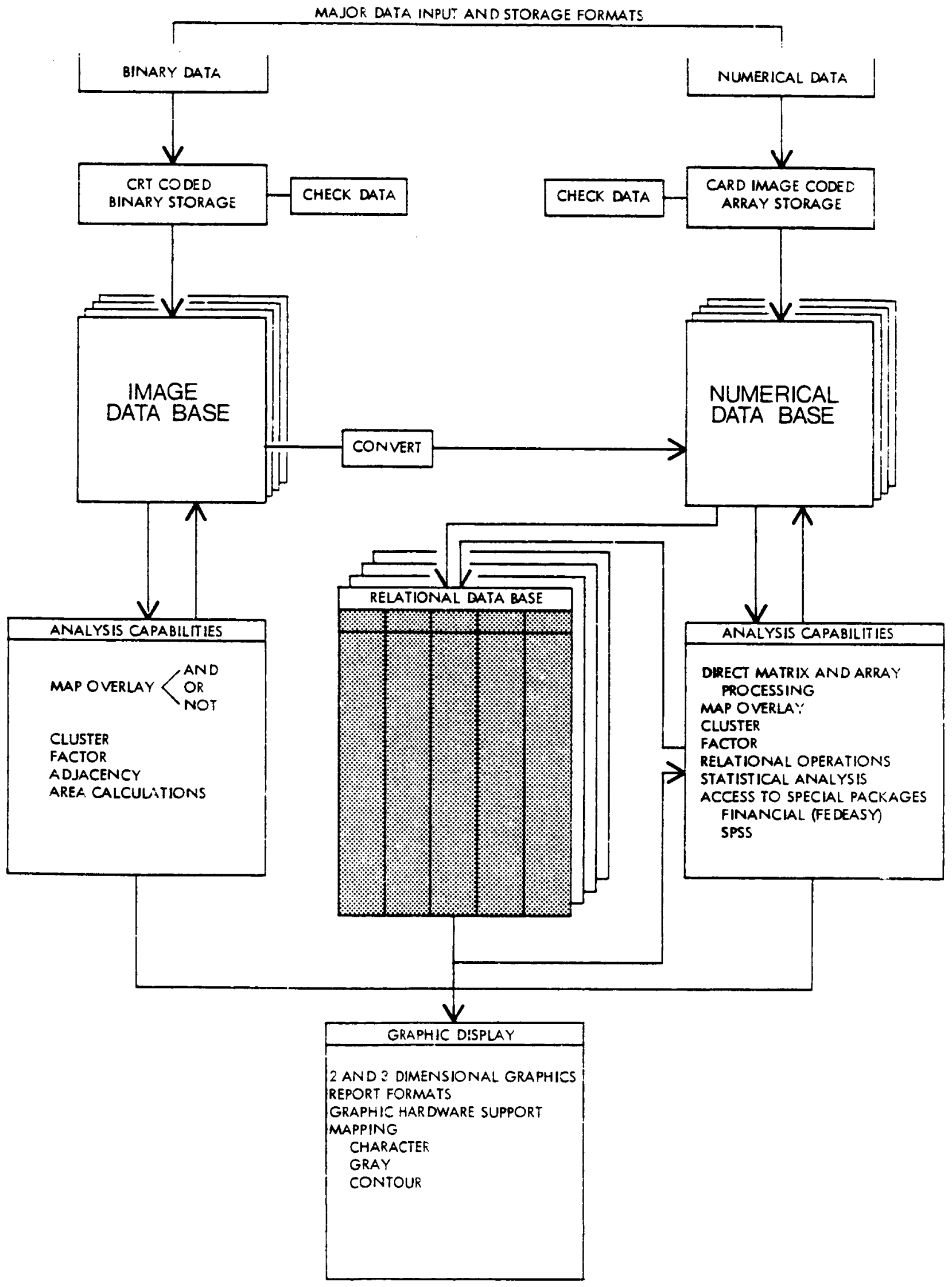


operating capabilities but also allows users to include functions and operations peculair to their classes of problems. These special functions or operations may in fact take the form of algorithms written and compiled in other system supported languages, such as FORTRAil, and simply linked into Speakeasy's processor. These linked load modules are called linkules. To the user linkules are a vocabulary of English language key words that allow the associated programs to be called and executed by name. During the development of RAGIS, an extensive number of linkules specifically related to mapping and spatial analysis were established. In fact, RAGIS has become a subsystem within Speakeasy consisting of more 250 programs and special operations for geographic information processing.

Data is encoded through the use of a CRT (Cathocie Ray Tube). A data encoding linkule establishes a uniform grid of cells (64 $\times 48$ ) as a two dimensional array across the CRT screen. Maps or other special features to be encoded are reproduced at the appropriate scale as black and white film positives. These film positives were taken from the 21 maps of the United States, with six individual 64 x 48 grid "cards" being required for each map to be encoded. The film positive is placed on the screen and the pattern of each feature is then visually coded in a raster-like fashion as a dot pattern. In this study, a feature was coded as either present or absent within the appropriate grid cell. Checking the encoded data is accomplished on-line at the CRT screen by simply displaying each dot pattern and checking it against the film positive overlay.

The coded data is stored in the computer memory as a logical bit stream with each image forming a distinct binary pattern. This form of storage utilizes the computer's memory switches and results in considerable savings for basic storage, retrieval and display operations. Each data pattern is assigned a unique alphanumeric code or name and becomes like any other word in the system from the user's standpoint. Access is achieved by simply calling for the pattern by name and having 
it displayed or integrated into a computational sequence in the appropriate manner.

In addition to various spatial display characteristics, RAGIS also employs a relational data base management subsystem Culled Rspeak (Schlicting, 1977) which complements other existing analytical capabilities such as multi-variate clustering and factoring. The major importance of the relational data base management capauilities relates to the ability it offers in understanding or perceiving the results of the analysis vis a vis the raw data. One use of the relational capabilities will be to analyze the results of a certain analytical exercise with respect to other variables that were not utilized in the analysis directly. In other words, through the development of tables of data, one can gain many insights about analytical results independently from the information gained directly through the analysis.

\section{Data Analysis}

In the determination of areas that are "eligible" for rectenna sites, the Rice University approach first identifies areas from which the rectenna would be excluded. The areas remaining after the exclusion area had been determined would be the "eligible" areas. This relatively simple concept is achieved through the use of overlay or sieve analysis. Generally, this technique requires that a list of environmental features be prepared and arranged so that features are ranked in order of assumed decreasing (or increasing) order of importance. In the case of this determination of exclusion areas, the absolute exclusion variables would be considered first with the potential exclusion variables and the design variables considered subsequently. These variables are displayed on transparent maps, and by overlaying these maps, the areas of composite shading becomes apparent. Unlike other uses whereby the darkness of the shading indicates the degree of developability (or non-developability), the approach utilized in this study weights all absolute exclusion variables equally. Therefore, the new set resulting from the union of mapped variable set $A$ with 
mapped variable set $B$ would be exclusion area 1. In this respect, the methodology utilized for this study differs from traditional studies such as those by Lewis (1962), Alexander and Manheim (1962) and McHarg (1969) because these planners were concerned with the intersection of the mapped variable sets and with interpretations of cevelopment suitability based upon the number of variables intersecting. Although the previously cited authors used map overlays rather than computer generated overlays, the applicability of a computer system to this type of analysis sould be obvious. Attempts io computerize the approach are fairly numerous (Ward and Grant, 1970; Krauskopf and Bunde, 1972; Rowe and Deleon, 1973), and several recent attempts to innovate the basic technique are well summarized by Hopkins (1976).

Therefore, the approach utilized for data analysis will be as follows. First, an initial overlay map will be composed by containing five variable sets to determine their cumulative coverage. This initial overlay will result in overlay Map 1, which will become a new variable. This resultant map will have shaded areas (exclusion areas) and white areas (eligible areas). A statistical profile will then be generated (utilizing the Rspeak capabilities) which will describe the number of eligible sites (grid cells) by state, and this table will also contain information about some of the design variables such as the number of eligible sites above 40 degrees north latitude, the number of sites subject to acid rain, etc.

Then, Exclusion Map 1 will be added to variable 6 to form Exclusion Map 2. The same statistical profile will then be used to describe the eligible areas. Then, additicnal variables will be added until several exclusion maps, each being more restrictive, will be compiled. In this manner, the effects of certain variables will be clearly identified.

Finally, these exclusion maps will be overlayed with at least one and possibility twc informational maps that will place the resulting 
sites in a better perspective from the standpoint of (1) the existing power distribution system and (2) the existing interstate highway system. In this manner, a strong description of eligible sites will exist.

III. DISCUSSION OF THE VARIABLES

As discussed in Section IIA, 21 maps consisting of 36 environmental variables were prepared during the course of this study. Prior to presenting the results of analyses performed using this data, the rationale for use of the information and an assessment of reliability of the data must be presented. In the sections that follow, each map is discussed from the perspective of (1) the rationale for the use of the information; (2) the source and reliability of the data and (3) the spatial coverage of the variable.

\section{A. LAND AND WATER - FIGURE 4}

Rationale: Two reasons exist for mapping land and water areas. First, a base map was needed for coding purposes that established a uniform treatment of grid cells ai the interface of land and water. As shown in Figure 4, the decision was made to code a cell as land if a portion of the cell included land area. This coding decision established a protocol for treating cells in subsequent mapping efforts. The second reasın for coding land and water areas was to identify the degree to which water sites need to be considered for rectenna sites. At this time, water sites are considered as potential exclusion areas because the reference SPS system does not include ofíshore construction specifications. At this point in the analysis, it is impossible to assess if offshore sites are needed. However, the expectation is that onshore sites may be difficult to locate within the eastern half of the United States. Therefore, potential water sites are identified to a distance of 32 miles offshore ( 2 grid squares). All of the Great Lakes are also 


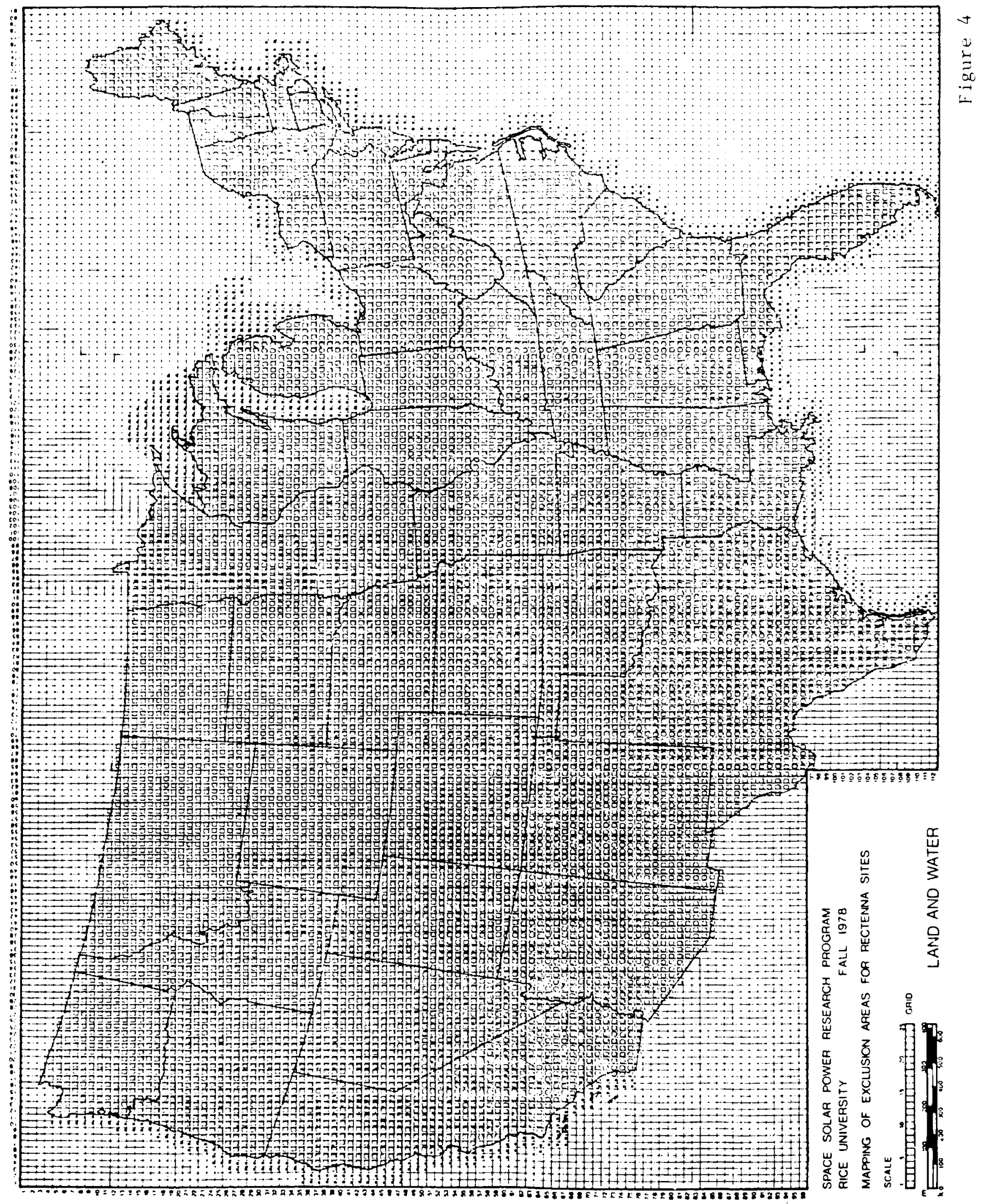


shown, although an international border does bisect the mapped waters.

Reliability of the Data: The base map from which the land and water areas were drawn was Richard Edes Harrison's map titled "Shaded Relief", wnich was published by the United States Geological Survey in the National Atlas of the United States. The map was drawn at a scale of $1: 7,500,000$, and $1 "$ was equal to approximately 118 miles. The coding decision with respect to land areas leads to an over representation of the land area of the United States. Therefore, the sum of the grid cells identified as land wouid represent a slightly larger land area than is actually to be found in the Continental United States. The only water areas mapped were coastal waters and the Great Lakes. Therefore, water areas are underrep'esented both with respect to coastal boundaries and with respect to smaller lakes within the borders of the United States. Nonetheless, the information from which the map was drawn is considered to be highly reliable.

Spatial Coverage: A: shown in Figure 4, land consists of 11699 grid cells. Because this map will be used as a reference map for coding purposes, the total number of grid cells available for coding of information is 11699.

\section{B. FEDERAL LANDS - FIGURE 5}

In Figure 5, a map of the lands under federal ownership is presented. Four distinct variables are displayed in the map. These are (a) National Recreation Areas; (b) Indian Reservations, (c) Military Reservations, and (d) Other Federal Lands. This map was assembled directly from a map which had all four variables of concern, and Figure 5 was compiled by first scoring grid cells over National Recreation Areas, then scoring Indian Reservations, then military reservations and then other federal lands.

1. National Recreation Areas

Rationale: Certain federal lands have been dedicated to 


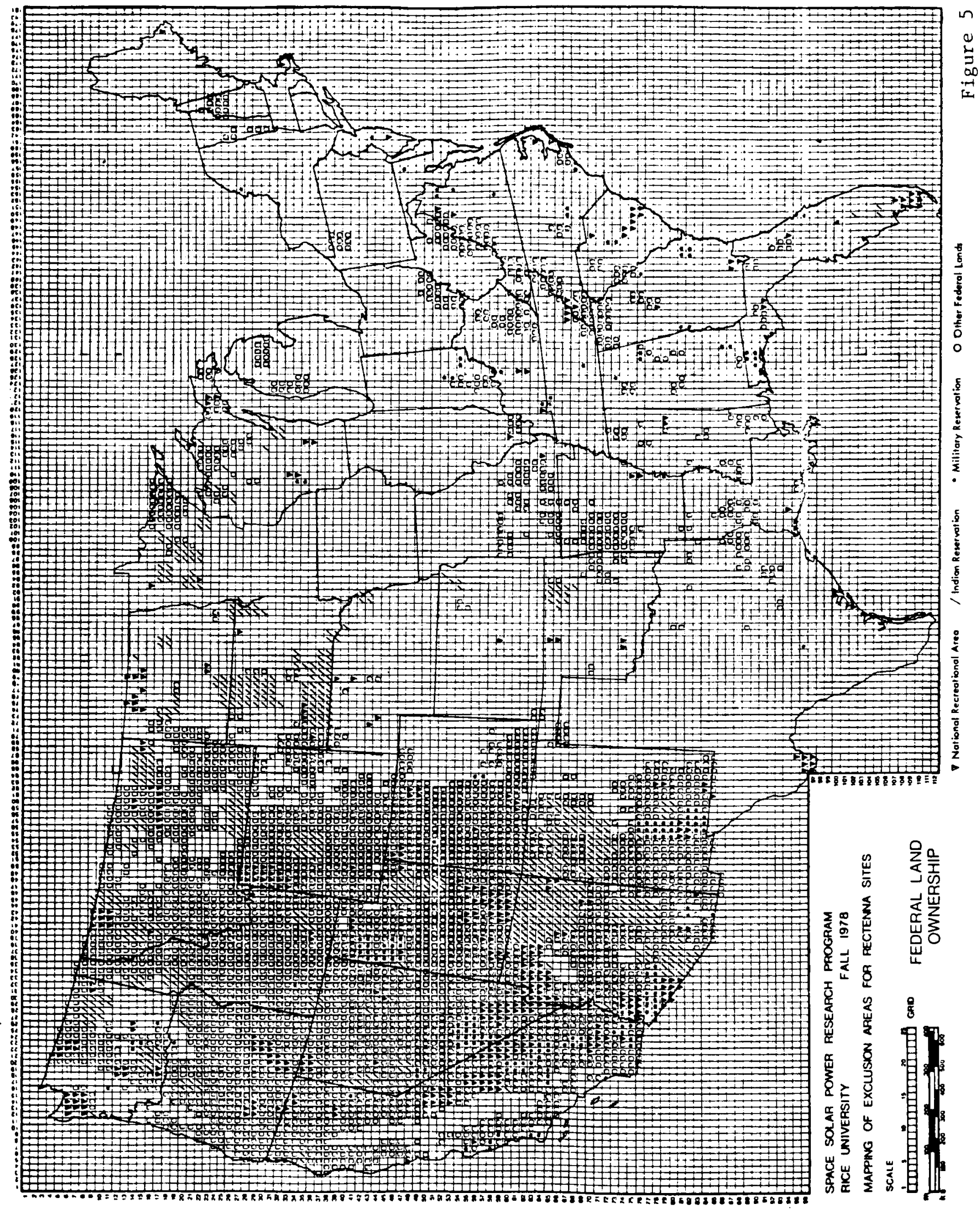


recreational or wildlife preservation uses. These lands are preserved as part of the heritage of the United States and their conversion to other uses is prevented by federal law. Although congressional action removing such prohibitions is possible, such action is unlikely. Therefore, these areas have been mapped and are considered as absolute exclusion areas. Included in the National Recreation Areas category mapped in Figure 5 are (1) National Parks, (2) National Monuments, (3) Federal Wildlife Reguges, (4) National Seashores and (5) National Recreation Areas.

Reliability of the Data: The areas coded as National Recreation Areas were taken from a United States Geological Survey map titled "Federal Lands". This map was published in the National Atlas of the United States and compiled by the USGS as of January 1, 1968. Therefore, this data is considered to be highly reliable as of that date, but land areas added to these categories since 1968 are not included. This variable was coded as being present in a cell if the variable occurred in any portion of that grid cell.

Spatial Coverage: The areas identified as National Recreation Areas are present in 424 grid cells.

2. Indian Reservations

Rationale: Indian reservations are federal lands that are administered, by tribes living on these reservations with the Department of Interior performing a guardianship function. This institutional situation gives the Indian tribes substantial control over the use of land within reservations, and there is a strong possibility that these tribes will not allow a rectenna to be constructed on their lands. Given this jurisdictional situation, Indian reservations were mapped and are considered as potential exclusion areas.

Reliability of the Data: The areas coded as Indian Reservations were also taken from the USGS "Federal Lands" map cited previously. The reservations mapped are considered accurate, but certain smaller 
reservations, such as the Alabama-Coushatta reservation north of Houston, Texas, are absent from this map, indicating that a size threshold was used by the USGS in assembling the "Federal Lands" map. Therefore, certain other smaller reservations may not be mapped. This variable was also coded as being present if the reservation appeared in the grid cell.

Spatial Coverage: The areas identified as Indian Reservations are present in 558 grid cells.

\section{Military Reservations}

Rationale: Two reasons exist for mapping military reservations. First, certain military reservations may not be desirable sites because sensitive radio and telecommunications equipment could be subject to radio frequency interference from the rectenna. Second, certain military reservations may have substantial acreages that are removed from population centers. These latter areas may provide excellent sites whereas the former would be undesirable sites. Therefore, military reservations are mapped and are considered as potential exclusion and potential inclusion areas.

Reliability of the Data: The information appearing on Map 4 was also obtained from the previously cited "Federal Lands" map. This data is considered reliable, but the utility of the generic classification (military reservation) is questionable. A more detailed investigation of military reservations will be necessary prior to determining the proper interpretation to ascribe to this generic land use type. Again, the variable was coded as being present if the land use were in a cell.

Spatial Coverage: The areas identified as military reservations are present in 175 grid cells.

4. Other Federal Lands

Rationale: Other Federal lands were mapped for consideration as an inclusion variable. These lands are either wholly or partially 
under the jurisdiction of the federal government, and they may be utilized for multiple purposes. Included in this category are national forests, as well as 1 ands with greater than $25 \%$ ownership by the Federal government. While these lands may not be indiscrimately used, they are potentially available as sites for rectennas.

Reliability of the Data: The areas coded as other federal lands also were obtained from the U.S.G.S.'s map titled "Federal Lands". The major shortcoming of this information is that much of the land area coded as other federal lands is only partially under the control of the federal government. While this partial ownership is helpful in aggregating $50,000+$ acres of land, the mapped information is misleading if one assumes all of these lands are under federal control. This variable was also coded if present in a cell.

Spatial Coverage: Other federal lands are coded in 3606 grid cells.

C. NATIONAL FORESTS - FIGURE 6

Rationale: Although multiple use of National Forests is allowed under Federal law, the conversion of portions of these forests into sites for receiving antennas would be opposed by environmental groups and the U.S. Department of Agriculture. Therefore, these national forests have been separated from the "Other Federal Lands" category and are mapped separately. From an analytical standpoint, these lands are considered as potential exclusion areas, although as a practical matter, these areas should not be considered as being available for rectenna sites unless no other alternative sites exist in the region of the United States being analyzed.

Reliability of the Data: The areas coded as National Forests also were taken from the USGS map of federal lands. This data is considered as being highly reliable and the variable was mapped if it was present within the grid cell. It should be noted that National Grasslands were 


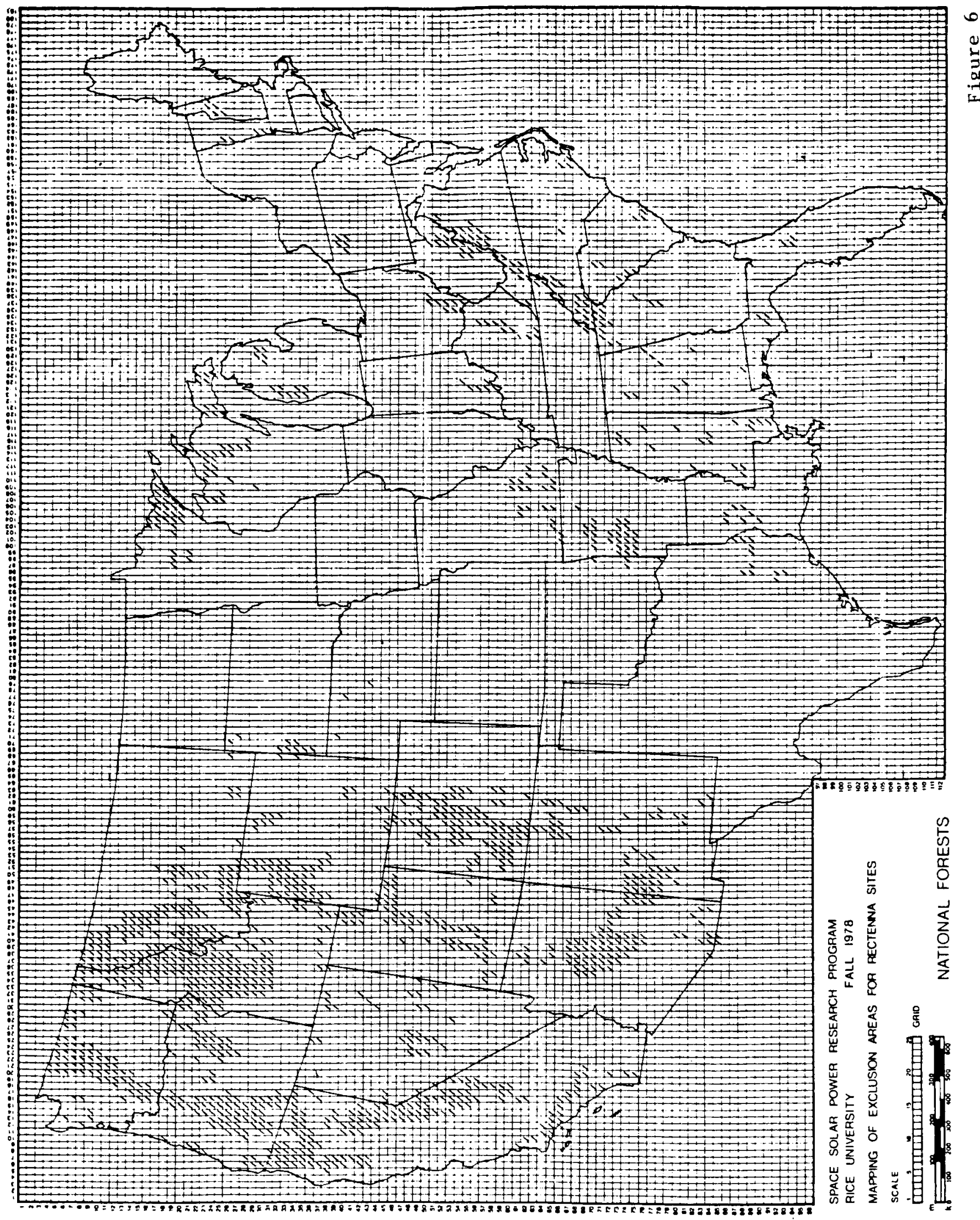


not mapped due to time constraints. National grasslands do not have the spatial coverage of the national forests but they should have been included on this national forest map. Therefore, the information contained in Figuire 6 should have been expanded to include national grasslands.

Spatial Coverage: The areas coded as national forests are present in 1323 grid cells.

\section{POPULATION - FIGURE 7}

Populated areas offer several constraints with respect to rectenna siting. First, populated areas represent dedicated land uses and the displacement of large numbers of people is considered to be highly undesirable. Second, land prices in more densely populated areas will be substantially higher than in other areas of the United States. Third, microwave exposure levels adjacent to the rectenna will be higher than the background non-occupational standard used by the Societ Union. Although much research will have to be conducted before definitive statements can be made about microwave effects, this study's approach was to avoid locations immediately adjacent to urbanized areas.

Given a desire to avoid populated areas, the next question to be addressed coricerns the definition of populated areas. Three variables were utilized in the map shown in Figure 7. These are (1) Standard Metropolitan Statistical Areas, (2) population density greater than 50 persons per square mile and (3) adjustec population distribution. The rationale for utilizing these variables is presented in the following sections.

Two general protlems must be raised at this stage. First, the source for population information is the United States census, with the last census having been conducted in 1970. Therefore, population data taken from the census is 8 years old. Because this information is dated, the issue of future growth is raised. Although it is difficult 


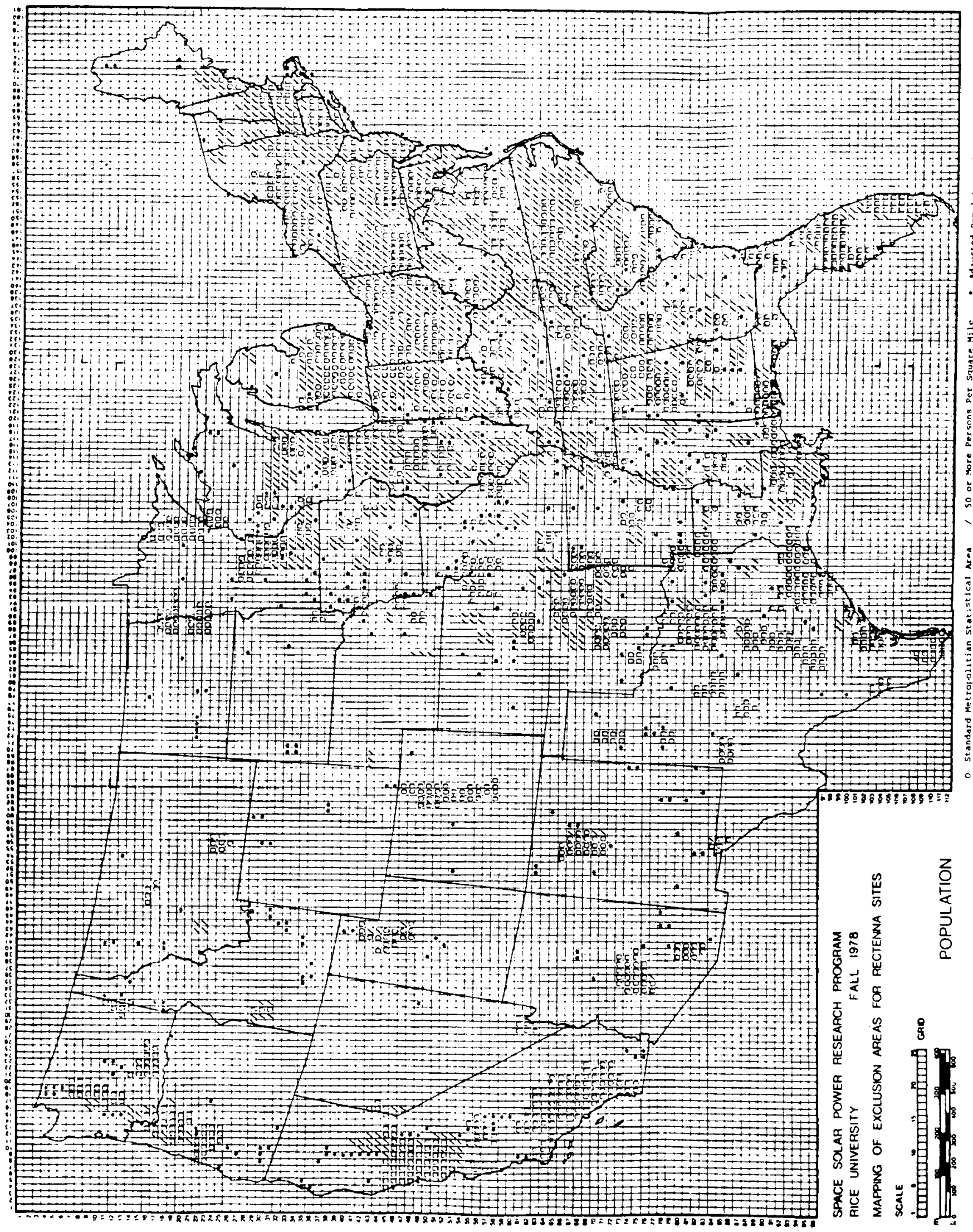


to project growth to the year 2000, certain trends are now evident that should be considered prior to a discussion of the variables mapped for exclusion purposes in this study. One of the best and most succint statements is found in the Council on Environmental Quality's seventh annual report. In this document, the Council states:

"There are three important patterns of population distribution evident in the United States in the 1970's, each with its own implications for the future. The dominant pattern of population settlement continues io be the growth of major metropolitan areas, a trend that accelerated in the post World War II period, but which has now slowed appreciably. The second pattern is a considerable regional shift of population from the north central and northeastern sections of the country to the southern and western regions. The third pattern is a more recently observed phenomenom: the relatively rapid growth of population in non-metropolitan areas. We have chosen to highlight this pattern in the Annual Report because it is a growing trend that runs contrary to the basic pattern of growth throughout most of our history. For the first time, population in non-metropol itan areas is increasing faster than that in metropolitan areas."

This non-metropolitan growth trend has many implications for recterna siting. Unfortunately, it is difficult to speculate at this time about the spatial characteristics of this trend. In this study, the goal was to identify areas where rectennas could not be located.

Therefore, the variables mapped and described below should be considered as a conservative indication of populated areas. Those areas that are not mapped should not be considered as automatically being without population. Instead, these areas did not have a sufficient density to indicate that rectennas could not be located there. In other words, the "white" areas do not indicate a locational carte blanche, and these areas should be studied in greater detail to determine the actual distribution of people within these areas.

1. Standard Metropolitan Statistical Areas (SMSA's).

Rationale: A substantial portion of the United States has been 
urbanized and these settlement patterns represent dedicated land uses. An initial indication of the location of these urban settlements may be gained by mapping Standard Metropolitan Statistical Areas (SMSA's). SMSA's are the major metropolitan areas of the United States and are also areas where future population growth is likely to occur. The research tean determined that these areas would exhibit settlement patterns precluding the aggregation of 50,000 + acres of land. Further, if such an agglomeration were indeed possible, the cost of the land would be prohibitive. These SMSA's are shown on Figure 7.

Another reason for identifying SMSA's as exclusion areas is that many other activities that represent siting constraints are present in these areas. For example, most of ti.ie major airports of the United States are found in SMSA's (as well as other densely populated areas), and the approach corridors most likely will be present within SMSA's. Additionally, substantial concern has been voiced concerning the potential radio frequency interference effects of the rectenna. Since the majority of sources that could be disturbed by radio frequericy interference are located in major metropolitan areas, the mapping of SMSA's (and other urbanized areas) begins to address the RFI issue. Reliability of the Data: The areas shown as SMSA's in Figure 7 are from a map prepared by the Geography Division of the Department of the Census. The definition of SMSA's was developed by the United States Office of Federal Statistical Policy and Standards as of December, 1977. The data is considered highly reliable. However, alterations were made to certain SMSA's prior to their being mapped on Figure 7.

These alterations were made because of the basis for determining the spatial coverage of SMSA's. Generally, SMSA's are delineated along county boundaries. For most areas of the United States, the approach is sensible because counties are relatively small. However, the western United States (notably California, Arizona, Nevada, Utah and oregon) has extremely large counties. To map the entirety of these 
SMSA's as exclusion areas would be misleading since large portions of these counties are not urbanized. Therefore, certain alterations were made to these defined SMSA's. Alterations were made by examining a "dot" map of population distribution, prepared by the Department of the

- Census from 1970 Census data, and eliminating grid cells from the SMSA that were indicated as having less than 500 pecple.

Spatial Coverage: Areas indicated as SMSA's on Figure 7 include 1871 grid cells across the United States.

2. Population Density Greater than 50 Persons per Square Mile

Rationale: As discussed previously, populated areas other than SMSA's need to be represented. A second type of indication is a population density analysis, and areas that were identified as having a population density greater than 50 persons per square mile were mapped and considered as exclusion variables.

Reliability of the Data: The areas mapped as having a population density greater than 50 persons per square mile were compiled from a map prepared by the Department of Census from 1970 census data. Therefore, the information represented by this variable is somewhat out of date. However, a more severe shortcoming of the data relates to the fact that the data was represented on a county by county basis. Although counties are commonly used for data representation purposes, the land area represented by many counties causes significant concentrations of people to be diluted when the data is mapped on a county by county basis. Therefore, while there is a great degree of confidence that the mapped information is an accurate representation of those counties with a population density greater than 50 persons per square mile, there are many areas of the United States that are not adequately represented through the use of this population variable.

Spatial Coverage: The land area represented as having a population density greater than 50 persons per square mile include 1276 grid cells. It should be noted that this count does not include the areas previously mapped as SMSA's. 


\section{Adjusted Population Distribution}

Rationale: Due to the problem of county land areas diluting the population density per square mile measure used above, a third population variable was mapped as an exclusion area. This area is identified as "adjusted population distribution" and it represents a third approach to determine the exclusion area for population.

Reliability of the Data: Unlike the two previous variables, adjusted population distribution represents a somewhat subjective approach to population density. Th. data was developed by overlaying the grid of the United States over the U.S. Department of the Census's dot map of the population of the United States. This dot map is based upon 1970 census data. It is important to note that certain counties of the United States are large enough that 10 to 20 grid cells fit within their boundaries. By overlaying the grid cells and the dot map, substantial areas were added to the populated areas map. Although replication of the process might lead to varying results, certain rules were followed. First, any grid cell with a city of 25,000 persons or more was added. Second, if there were two towns of 10,000 persons or more, the grid cell was scored. Third, if there were combinations of a town of 10,000 or more and a number of dispersed, smaller dots, the grid cell was scored. As stated earlier, this process was subjective and was based upon visual examination of the dot map. However, it is felt that those areas covered by the "adjusted population density" variable should not be considered as sites. The important point is that the combination of the three population variables represents a rather conservative assessment of the land areas unavailable as potential sites on the basis of population.

Spatial Coverage: The land area mapped as "adjusted population distribution" consists of 419 grid cells. 


\section{E. WETLANDS - FIGURES 8 and 9}

Rationale: Wetlands have been a focal point of environmental soncern for many years now. The United States Army Corps of Engineers has jurisdiction over dredge and fill activities in most wetland areas of the United States under Section 404 of the Federal water Pollution Control Act Amendments of 1972 and 1977, and the U.S. Environmental Protection Agency has issued guidelines that are intended to prevent the conversion of wetlands to other uses. Wetland areas are extremely important habitat areas, both for marine and avian species. Although it is possible under existing federal statutes to convert wetlands, it is clear that the intent of Congress is to protect wetland areas. Therefore, wetlands are considered as absolute exclusion areas, and are shown in Figures 8 and 9.

Reliability of the Data: While the intent of Congress may be clear, the spatial distribution of wetlands is more obscure. Wetlands may be marshes, swamps or ponded areas within farmlands or forests. At this time, the United States Fish and Wildlife Service is attempting to compile a comprehensive inventory of wetland areas, but this study is not complete. For this reason many smaller wetland areas are not included in Figures 8 and 9. A 1955 Department of the Interior publication titled "Wetlands of The United States" identified important wetlands in a very generalized fashion. This publication determined that there were $22,400,000$ acres of wetlands of primary importance to waterfowl and 52,000,000 acres of wetlands of lesser importance. However, these areas could not be mapped with a sufficient degree of accuracy. Therefore, a need exists for additional information before this issue can be adequately addressed. The two maps presented in Figures 8 and 9 include only larger wetland systems, and these figures should be considered as conservative indications of the spatial coverage of wetland areas. 


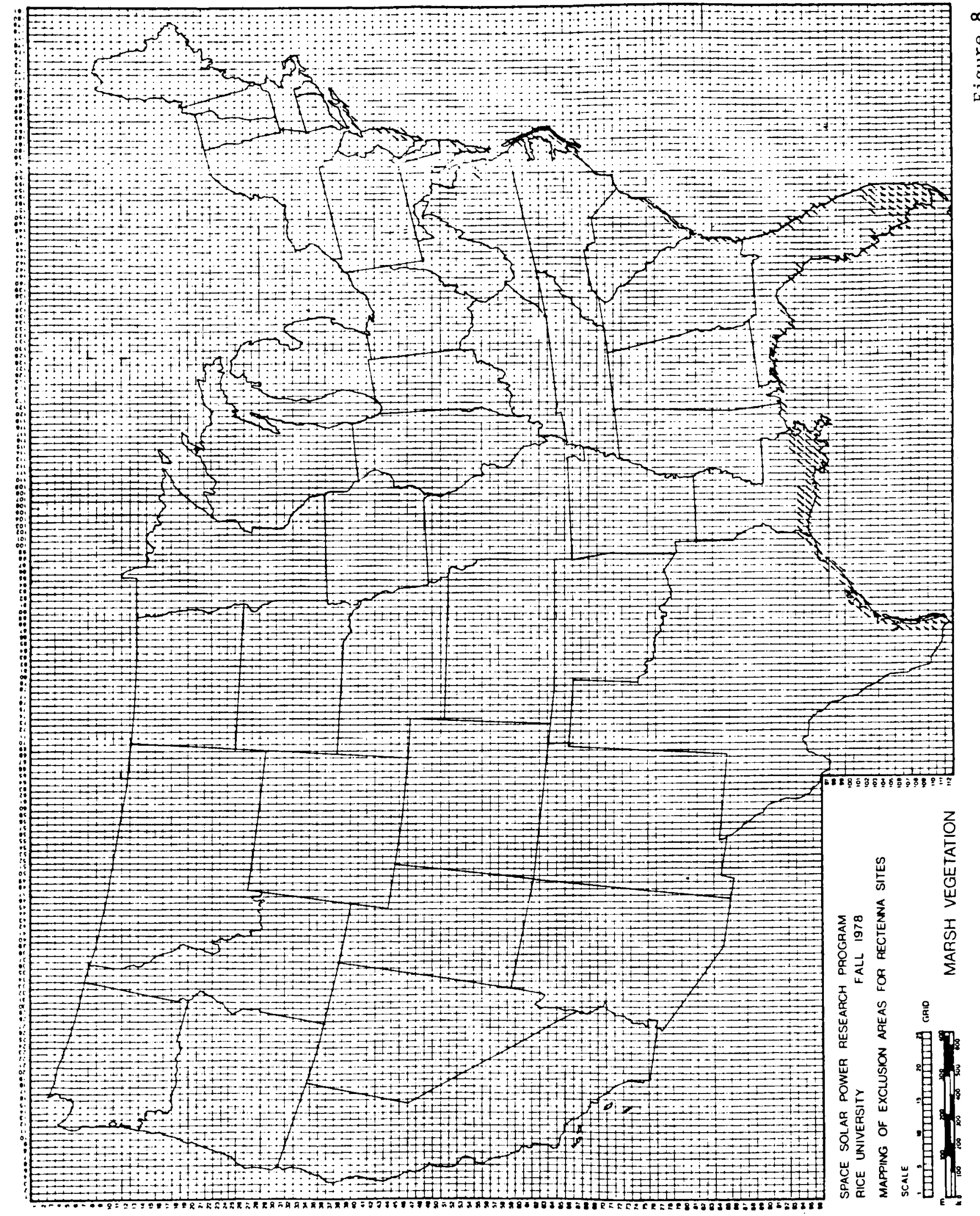




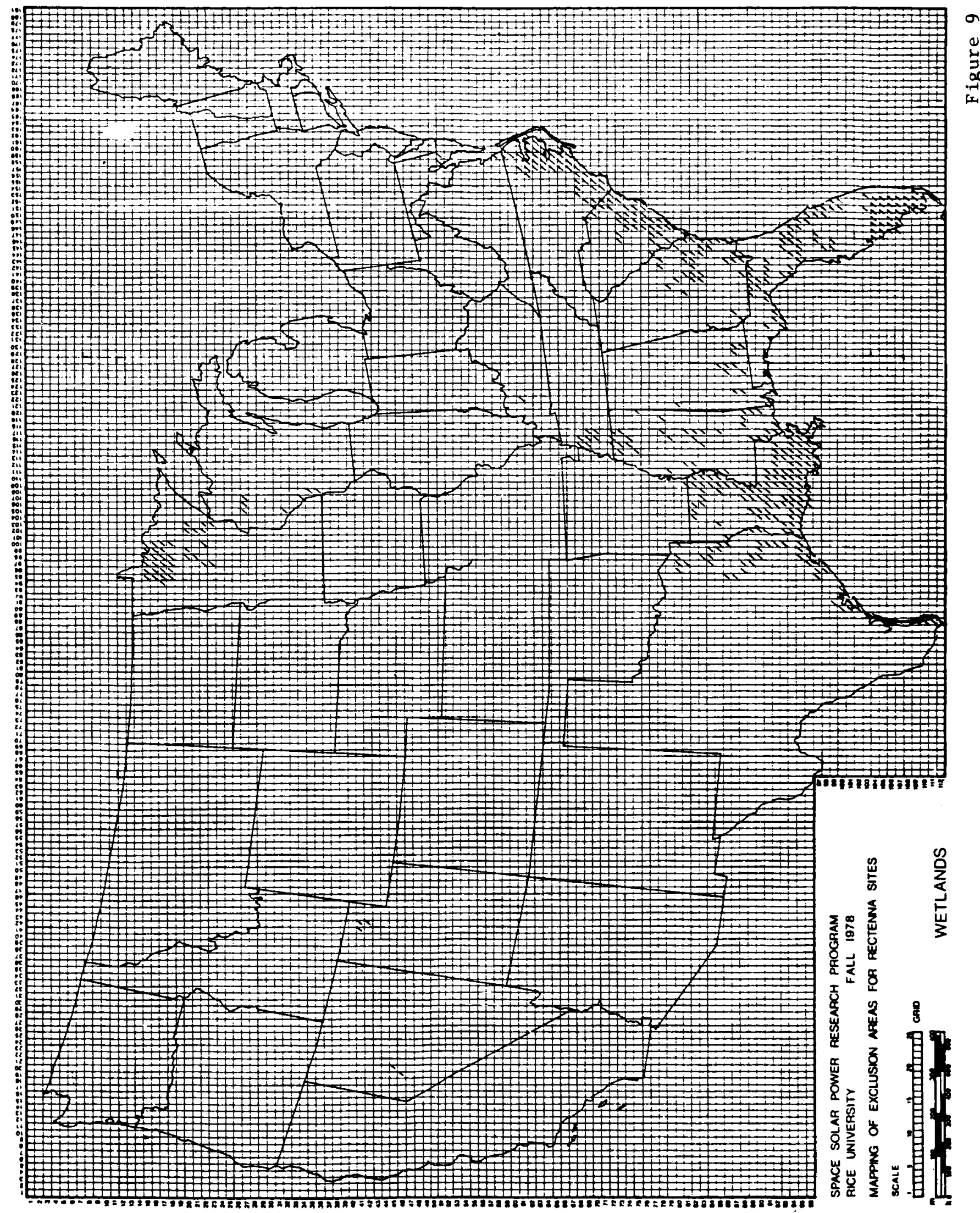




\section{Marshes - Figure 8}

Marshes were identified on the basis of vegetation. The source of this information was A. W. Kuchler's 1966 map titled "Potential Natural Vegetation". This map was included in the National Atlas of the United States, published by the United States Geological Survey in 1970. Those vegetation types mapped included (1) the Mangrove broadleaf forest, (2) the Everglades grassland, (3) the Cypress Savanna grassland, (4) the live oak-sea oats grassland, (5) the southern cordgrass prairie and (6) the northern corcgrass prairie. This information is considered to be highly reliable. However, a disparity may arise because a grid square was coded if a marsh was present (but not necessarily dominant) in that grid square.

\section{Wetlands - Figure 9}

Wetlands were identified from the United States Geological Survey map titled "Major Land Uses", also from the National Atlas of the United States. In this mapping effort, the areas of the United States classified as swamps were entered in the grid scares shown in Figure 9. It should be noted that this USGS map only showed the dominant land uses within mapped areas, and many other portions of the United States would have substantial acreages of wetlands that are not the dominant land use type. A grid cell was coded for wetlands if any portion of the grid cell intersected mapped swamp areas.

Spatial Coverage: The areas mapped as marshes in Figure 8 consist of 219 grid cells and the areas mapped as wetlands in Figure 9 consist of 487 grid cells.

\section{F. TOPOGRAPHY UNACCEPTABLE - FIGURE 10}

Rational: Excessively steep slopes are considered to be unacceptable for rectenna construction, either because the microwave beam cannot intersect the rectenna or because the problems of construction are too severe. With one exception, discussed in Section 7, infra, those areas mapped as having unacceptable topography are considered as absolute exclusion variables. 


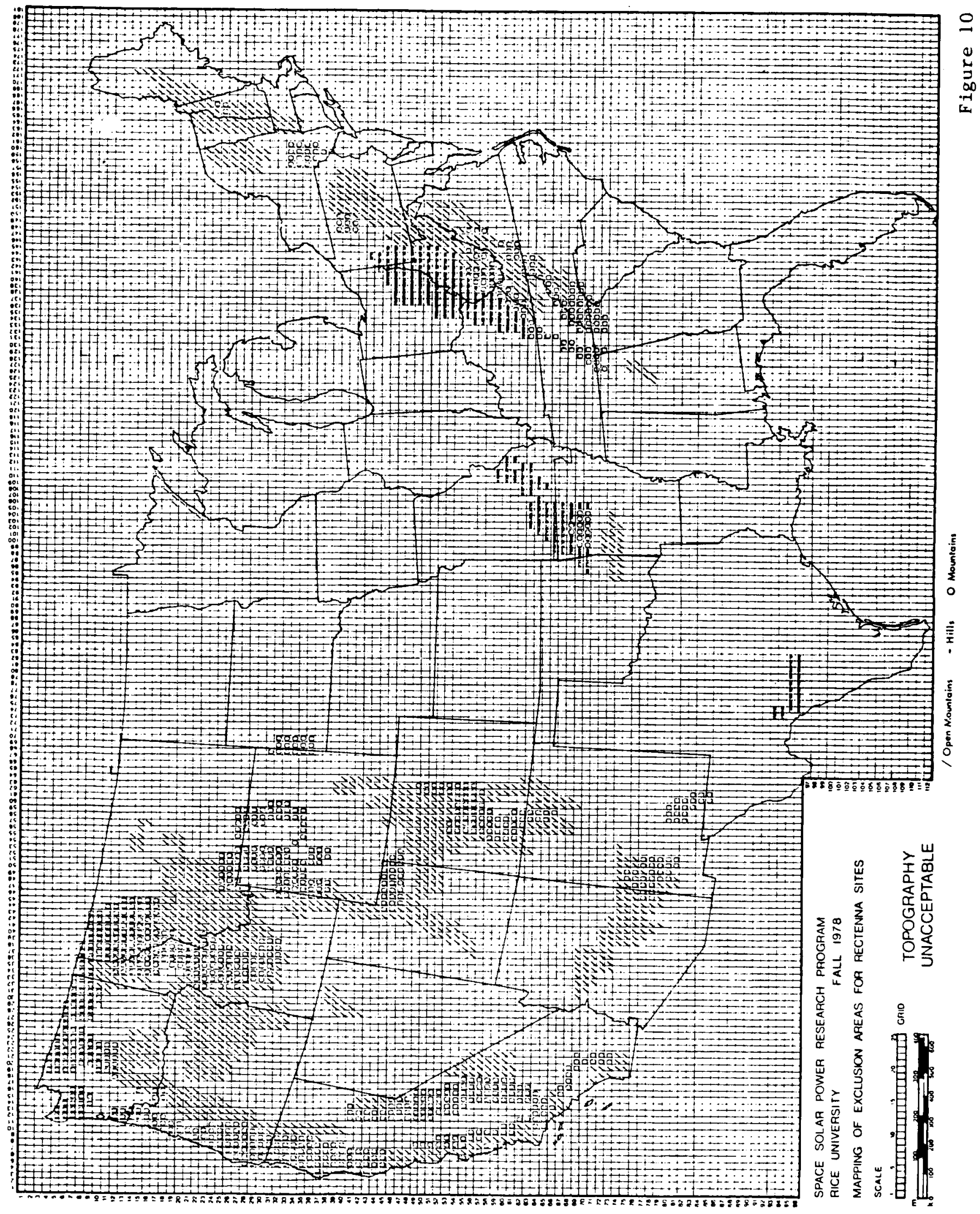


Reliability of the Data: The source of topographic information presented in Figure 10 is the U.S.G.S. map titled "Classes of Land Surface Form" which was adapted from a map by Edwin H. Hammond. This map was also published in the National Atlas of the United States. This USGS map sets forth five general land surface form categories with some 21 subcategories. For exclusion purposes, three of these 21 subcategories were mapped. These were high hills, low mountains and high mountains, with less than $20 \%$ of the land area gently sloping. These were chosen because they were the trree categories that indicated the most severe slope constraint. Therefore, these mapped areas include only those areas where it is felt that a definite slope problen exists. Certain other areas of the United States that are not shown in Figure 10 could cause problems with respect to topography.

Spatial Coverage: The variables mapped in Figure 10 comprise 2436 grid cells.

\section{G. SOUTH SLOPES - FIGURE 11}

Rationale: Because the satellite will be in geosynchronous orbit at the equator, the microwave beam could reach a rectenna sited on the south side of ridges or mountains that run predominantly east-west. For this reason, areas with otherwise unacceptable topography may be potential sites, and, this subset of the high hills, low mountains and high mountains category is considered as a potential exclusion variable.

Reliability of the Data: The information concerning the east-west ridges is taken from the U.S.G.S. map titled "Shaded Relief", also from the National Atlas of the United States. This information is considered to be highly reliable, although the determination of the dividing line between the northern and southern boundaries of such east-west ridges is subject to interpretation and some error. This information, shown on Figure 11 is considered to be reasonabiy accurate.

Spatial Coverage: The variables mapped in Figure 11 cover 142 grid cells. 


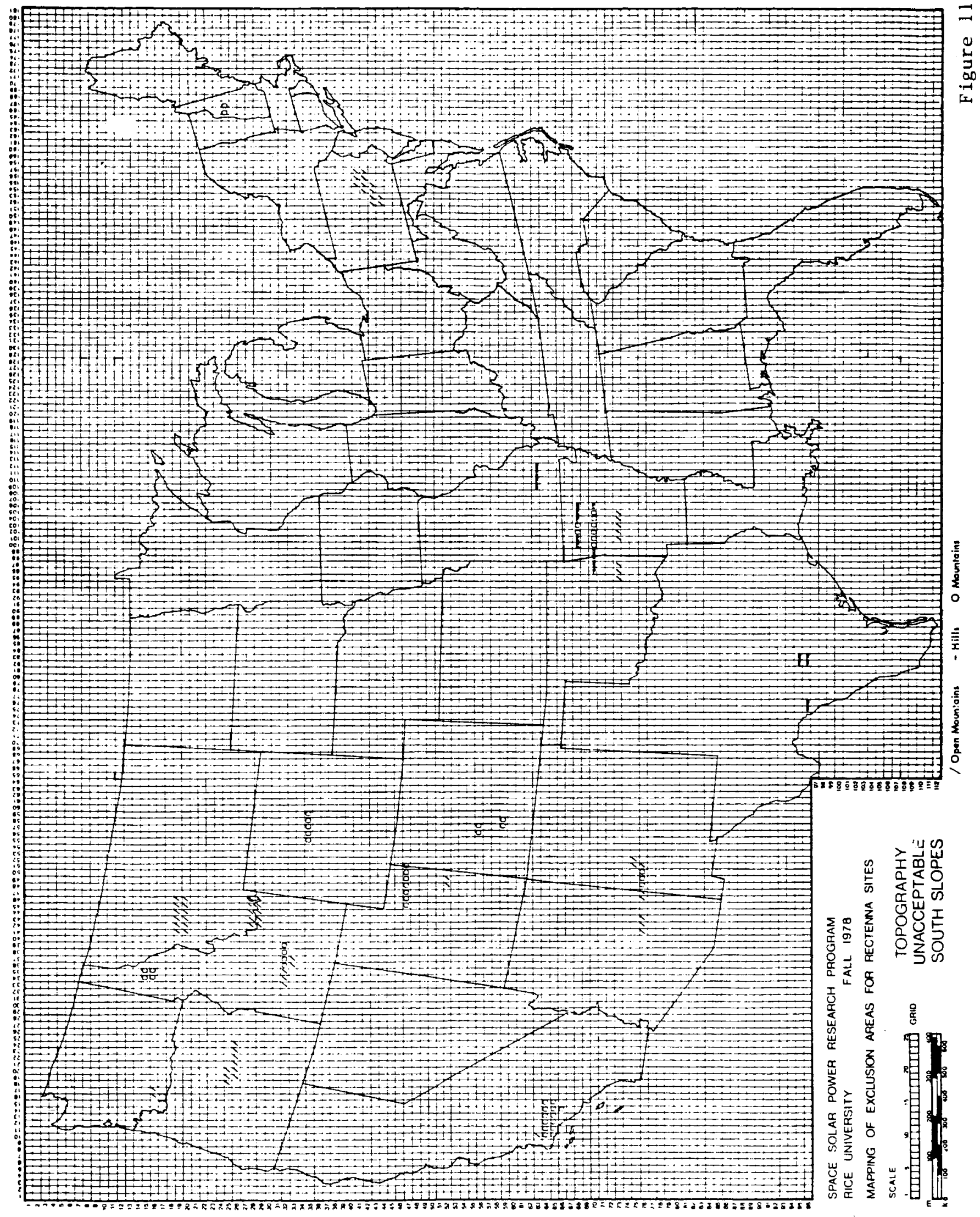




\section{H. NAVIGAELE WATERWAYS - FIGURE 12}

Rationale: Navigable waterways were considered as absolute exclusion variables due to the possibility that the microwaves beamed to the rectenna could interfere with sensitive navigational equipment. Adaitionally, these navigable waterways could not be spanned by the rectenna due to physical interference with navigation.

Reliability of the Data: Those waterways indicated as being navigable were mapped from the Oxfor: Regional Economic Atlas: United States and Canada, published by the Clarendon Press in 1967. Those rivers marked as navigable include some areas with less than six feet of controlling depth, but the majority of these waterways have a navigable depth of 10 or more feet. There are certain problems with this map. First, new navigation projects that have been completed since 1967 may not be included. Second, routes through the Great Lakes may be less rigid in fact than is indicated on the 0xford Map. Third, the seaways adjacent to the coastline and the entry and exit routes from the seaways into coastal seaports are not included on this map. This information exists in the form of numerous maps of various segments of the United States coastline, but there was insufficient time to assemble this information for inclusion in Figure 12 . These seaways adjacent to the coast would be a major exclusion variables for rectenna sites on the Outer Continental Shelf.

Spatial Coverage: There are 582 grid cells that are identified as cells where navigable waterways exist.

\section{INTERSTATE HIGHWAYS - FIGURE 13}

Rationale: Due to the large capital outlays for interstate highways and the investment patterns associated with these infrastructure items, the decision was made to map these arterials and to consider them as absolute exclusion variables. Although this designation is question- 


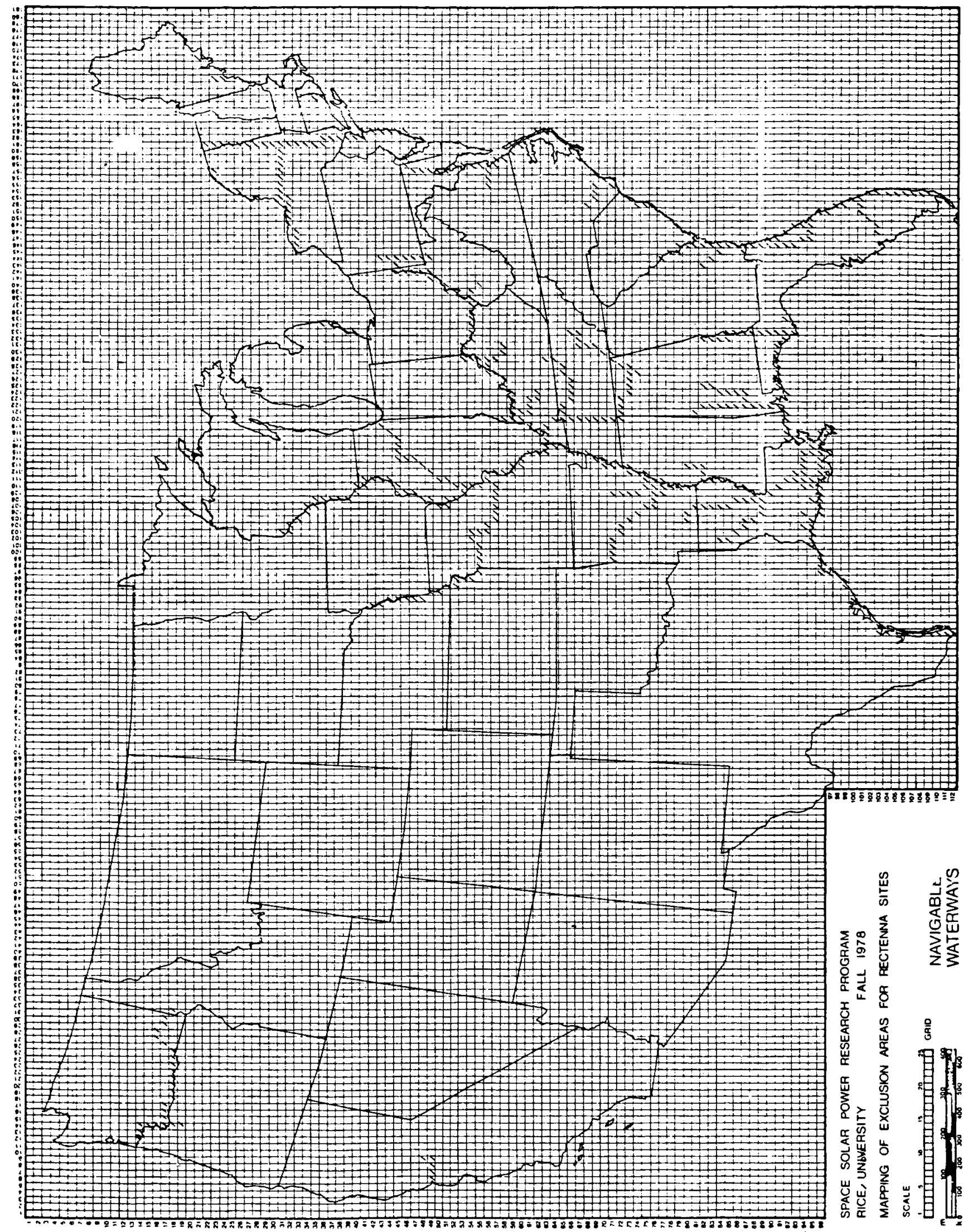




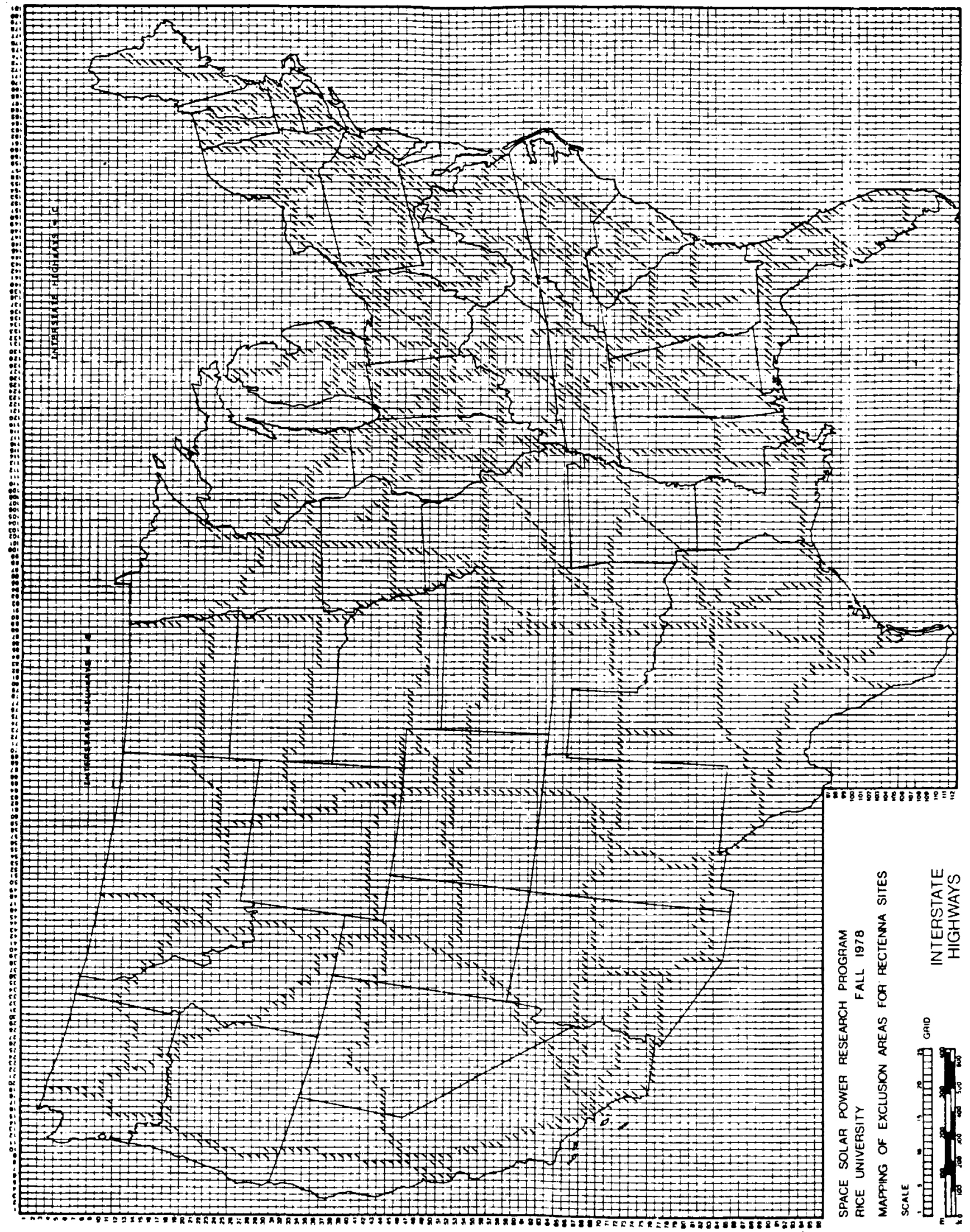


able, it is felt that it is realistic to expect large portions of the land areas adjacent to these highways to be unavailable for rectenna sites.

Reliability of the Data: The data on interstate highways is quite good, and the major criticism of the mapping of this variable would be the fact that an entire grid square was coded if an interstate highway were present in that grid. This problem can only be remedied by selecting a smaller grid square size, which is beyond the resources of this project.

Spatial Coverage: Figure 13 shows Interstate Highways being represented on 2163 grid cells.

\section{J. ENDANGERED SPECIES HABITATS - FIGURE 14}

Rationale: Known habitats of endangered species are protected by the Endangered Species Act if these areas have been designated as "critical habitats". Federal agencies are prevented from altering such designated habitats as the law is currently written. However, this variable was classified as a potential exclusion variable because of amendments currently pending in Congress. These amendments, if passed, may allow the conversion of such critical habitats. Although this course of action (conversion of these habitat areas) would lead to substantial controversy, the possibility exists that such a conversion could occur under the pending amendments to the Endangered Species legislation. These areas should not be considered if any alternatives exist in the area of concern.

Reliability of the Data: The information shown in Figure 14 was taken from maps appearing in the Federal Register which were compiled by the United States Fish and Wildlife Service. This information is very specific, and in certain cases covers relatively small areas. However, it is very reliable. It should be noted that designated riverine habitats of endangered fish species were not mapped, due to 


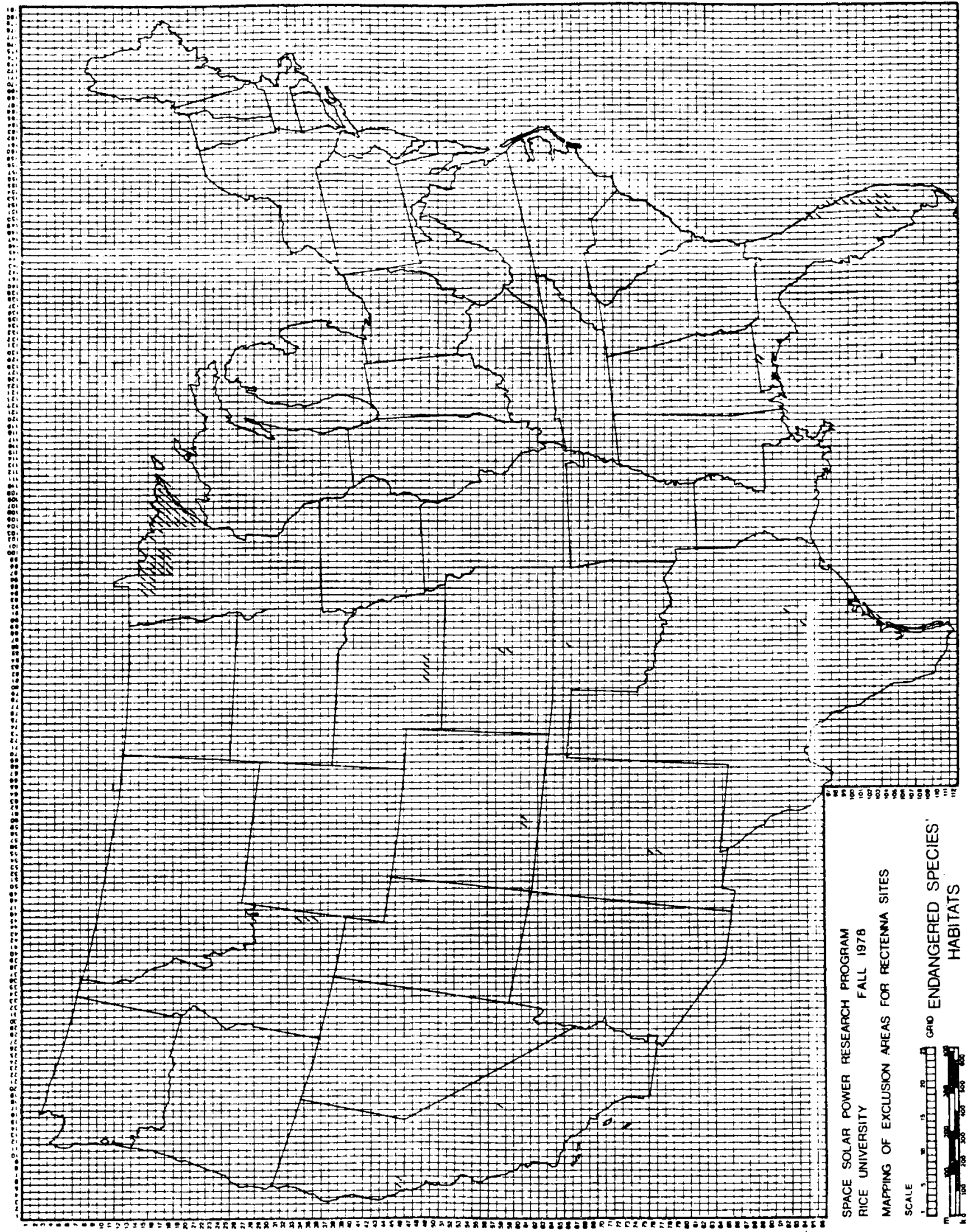


the probability that such sites would not be utilized for rectennas. It is also important to note that this map only shows designated critical habitat areas. There are many other areas throughout the United States that provide habitat for endangered species, but these areas have not been formally designated. Therefore, Figure 14 should be considered as a legally based map rather than a biologically derived map.

Spatial Coverage: There are 89 grid cells indicated as being habitat for endangered species.

\section{K. "PRIME AGRICULTURAL LANDS" - FIGURES 15 and 16}

Rationale: A substantial amount of attention has been recently focused upon "prime" agricultural lands. The United States Soil Conservation Service has been concerned for years about the conversion of agricultural lands to other uses, and this concern is best expressed in two U.S. Department of Agriculture publications titled "Perspectives on Prime Lands" and "Recommendations on Prime Lands". At least two reasons have been mentioned for this concern. First, prime agricultural lands are being converted into residential and commercial land uses because these lands are generally flat and well drained. Secondly, as energy costs increase, more land may be needed for agricultural productivity. At this time, many states have programs to prevent or minimize the conversion of agricultural lands to other uses, but a formal United States governmental policy has yet to be articulated. In other words, while prime lands are not currently protected under federal law, they may come under protection in the twenty year period before the SPS is implemented.

Due to this questionable legal status, "prime" agricultural lands are considered as a potential exclusion variable. This potential exclusion variable could be addressed if multiple use of the area beneath the rectenna were possible. According to Dick Siler at NASA, 


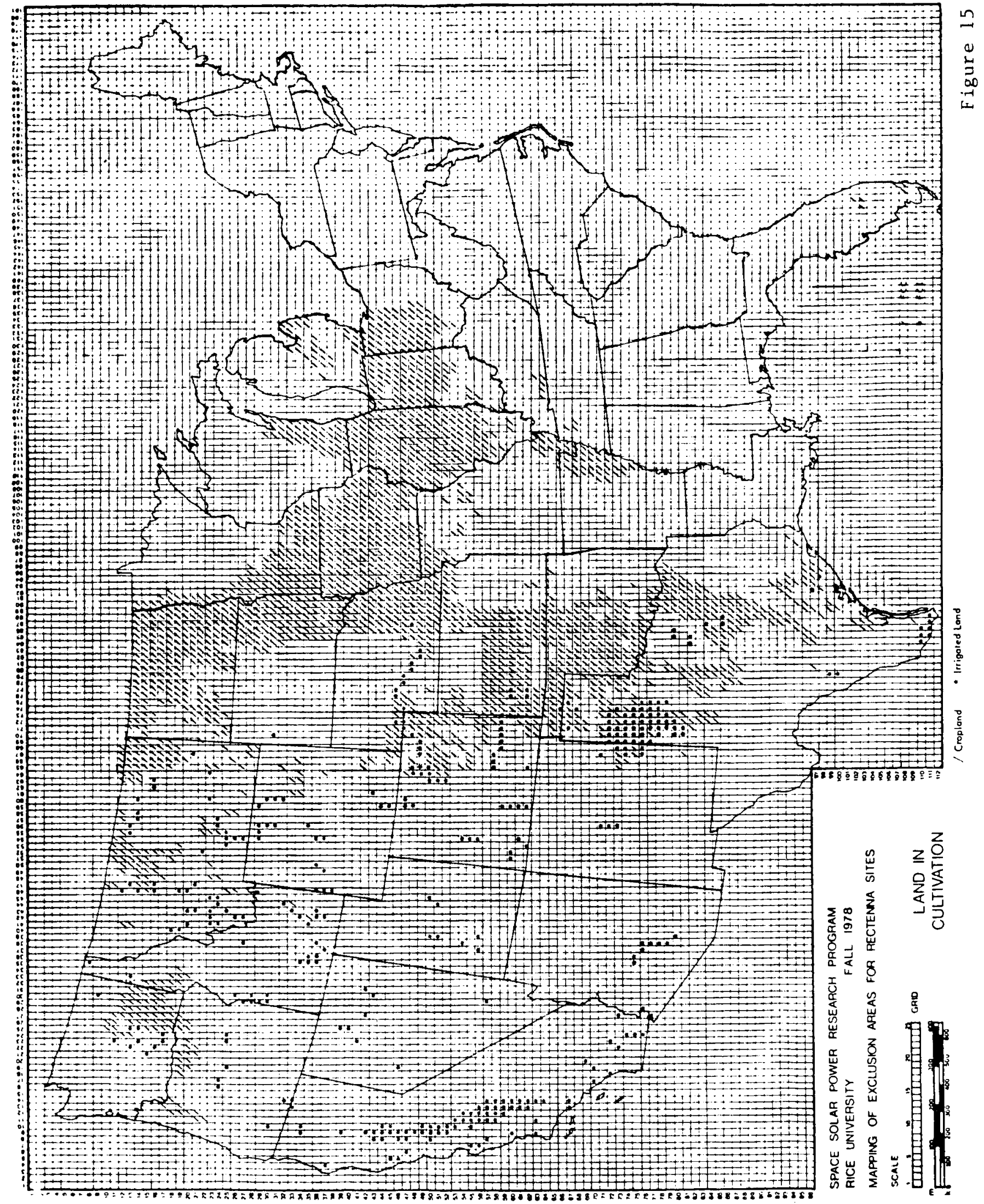




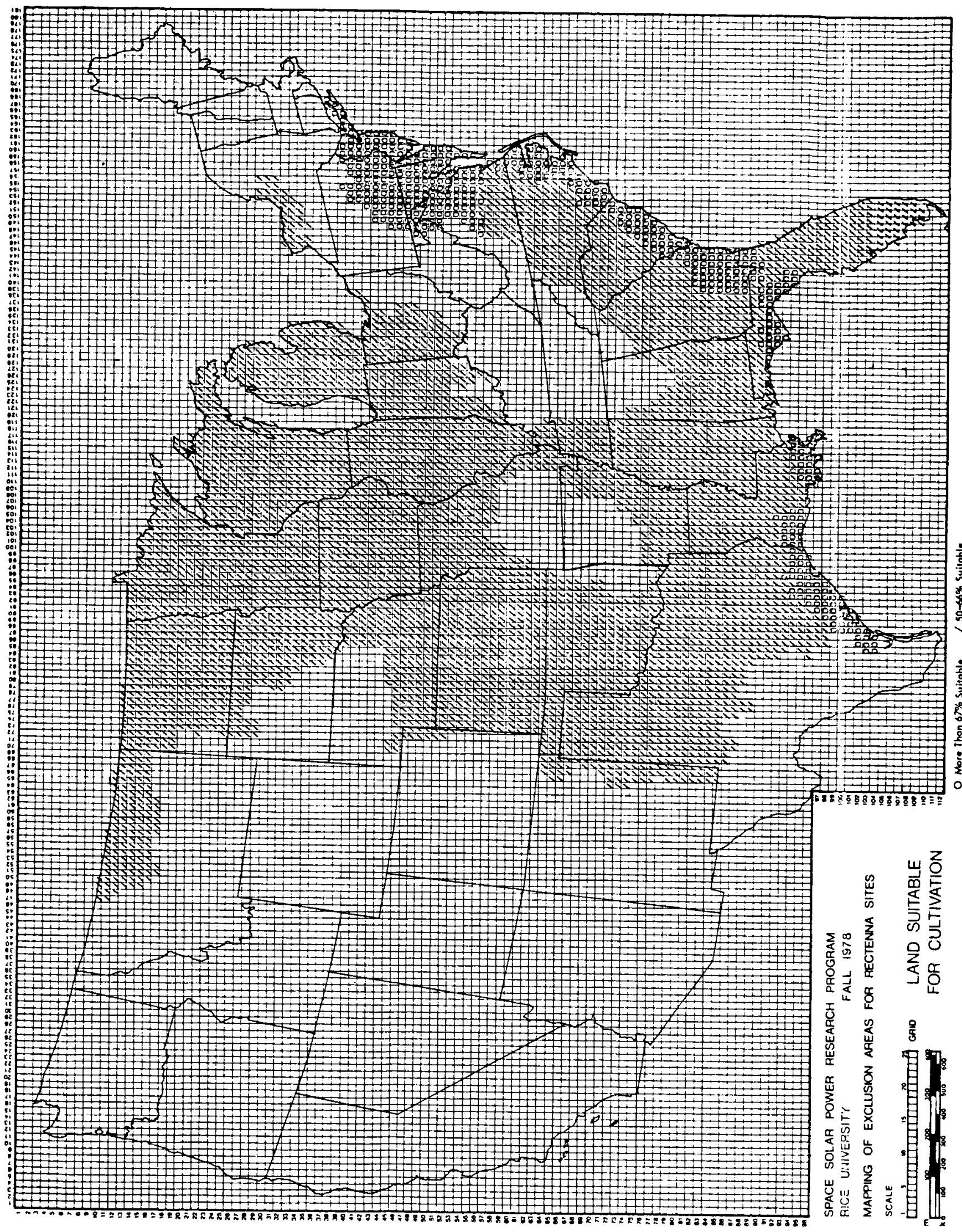


$80 \%$ of the incident sunlight should pass through the rectenna and the expected heat rise beneath the rectenna should be approximately one degree centigrade. From this information, multiple use cannot be said to be precluded. However, the use of land area beneath a rectenna will pose cultivation problems, repair and maintenance problems and will require design modifications. This alternative of multiple use should be examined in much greater detail prior to determining its feasibility.

Reliability of the Data: At this time, the U.S.D.A. is compiling detailed maps of the prime agricultural lands of the United States. The definition of "prime" agricultural lands is exceedingly complex, having several categories and subcategories. The expectation is that prime lands will vary substantially at the county level, and only by examining detailed maps on a county by county basis can one determine whether the agricultural lands in question are indeed "prime". This data may not be available for the entire United States until the early 1980's.

Given this situation, two "proxy" variables were established for prime lands. In Figure 15, areas that are irrigated farmland and areas that are almost totally cropland are mapped. In Figure 16, regional classifications of land area on the basis of its suitability for cultivation are shown. Figure 15 was derived from the U.S.G.S.'s Land Use Map of the United States in the National Atlas of the United States. Although all of the areas mapped in Figure 15 may not meet the S.C.S.'s definition of prime or unique farmlands, the expectation is that most of the land areas included in this map would be so classified. The major shortcoming of this map is that substantial acreages of prime agricultural lands exist beyond those areas mapped in Figure 15. For this reason, Figure 16 was developed. This map was derived from a United States Soil Conservation Service publication titled "2/3 of Our Land: A National Inventory", published in 1971. This figure classi- 
fies SCS regions from the standpoint of the percentage of lands that are suitable for cultivation. In Figure 16, two levels of suitability are indicated with one level being more than $67 \%$ of the land suitable and the second level being from $50 \%$ to $66 \%$ of the land suitable for cultivation. This map is considered to be less reliable than figure 15 , and the agricultural variable is overrepresented in Figure 16. Together, figures 15 and 16 should include most of the land area that would be considered as prime agricultural land under the SCS classification program.

Spatial Coverage: In Figure 15, 341 grid cells are classified as irrigated land and 2025 grid cells are classified as cropland. In Figure 16, 4741 grid cells are mapped as more than $67 \%$ of land suitable for cultivation and 507 grid cells are mapped in the 50\% to $66 \%$ suitable category.

\section{FLYWAYS OF MIGRATORY WATERFOWL - FIGURE 17}

Rationale: Implementation of the Satellite Power System will result in microwaves being beamed from the satellite to the rectenna. Migrating birds and other life forms that fly would be exposed to microwave levels with a power density as high as 23 miliwatts per square centimeter if they flew between the rectenna and the satellite. At this time, little if any research has been conducted on the effects of these microwave levels on unshielded species. Prior to the implementation of the SPS, this research will need to be conducted. If the results of this research effort indicated significant effects from these microwaves, then areas that are utilized extensively by migrating birds would be treated as exclusion variables. Because of time constraints, the Rice University team did not attempt to study the migration habits of all migratory bird species. However, the flyways utilized by migratory waterfowl are fairly well known and the decision was made to map these corridors to examine the effect that these flyways could 


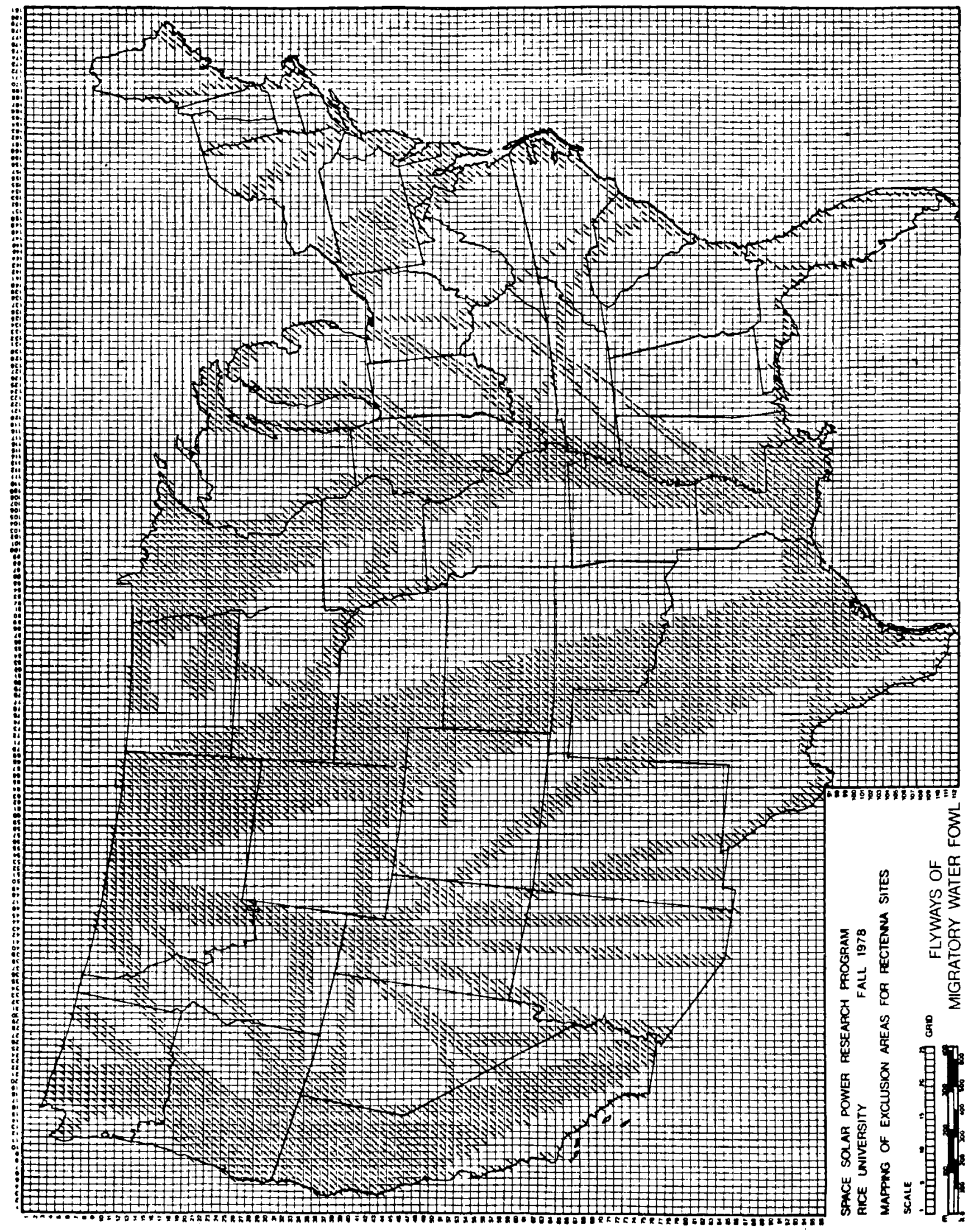


have upon the location of receiving antennas. This variable was treated as a potential exclusion variable due to the uncertain results of future research activity.

Reliability of the Data: The data mapped in Figure 17 was obtained from very general maps published by the U.S. Fish and Wildlife Service. The Pacific, Central, Mississippi and Atlantic flyways were combined from individual maps of those areas. The boundaries of these flyways were $i 11$ defined in the original information and the limits of the flyways are somewhat arbitrary. Perhaps more importantiy, graphs showing the distribution of migrating birds across these corridors or other similar data was not available to the project team. Therefore, while the land areas mapped as flyways appear correct, there may be discrepancies from state to state. The best approach to this variable would have been to compile information for each state from the state fish and wildlife agency and compile the map nationally from this more specific information. However, time constraints prevented this approach from being utilized. The information shown in Figure 17 does have factual validity and it certainly indicates the importance of research in the area of microwave effects on migratory bird species.

Spatial Coverage: 5441 grid cells are indicated as being within the flyways of migratory waterfowl.

\section{SEISMIC HAZARDS - FIGURE 18}

Rationale: Published information about the receiving antennas indicate that they are not designed to withstand earthquakes. Although this variable could be considered as a design variable, it may be that the cost for undertaking earthquake resistant rectennas would be extremely high, and, the areas with high quake risks would be avoided. Therefore, seismic hazards were mapped and are considered as potential exclusion varibles. 


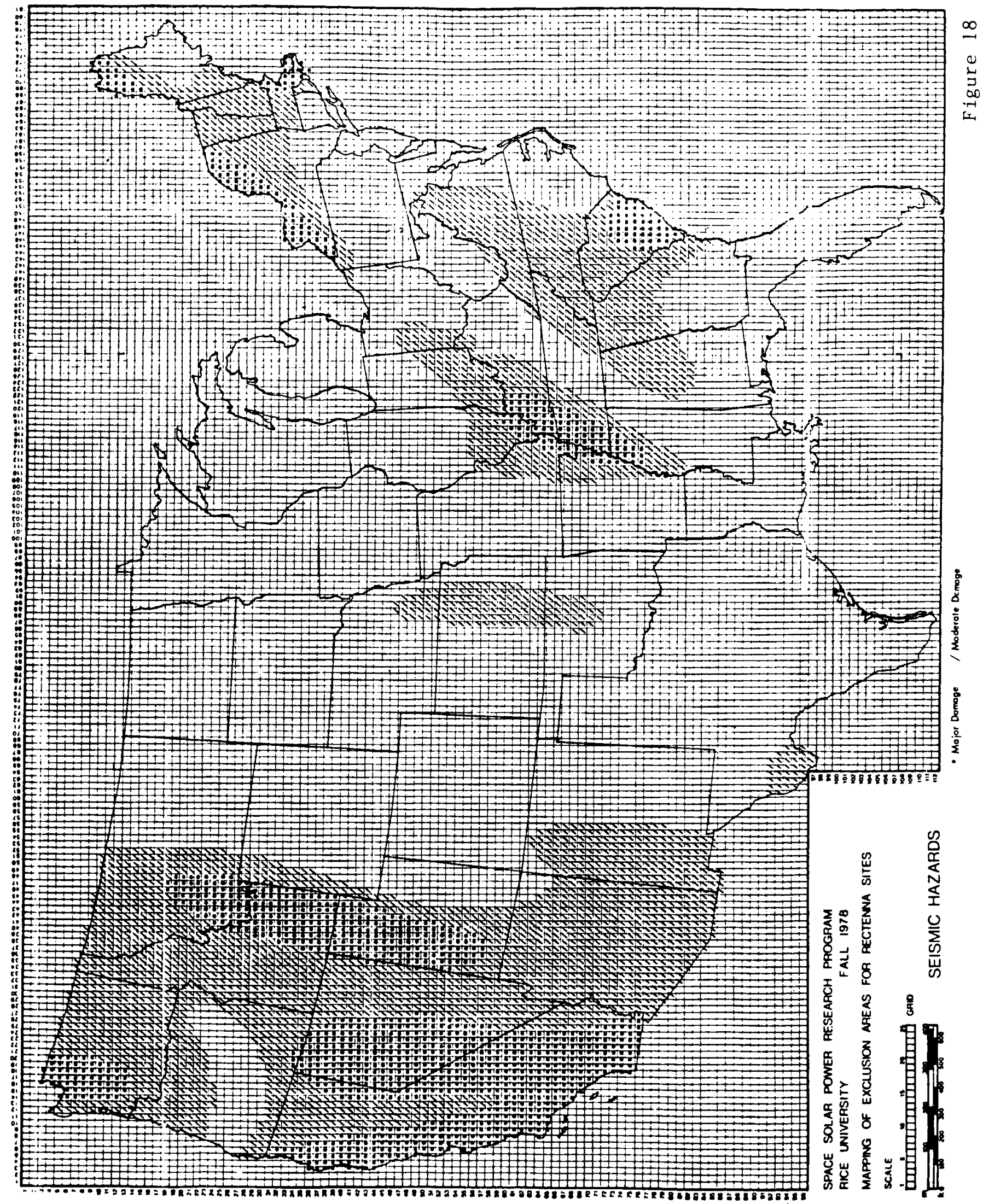


Reliability of the Data: In Figure 18, two areas of earthquake risk are mapped. These are areas of major seismic risk and areas of moderate seismic risk. The source of this information is a book by David M. Cargo and Bob F. Mallory titled Man and His Geologic Environment. The zones are based on the distribution of historical, damaging earthquakes, their intensities, evidence of strain release and distributions of geological structures related to earthquake activity. The frequency of possible earthquakes within the zones is not reflected in this data. Areas of major seismic risk are areas where an earthquake rated at VIII or higher of the Modified Mercali Scale is possible and areas of moderate seismic risk correspond to VII of the Modified Mercali Scale. If a site is to be located in these areas, much more detailed analysis will have to be undertaken to determine the best locations within these high and moderate risk areas.

Spatial Coverage: 1295 grid cells are indicated as being subject to major damage from earthquakes and 3247 grid cells are indicated as being subject to moderate damage from earthquakes.

\section{N. 40 DEGREE LATITUDE - FIGURE 19}

Rationale: Areas north of the forty degree latitude line were mapped and considered as potential exclusion areas. The reason for this consideration is that certain studies have indicated that the rectenna size and configuration will become larger and more expensive for sites north of the 40 degree latitude line. Therefore, this potential exclusion variable is related to the baseline design and represents a constraint that may be mediated by design changes.

Reliability of the Data: The location of the 40 degree latitude line is readily available and the only issue relates to the fact that this line is not coterminous with the grid cells. Therefore, all grid cells intersecting the forty degree latitude line were coded, incorporating minimal land areas south of this line. 


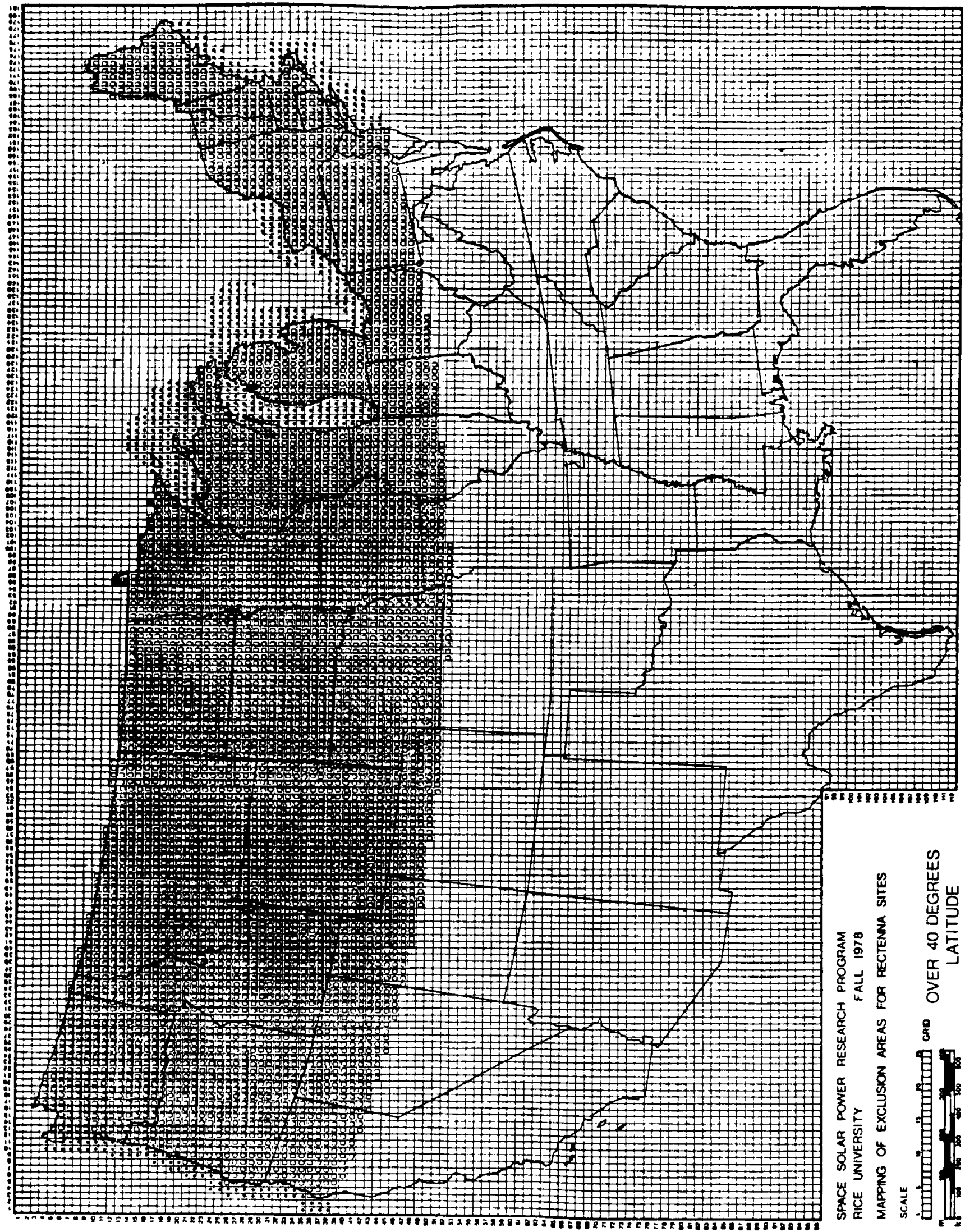


Spatial Coverage: 5332 grid cells are indicated as lying north of the 40 degree latitude line.

\section{WINDS GREATER THAN 50 KNOTS - FIGURE 20}

Rationale: In certain of the documentation concerning the design of the rectenna, it was stated that the rectenna would be designed for wind speeds less than or equal to $90 \mathrm{mph}$. At the data gathering stage, this information was not directly available. Therefore, a "proxy" variable was developed from a NOAA document titled " $\mathrm{Cl}$ imates of the United States". This "proxy" variable was titled \% winds over 50 knots, with two areas being mapped. These were areas where winds were over 50 knots for $2 \%$ of the year and areas where winds were over 50 knots $1 \%$ of the year. Although this variable does not directly apply to the $90 \mathrm{mph}$ criteria, it offers some idea of the spatial dimension of the wind issue.

Reliability of the Data: The map titled winds over 50 knots was developed from a NOAA publication titled "Climates of the United States". The data was extrapolated from a map indicating the number of days over a thirteen year period which had winds of greater than 50 knots. This data was reduced to a $\%$ form, indicating the $\%$ of a year with winds over 50 knots. This extrapolation was an attempt to offer an order of magnitude difference between various regions of the United States with respect to wind. This data does not include information relative to hurricanes, which have their primary influence on the Gulf and Atlantic Coasts. This variable needs further work prior to the project team having confidence that it directly relates to the issue of the ability of the rectenna to withstand high winds.

Spatial Coverage: 1667 grid cells are mapped as being subject to to 50 knot winds more than $2 \%$ of a year and 4810 grid cells are mapped as being subject to 50 knot winds more than $1 \%$ of a year. 


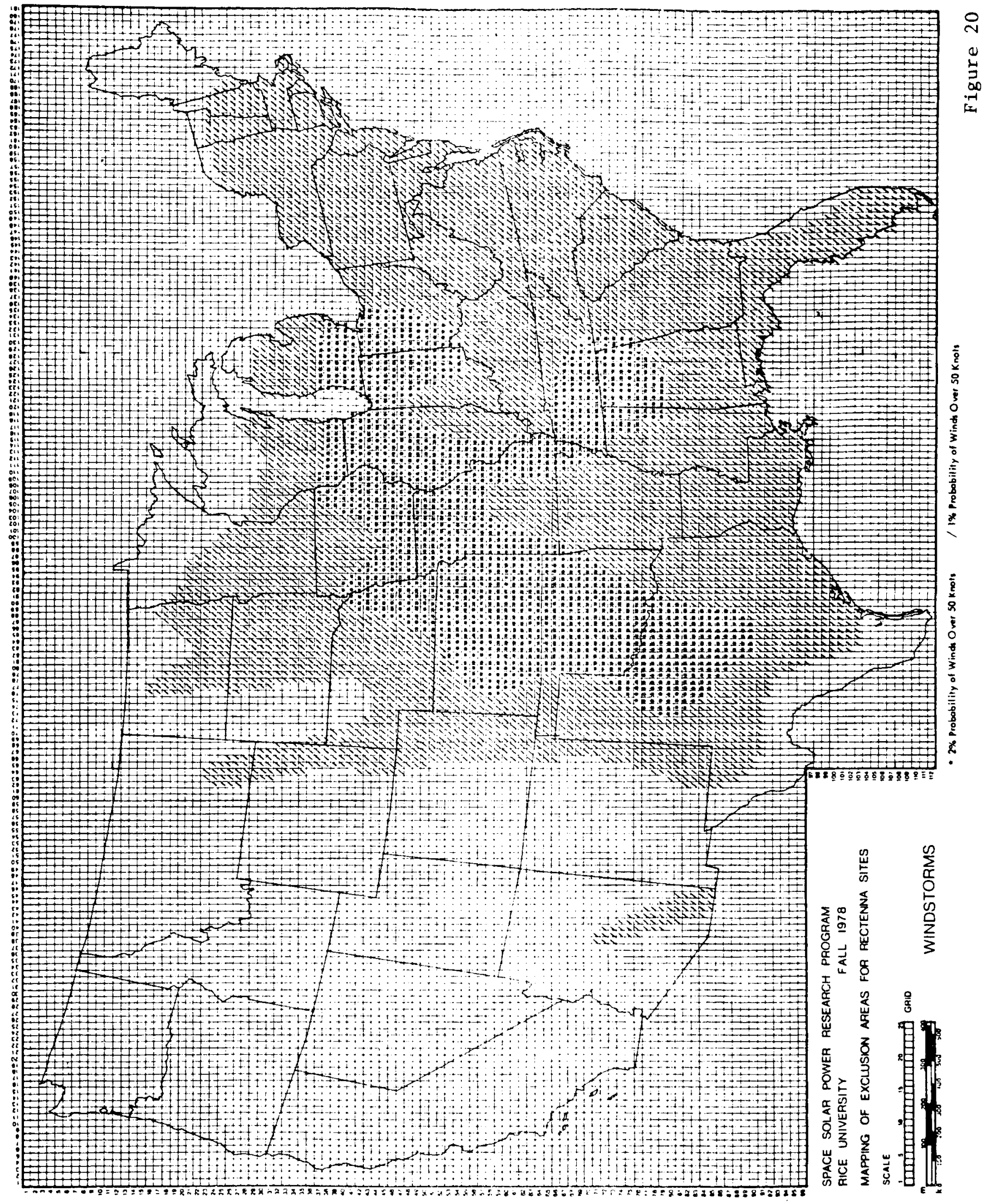




\section{P. NUMBER OF DAYS WITH HAIL - FIGURE 21}

Rationale: The number of days with hail is a variable of importance due to the potential for damage due to these severe storm events. The major importance of the inclusion of this variable is to identify areas with a high risk of hail damage, and to indicate where design alterations need to be considered. This variabie is considered a potential exclusion variable.

Reliability of the Data: This information was taken from a NOAA document titled "Climates of the United States" and is an extrapolation from various weather reporting stations. More important, however, is the absence of information regarding hail size, which is the best indicator of potential damage due to hail. Absent hail size data, the decision was made that the presence of more than four days of hail per year should yield a reasonable probability of large size hail. Therefore, areas were mapped in Figure 21 that exhibited more than four days of hail per year, with the intent that this information be used as a proxy for hail size.

Spatial Coverage: 1469 grid cells are indicated as being subject to potential hail damage.

Q. NUMBER OF DAYS WITH THUNDERSTORMS - FIGURE 22

Rationale: The number of days with thunderstorms was included because of the possibility of danage due to lightning. This information is considered as a potential exclusion variable, both from the perspective of damage and also from the standpoint that alterations may be required in the design of the rectenna.

Reliability of the Data: The number of days with thunderstorms is intended as a proxy variable for lightning density. At this time, a detailed study is underway at Rice University under the direction of Dr. Arthur A. Few to compile a detailed map of the risk posed by 


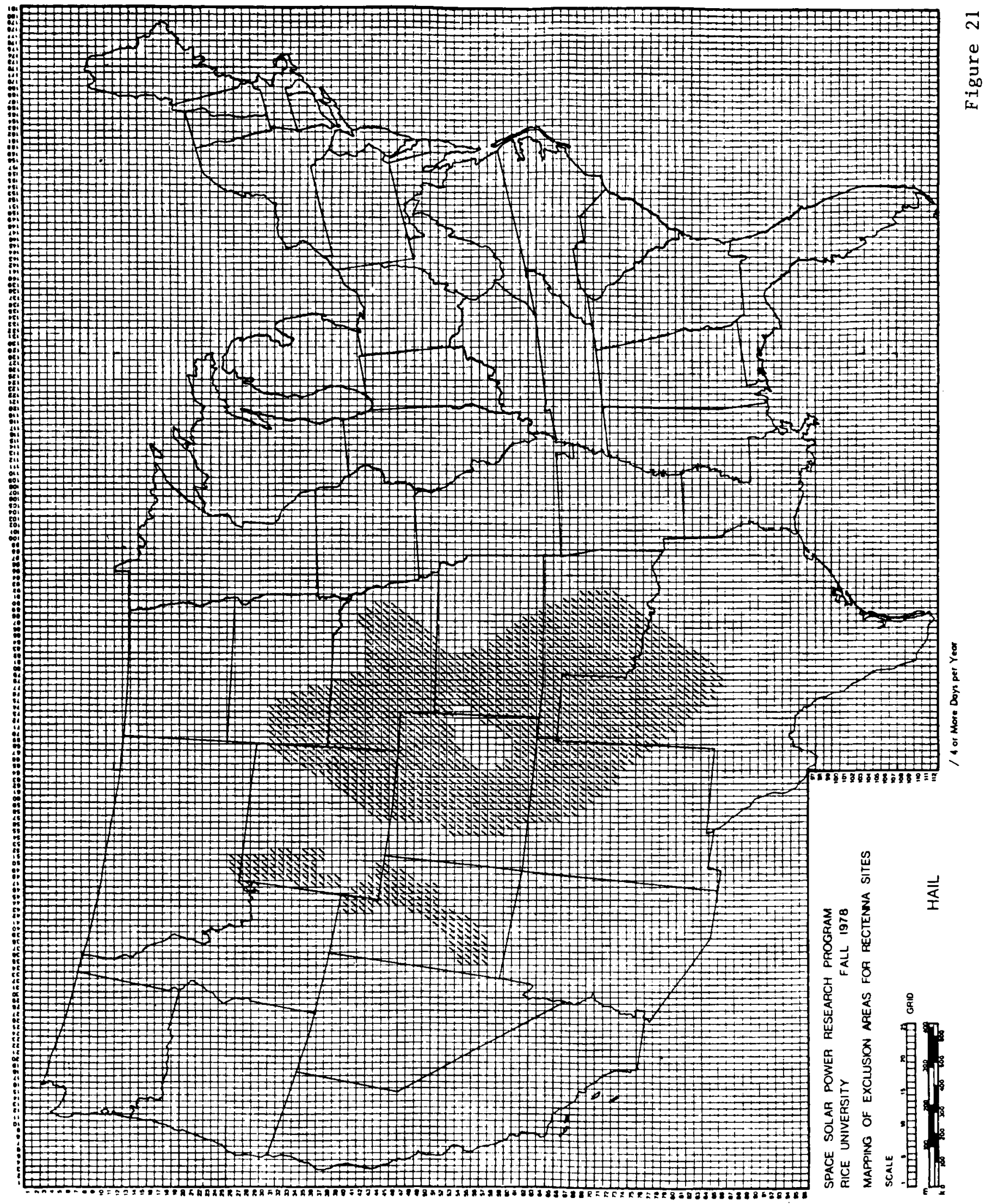




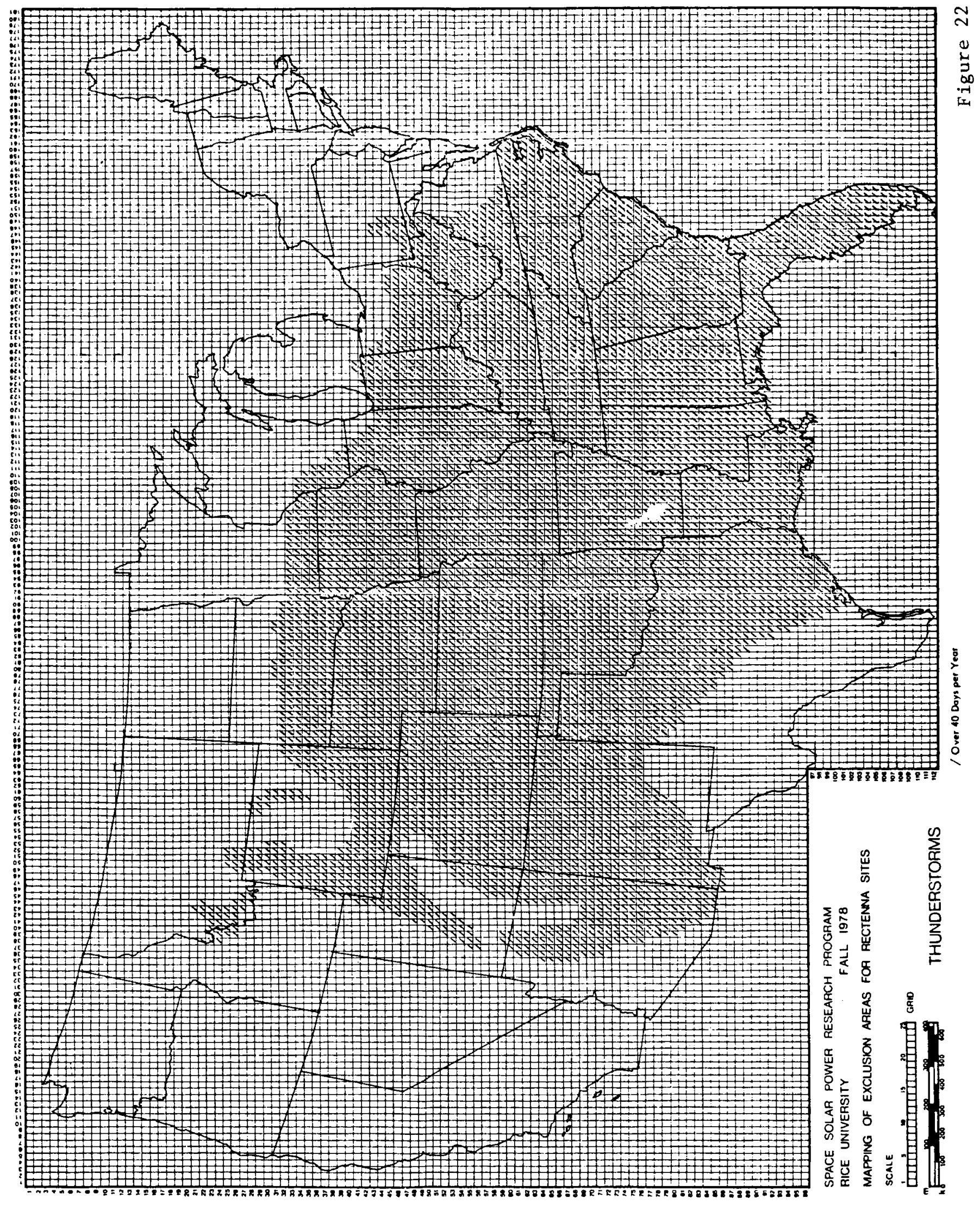


lightning. This use of thunderstorm information should serve as a general "proxy" variable until more detailed research into this phenomenon is completed. The basic information was obtained from the NOAA document titled "Climates of The United States," and was extrapolated by Dr. Few for the project team.

Spatial Coverage: 6118 grid cells are indicated as being subject to thunderstorms.

\section{R. SHEET RAINFALL - FIGURE 23}

Rationale: The possibility exists that heavy rainfalls can produce rain sheeting on the rectenna face, shielding the rectenna from microwaves. This is true of the Marshall Design Type and other designs are also susceptible to this phenomena. The extent to which this factor is considered in the reference design is not clear, but this factor does need to be considered. For this reason, this variable is considered as a potential exclusion variable.

Reliability of the Data: The areas mapped in Figure 23 are interpreted from a map in the NOAA document titled "Climatic Atlas of the United States". This map specified mean annual precipitation in terms of million gallons of water per square mile. Those areas exhibiting a mean annual precipitation greater than 700 million gallons per square mile are shown in Figure 23. This data is based upon extrapolations of recording data stations and is considered reliable.

Spatial Coverage: 3472 grid cells are indicated as being subject to sheet rainfall.

\section{S. ACID RAIN - FIGURE 24}

Rationale: The presence of a low pH in rainfall is a design criteria that should be incorporated into materials specifications for rectennas being constructed in these areas. To the extent that acid 


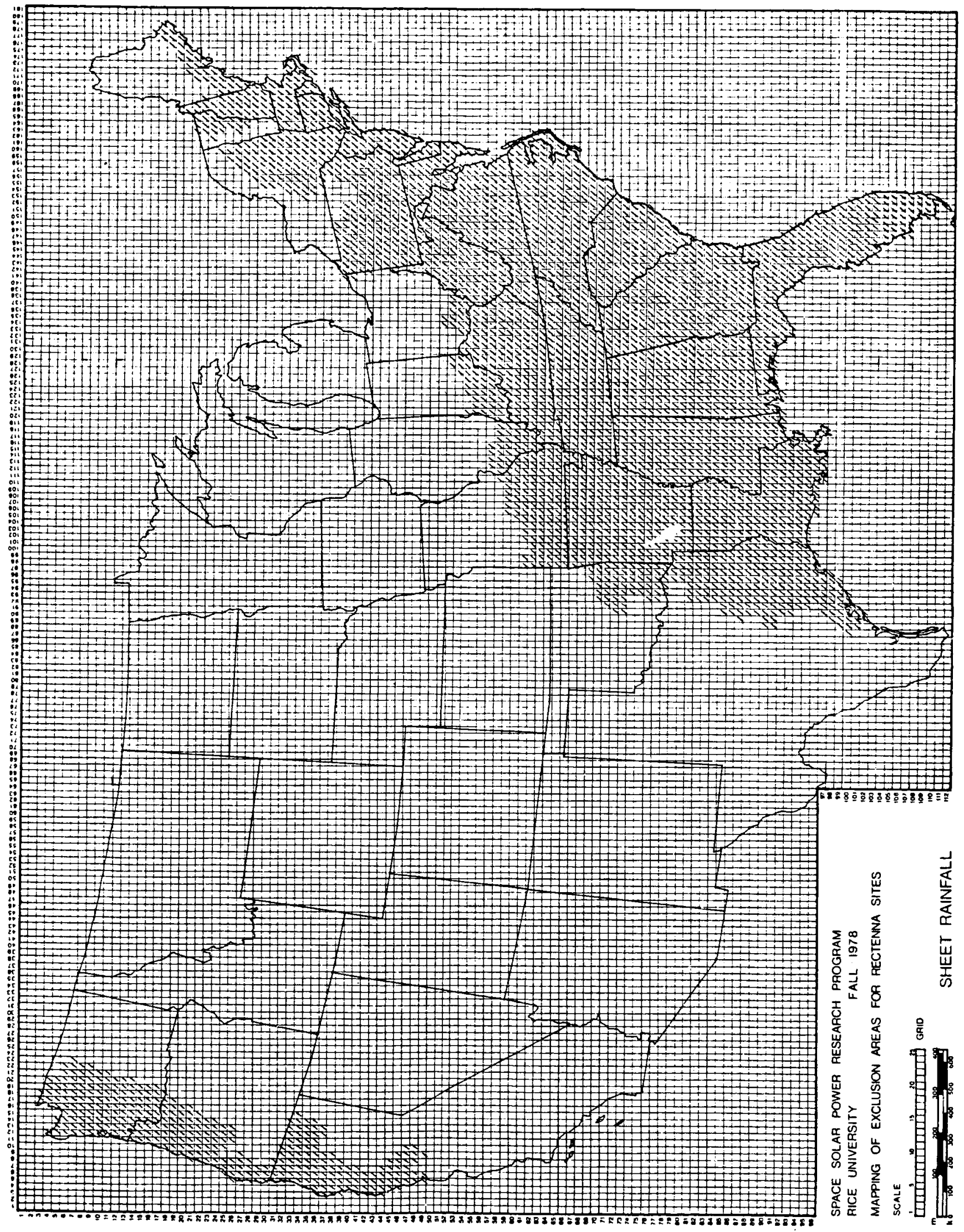




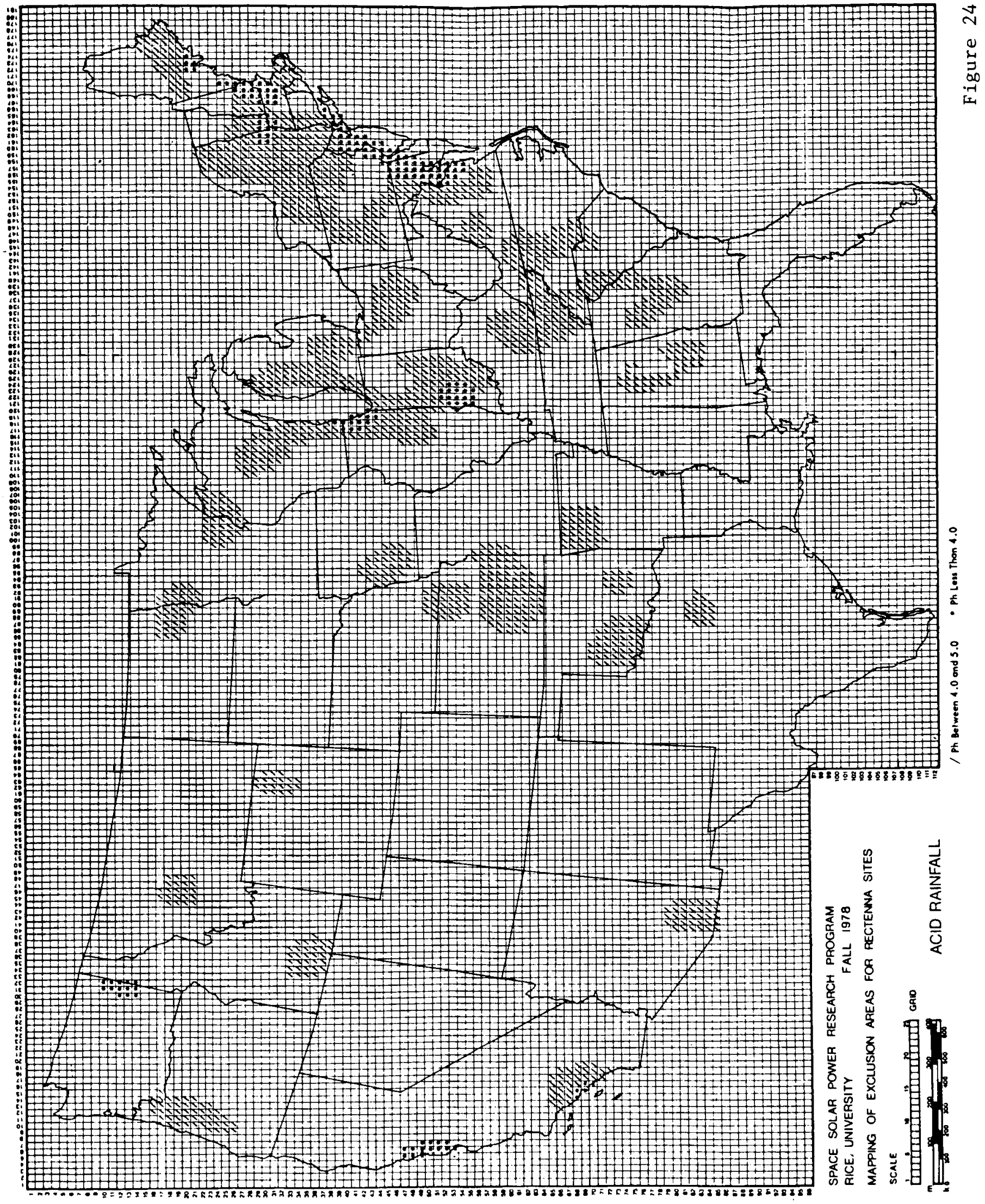


rainfall is not considered in the current reference design, this variable should be considered a potential exclusion variable.

Reliability of the Data: This data was obtained from Scientific American: "The Amateur Scientist" 230: 122-127 (June, 1974). This map offers a general definition of the scope of the problem and is fairly reliable as of the date of its publication. As more use is made of coal for fuel purposes, the spatial coverage of this variable should increase. Therefore, this variable should be updated and perhaps even extrapolated into the future to more reasonably reflect those areas of the United States where acid rainfall represents a design constraint.

Spatial Coverage: 1493 grid cells are indicated as being subject to acid rain of $\mathrm{pH} 4.0-5.0$ and 168 grid cells are indicated being subject to acid rain of $\mathrm{pH}$ less than 4.0 .

\section{T. STATES - FIGURE 25}

For coding purposes, the grid cells had to be placed in one state or another. This informational variable is of importance only to the the extent that compilations are desirable on a state by state basis. However, since the coding of grid cells may lead to one state containing more grids than are in fact in that state, Figure 25 is offered to show the relationship of cells coded as states to state boundaries.

\section{U. CONCLUSION}

In conclusion, the assumptions used in assembling these maps have been set forth. While there are shortcomings in many of these data items, the overall effort should be considered credible. If this approach is considered desirable, the Rice University project team has a number of alternative approaches that should be considered in future work with respect to data collection and appropriate variables. Considering the preliminary nature of this exclusion effort, this data should be sufficient. 


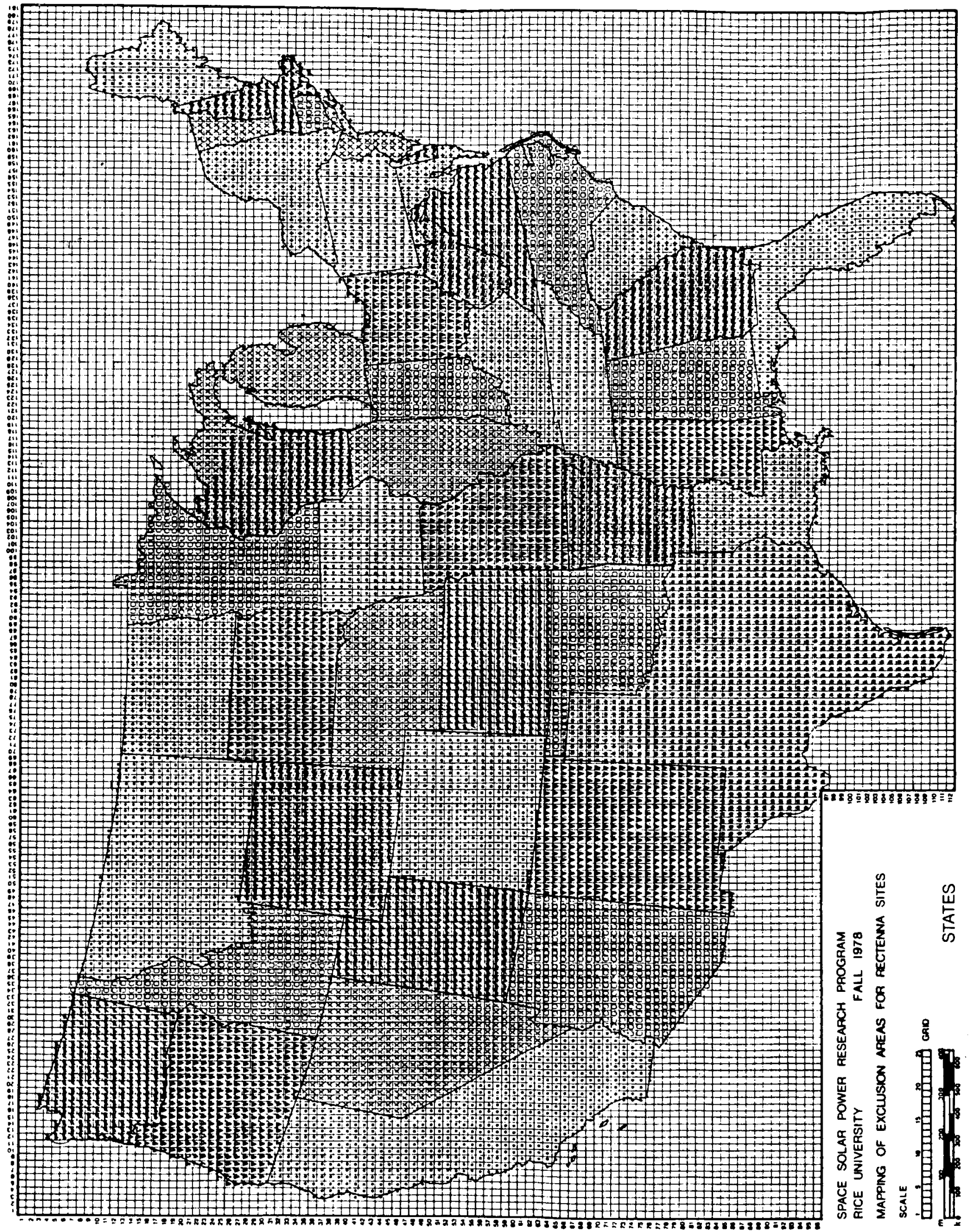




\section{ANALYSIS OF THE DATA}

In this section, the results of the overlay or sieve analysis discussed in the methodology section of this report are presented. Prior to presenting the results of this effort, a number of issues need to be discussed concerning the analytical format and the interpretation of the results. First, through the establishment of a computer overlay capability, a very large number of maps could have been produced. The actual number of potential maps would be 36 factorial. For this reason, only 11 overlay maps (called summary maps) are included in this report. However, a tabular description of the "eligible" areas is included in a table accompanying the synthesis map. Therefore, an attempt was made to show all of the data in a consistent format. It is important to note that all of this data does exist on data tapes, and an operator at the terminal could pick and choose those variables to be overlayed.

In many respects, the results of the analysis require little if any accompanying written explanation: The major information needed for interpretation is the base map used and the new variable added to the overlay. The protocol established was to create a synthesis map, and then to add a new variable to the existing synthesis. The protocol followed in the 11 synthes is maps is as follows:

1. Summary Map 1: This map consists of overlaying five variables. Those variables utilized were (1) National Recreation Areas, (2) Population (all 3 variables), (3) Topography Unacceptable Without South Slopes, (4) Navigable Waterways and (5) Marshland Vegetation.

2. Summary Map 2: This map was composed by overlaying Summary Map 1 with Wetlands.

3. Summary Map 3: This map was composed by overlaying Summary Map 2 with South Slopes of Unacceptable Topography. 
4. Summary Map 4: This map was composed by overlaying Summary Map 3 with National Forests.

5. Summary Map 5: This map was composed by overlaying Summary Map 4 with Indian Reservations.

6. Summary Map 6: This map was composed by overlaying Summary Map 5 with Endangered Species' Habitats.

7. Summary Map 7: This map was composed by overlaying Summary Map 6 with Interstate Highways.

8. Summary Map 8: This map was composed by overlaying Summary Map 7 with Land In Cultivation (both irrigated and cropland).

9. Summary Map 9: This map was composed by overlaying Summary Map 8 with Land Suitable For Cultivation.

10. Summary Map 10: This map was composed by overlaying Summary Map 7 with Flyways of Migratory Waterfowl.

11. Summary Map 11: This map was composed by overlaying Summary Map 7 with Seismic Hazards.

In addition to the 11 summary maps, each summary map is followed by a grid square profile. This grid square profile was compiled upon the "eligible" areas emerging from each synthesis map. The "eligible" areas are those areas that are not marked by an " $X$ " on the summary map, or the white areas. The information contained in the grid square profile is as follows:

1. States: All eligible areas are broken down on a state by state basis, with the total number of cells in the eligible areas being reported.

2. Land: The number of grid cells in the "eligible" areas are set out in this column. Additionally, the total number of cells for the United States are compiled at the bottom of the column.

3. Percent of Total Land Area: This percentage represents the relationship of the eligible cells to the total cells as a percent. 
4. Over 40 Degree Latitude: The number of grid cells lying north of the 40 degree latitude line are set forth in this column.

5. Federal Land Ownership: The number of eligible cells that are (1) on military reservations and (2) in other federal lands (national parks) category are displayed in this column.

6. Windstorms Over 50 knots: The number of eligible cells that are subject to windstorms over 50 knots are shown in this column, broken down with respect to a $1 \%$ and $2 \%$ occurrence of windstorms.

7. Hail: The number of eligible cells that are subject to Hail are shown in this column.

8. Thunderstorms: The number of eligible cells subject to thunderstorms are shown in this column.

9. Sheet Rainfall: The number of eligible cells subject to sheet rainfall are shown in this column.

10. Acid Rainfall: The number of eligible cells subject to acid rainfall are shown in this column, both with respect to $\mathrm{pH}$ from 4.0 to 5.0 and with respect to $\mathrm{pH}$ less than 4.0 .

It is important to remember that this grid square profile summary is not a profile of the entire state with respect to the identified variables. Instead, it is a profile of the "eligible" cells within the state. Therefore, if an entire state was excluded through the overlaying of the exclusion variables, the number of "eligible" cells would be zero and the statistical analysis of those cells would also be zero. A state by state summary across all variables is included in Appendix A.

Finally, it is important to recognize that "eligible" cells are not necessarily proper sites for rectennas. The only meaning to be given to these areas is that they were not excluded on the basis of the exclusion criteria used to assemble the summary map. Therefore, these are the areas that are not el iminated. 
This map was assembled by combining (1) National Recreation Areas, (2) Population (all 3 variables), (3) Topography Unacceptable Without South Slopes (all 3 variables), (4) Navigable Waterways and (5) Marsh Vegetation. The areas marked with an " $X$ " are excluded as potential sites. Those areas not marked by an " $X$ " are not excluded on the basis of the variables mapped and combined. 


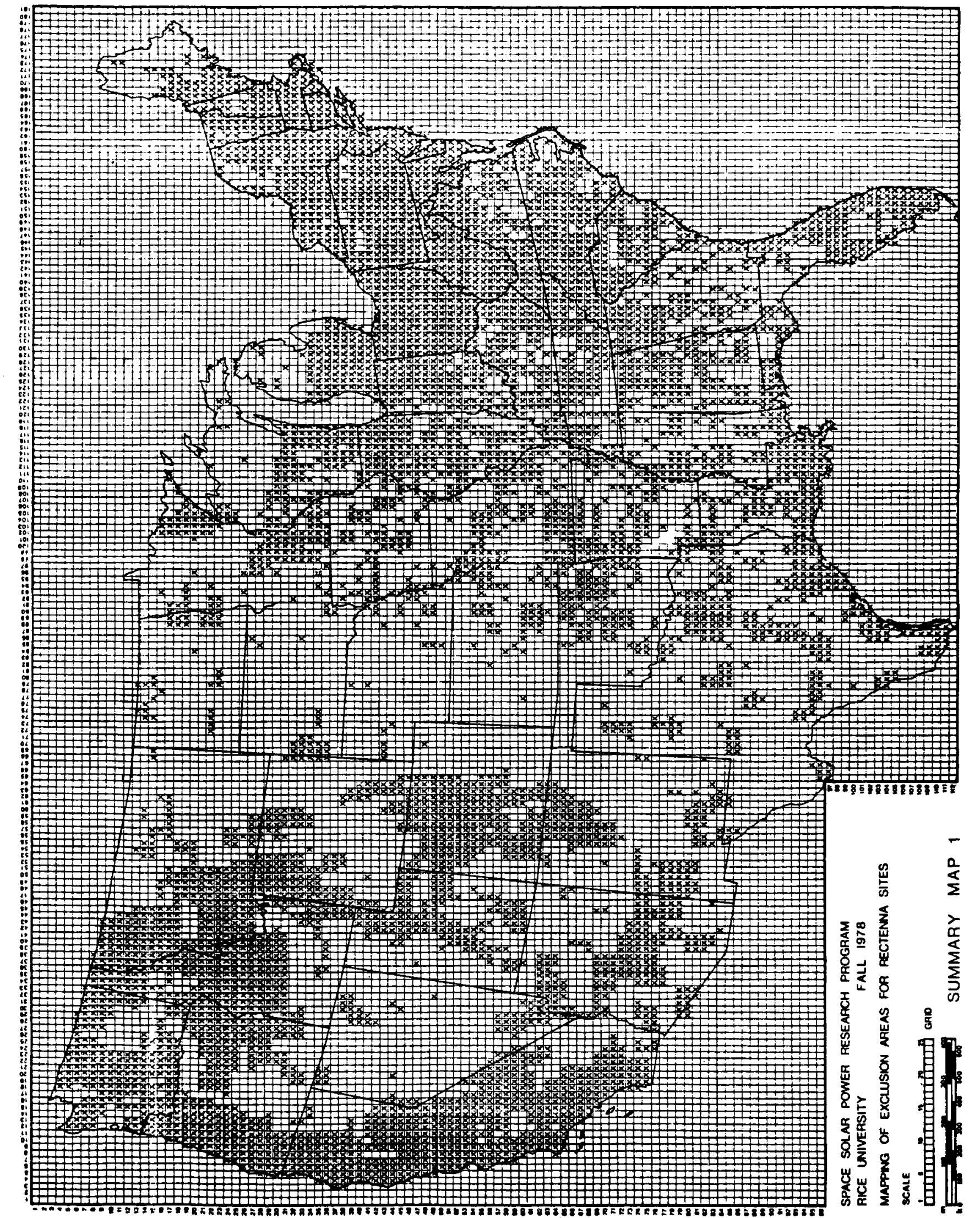




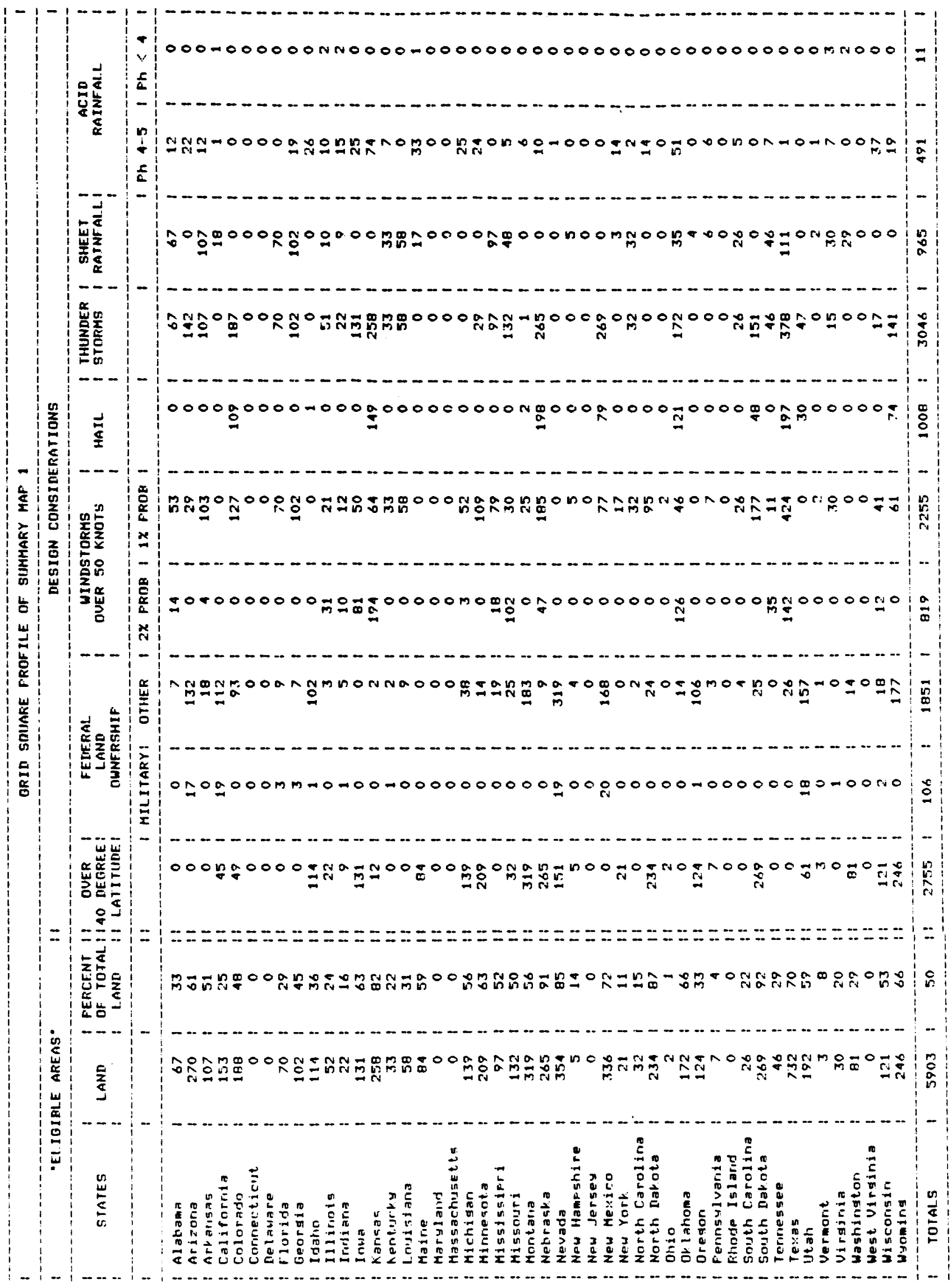


SUMMARY MAP 2

This map was assembled by combining Summary Map 1 with Wetlands. 


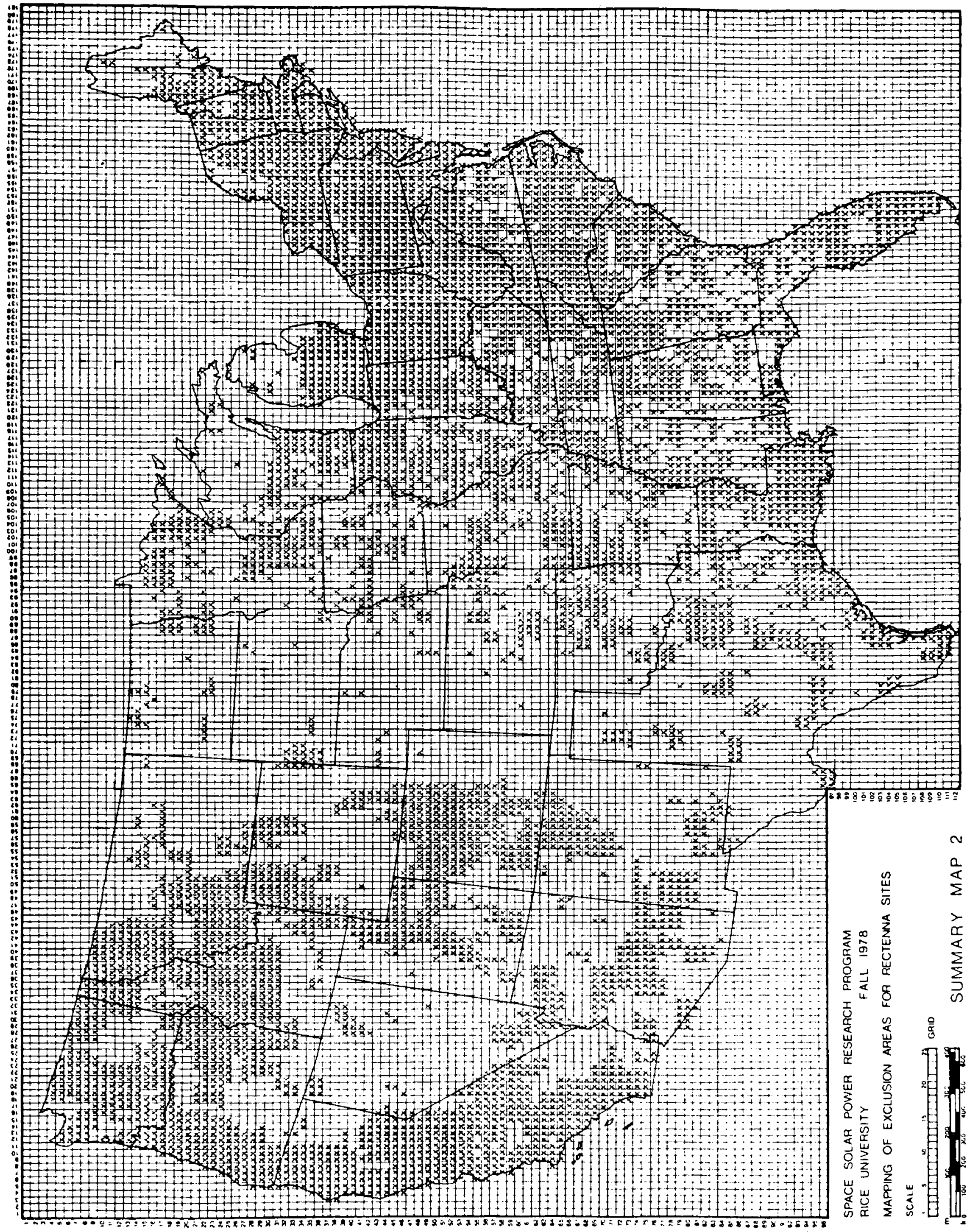




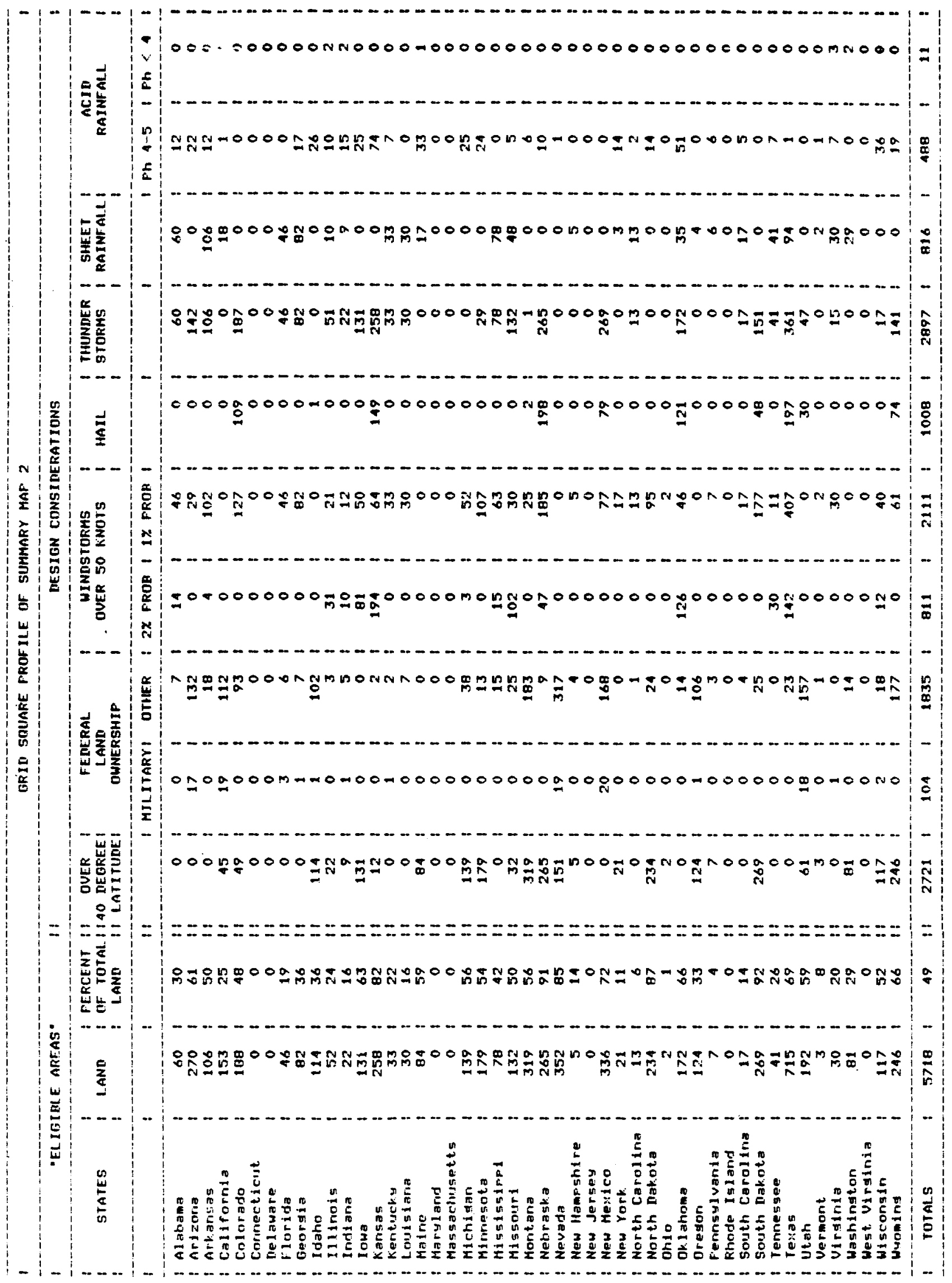


SUMMARY MAP 3

This map was assembled by combining Summary Map 2 with South Slopes of Unacceptable Topography. 


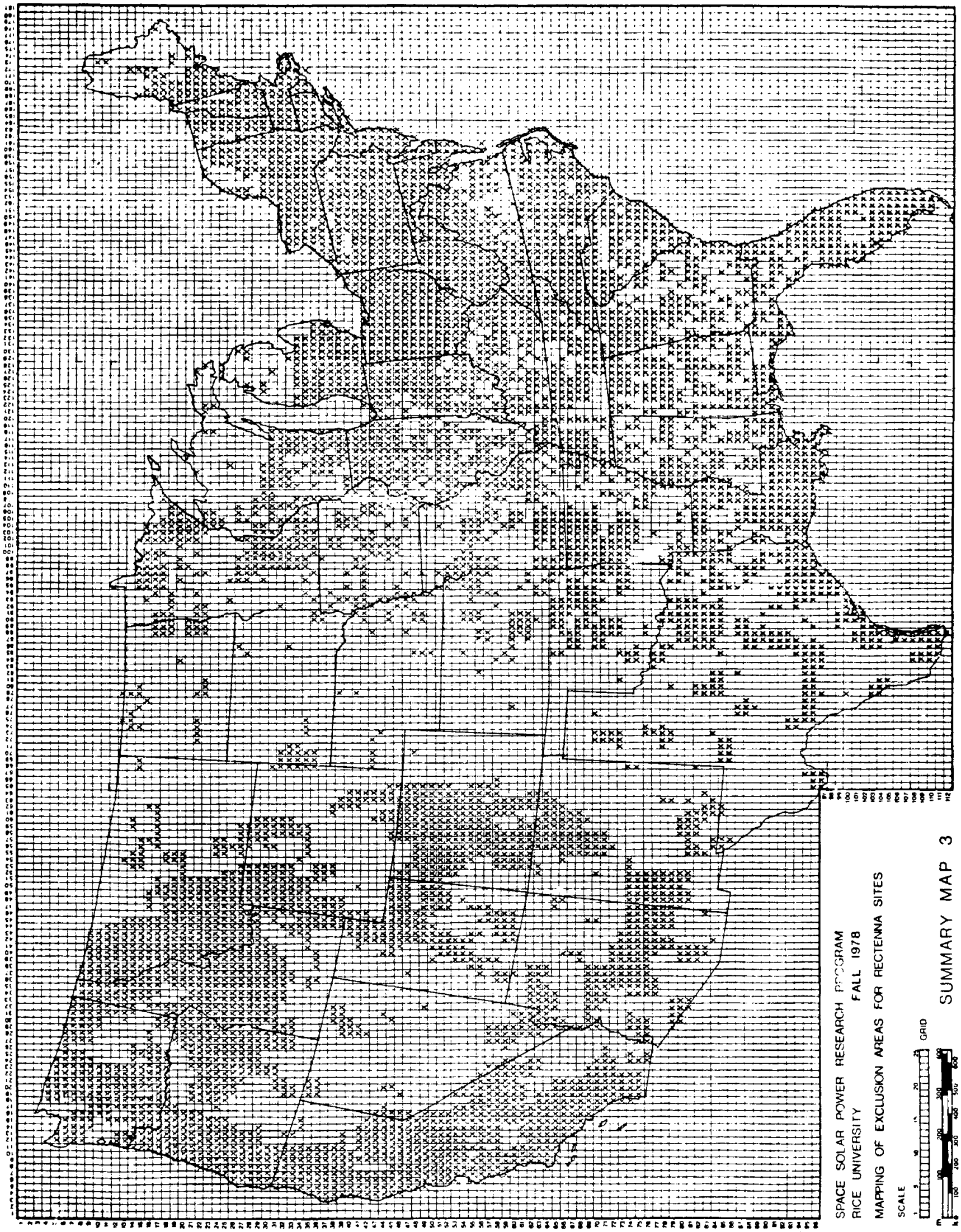




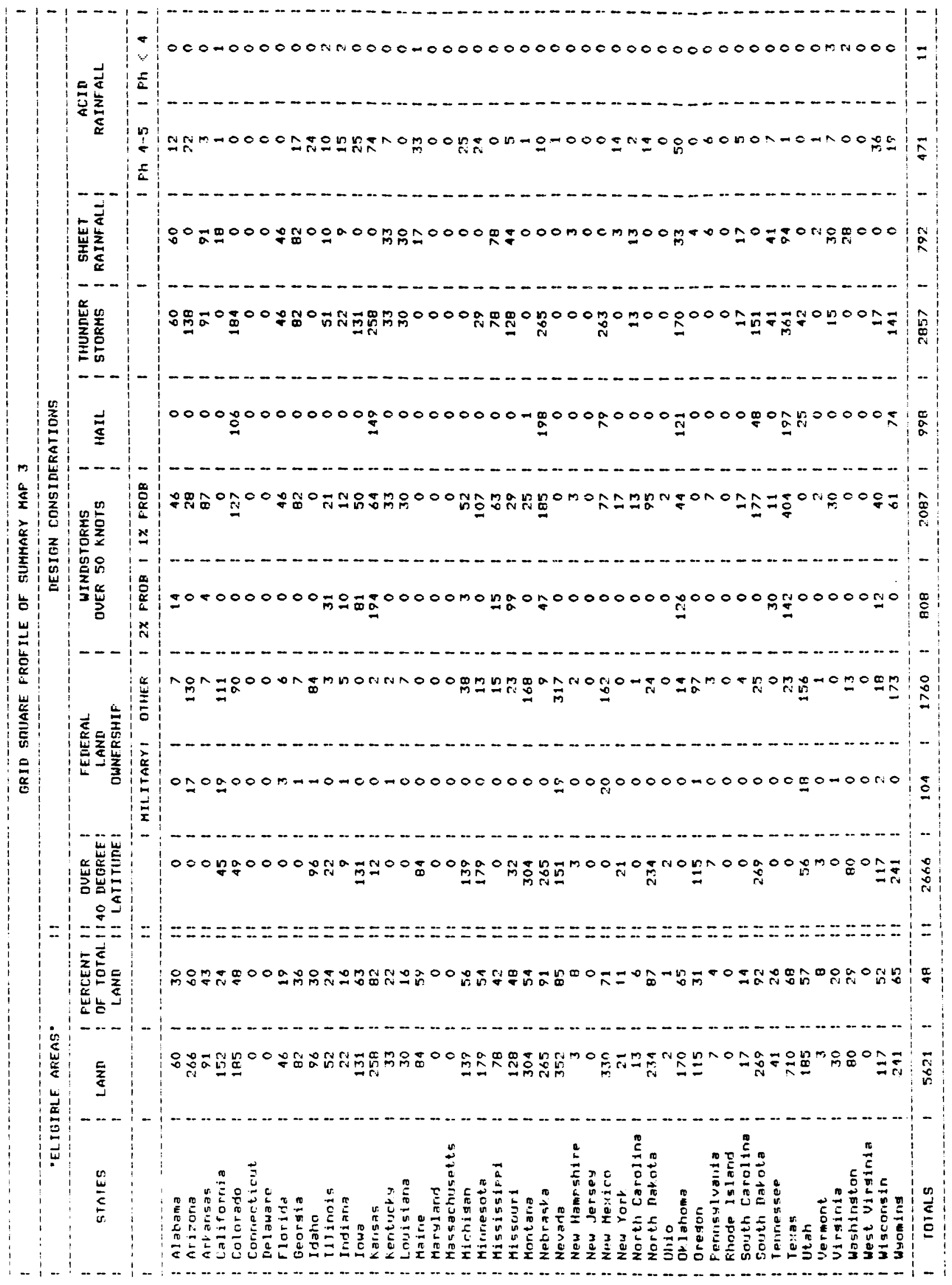


SUMMARY MAP 4

This map was assembled by adding Summary Map 3 with National Forests. 


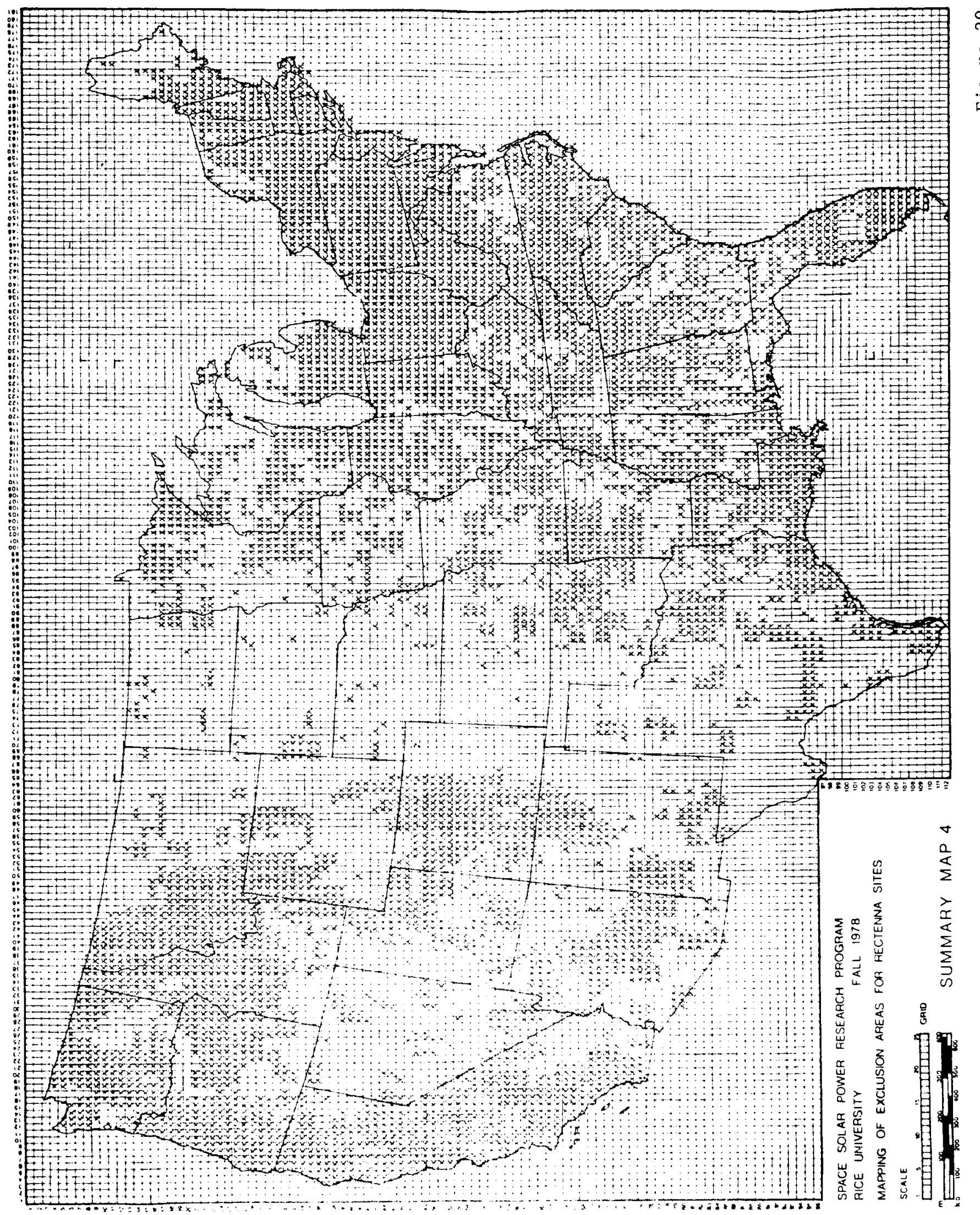




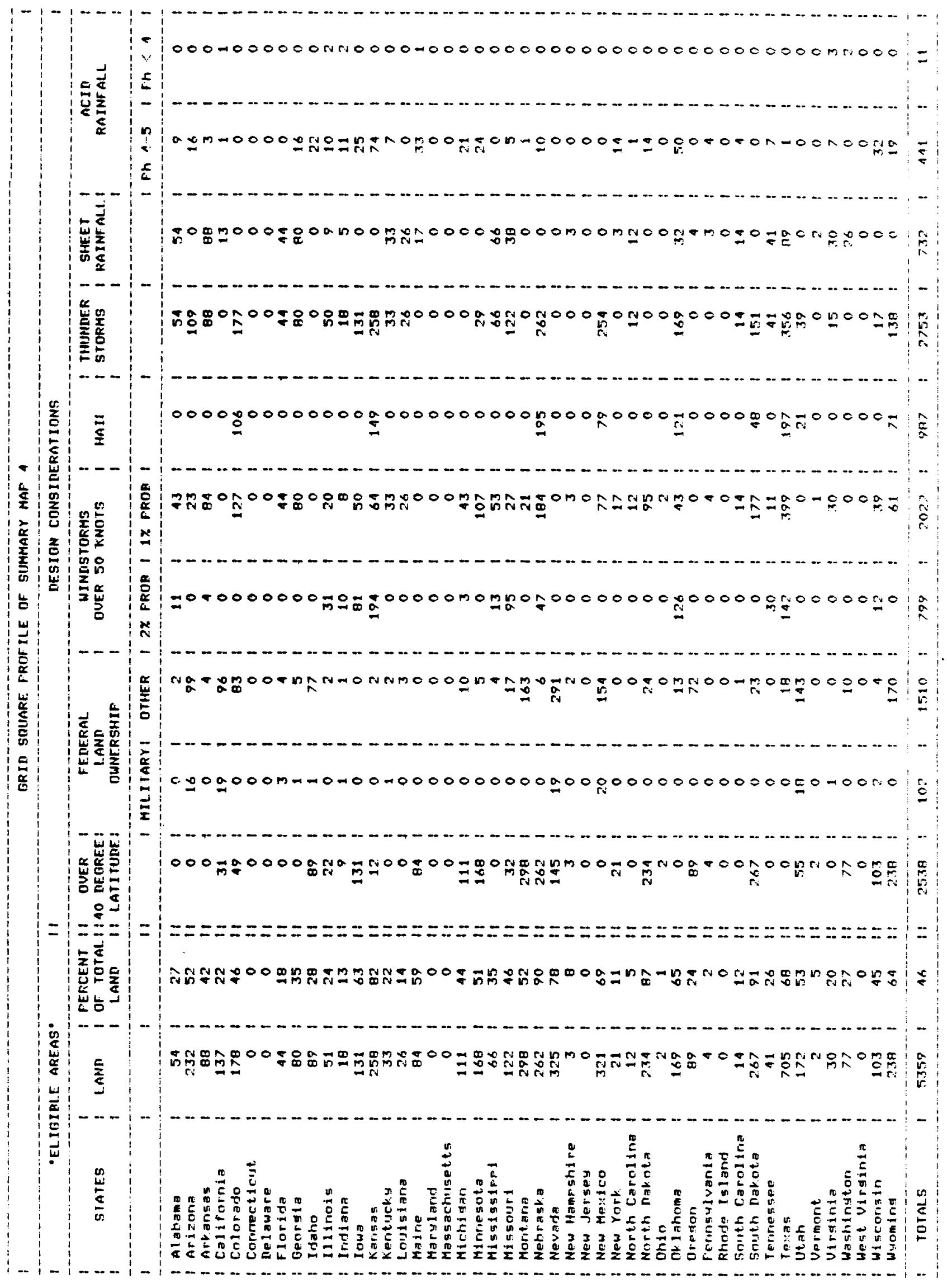


SUMMARY MAP 5

This map was assembled by adding Summary Map 4 with Indian Reservations. 


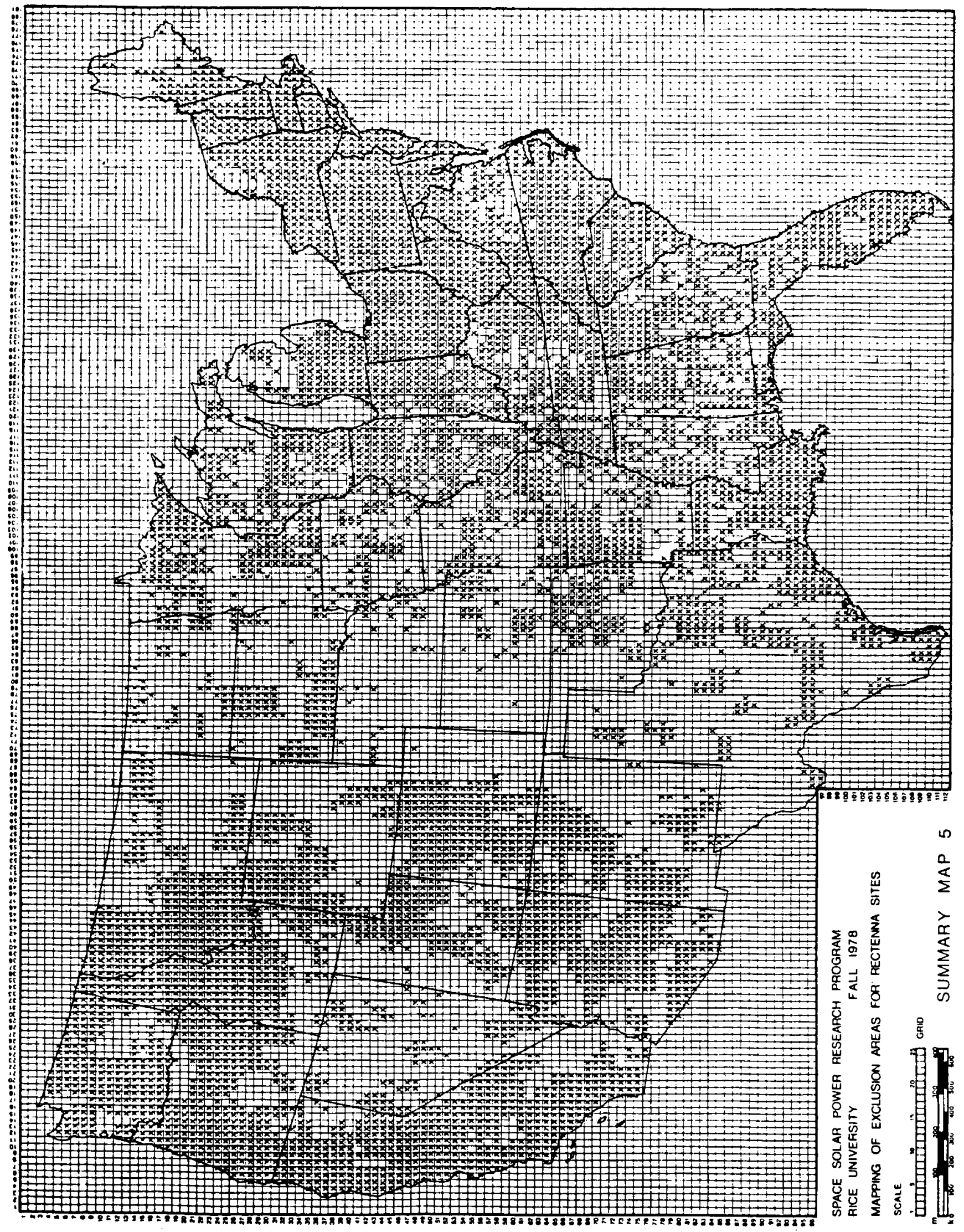




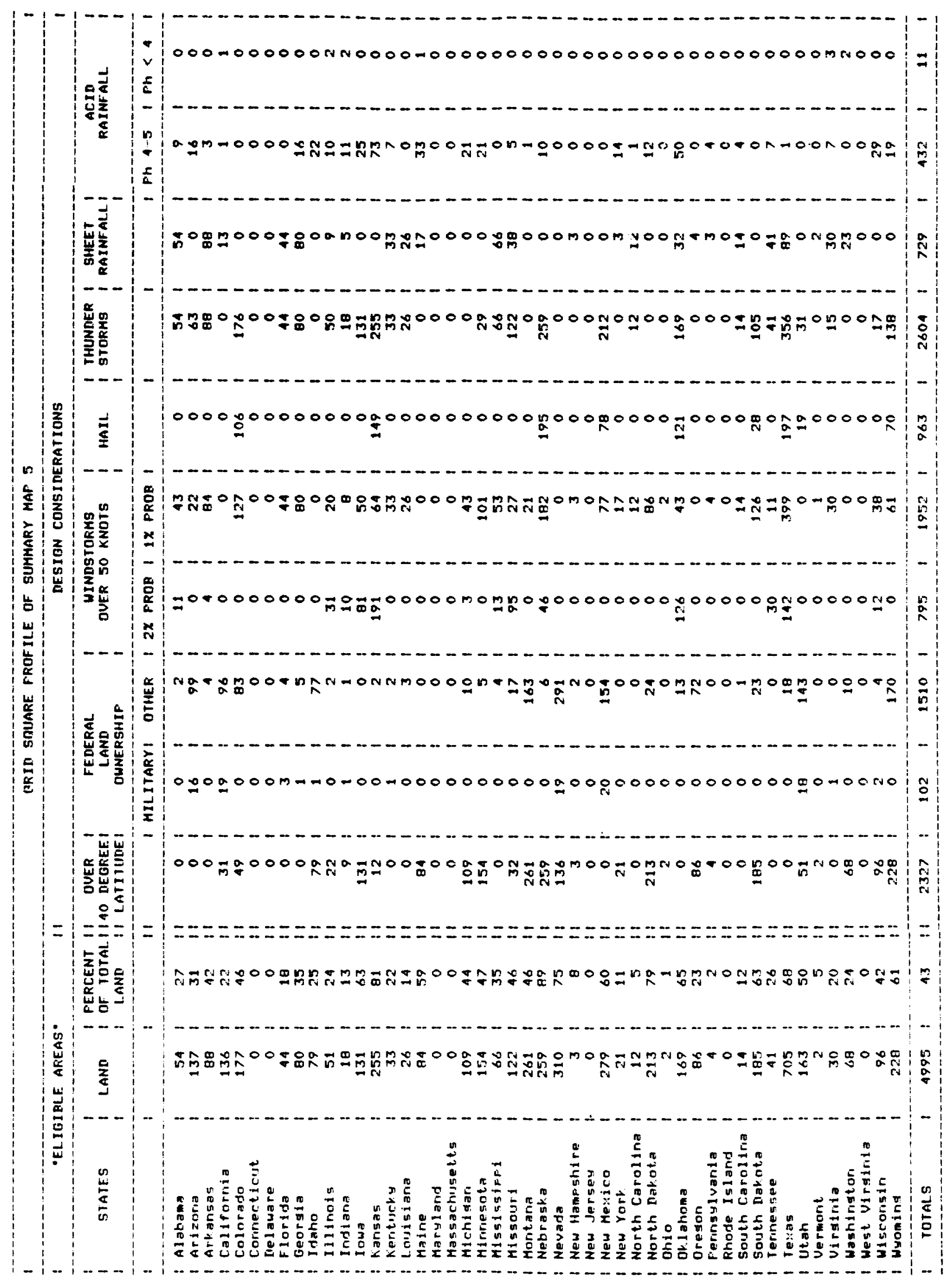


SUMMARY MAP 6

This map was assembled by adding Summary Map 5 with Endangered Species Habitats 


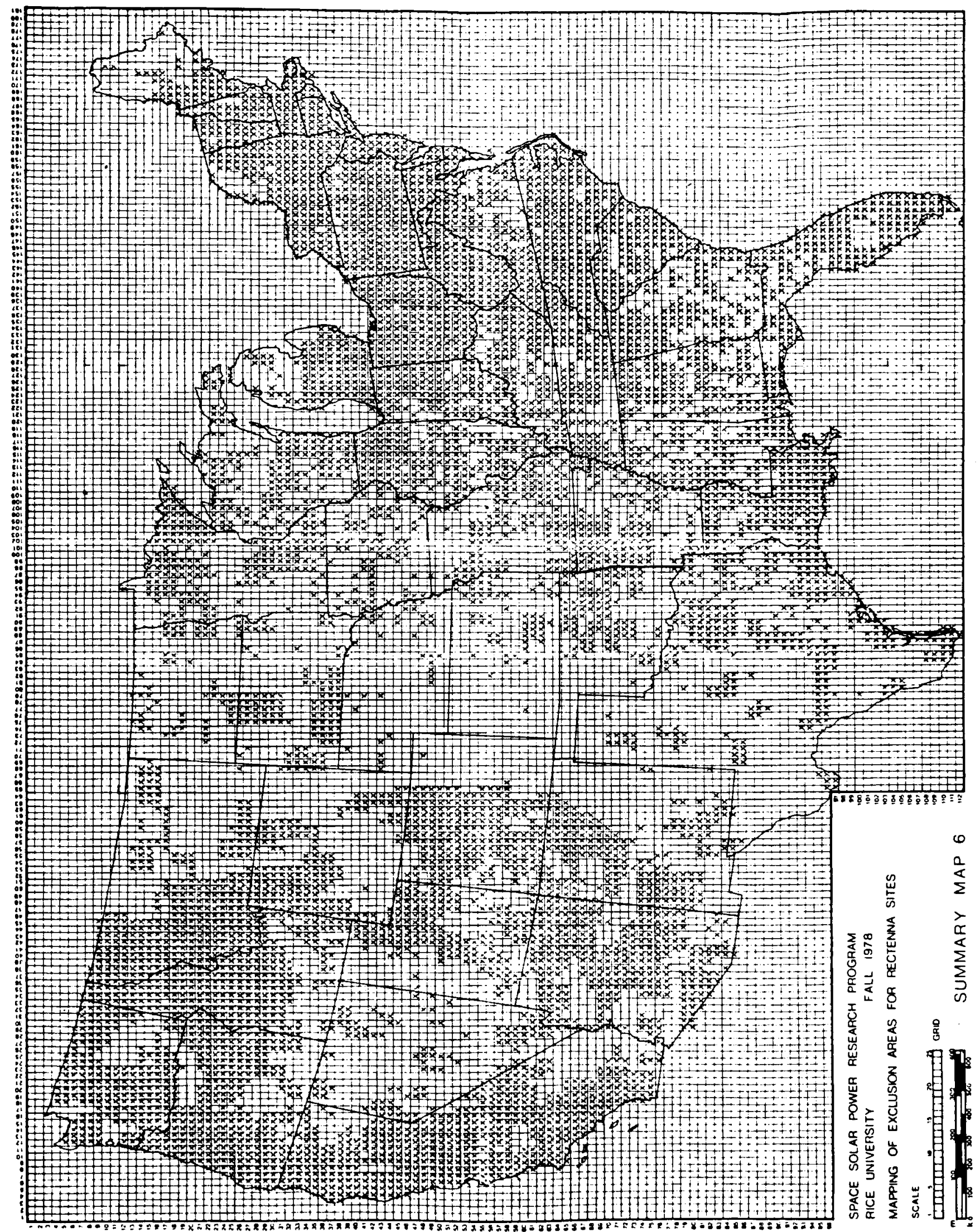




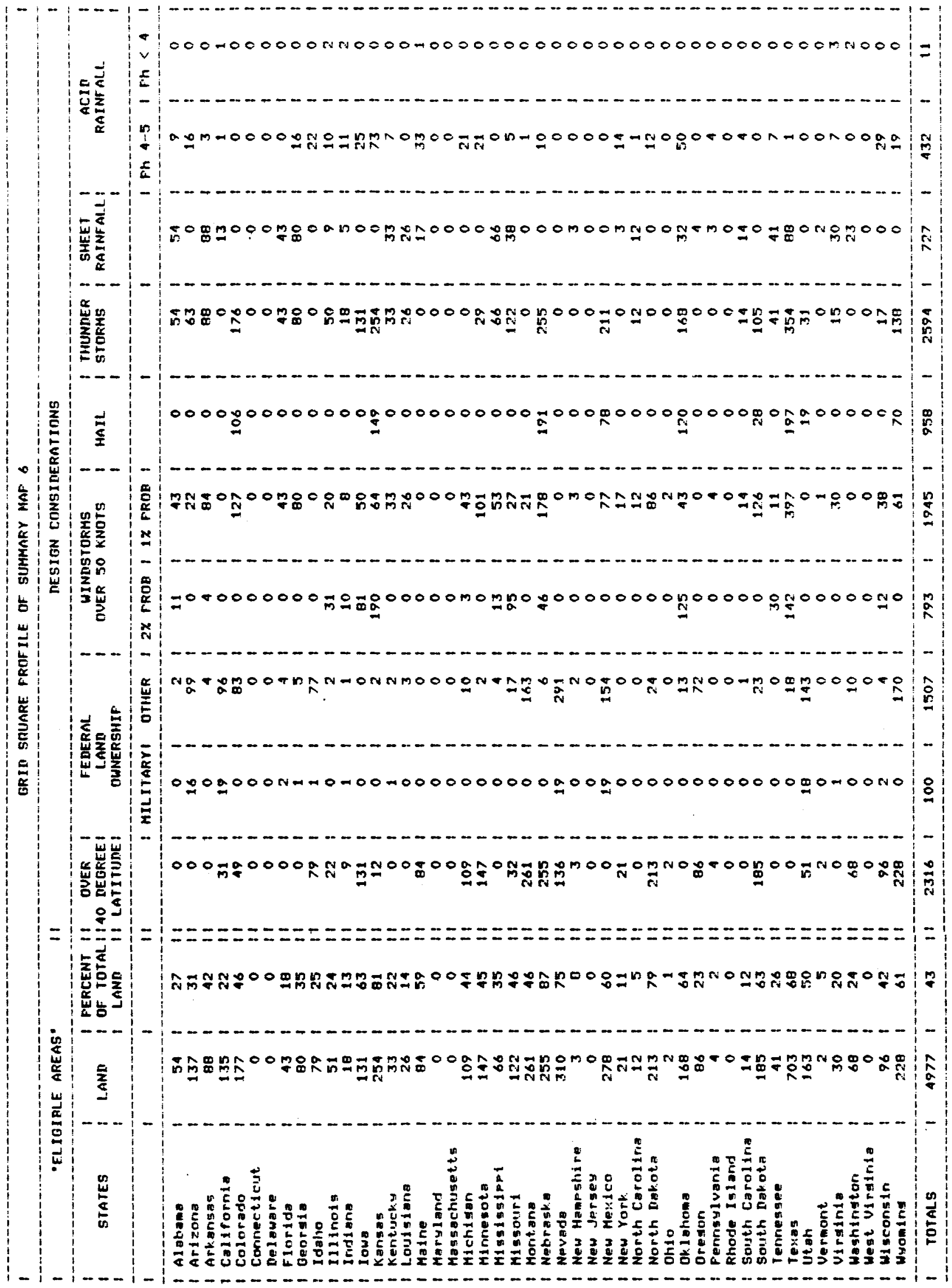


SUMMARY MAP 7

This map was assembled by adding Summary Map 6 with Interstate Highways . 


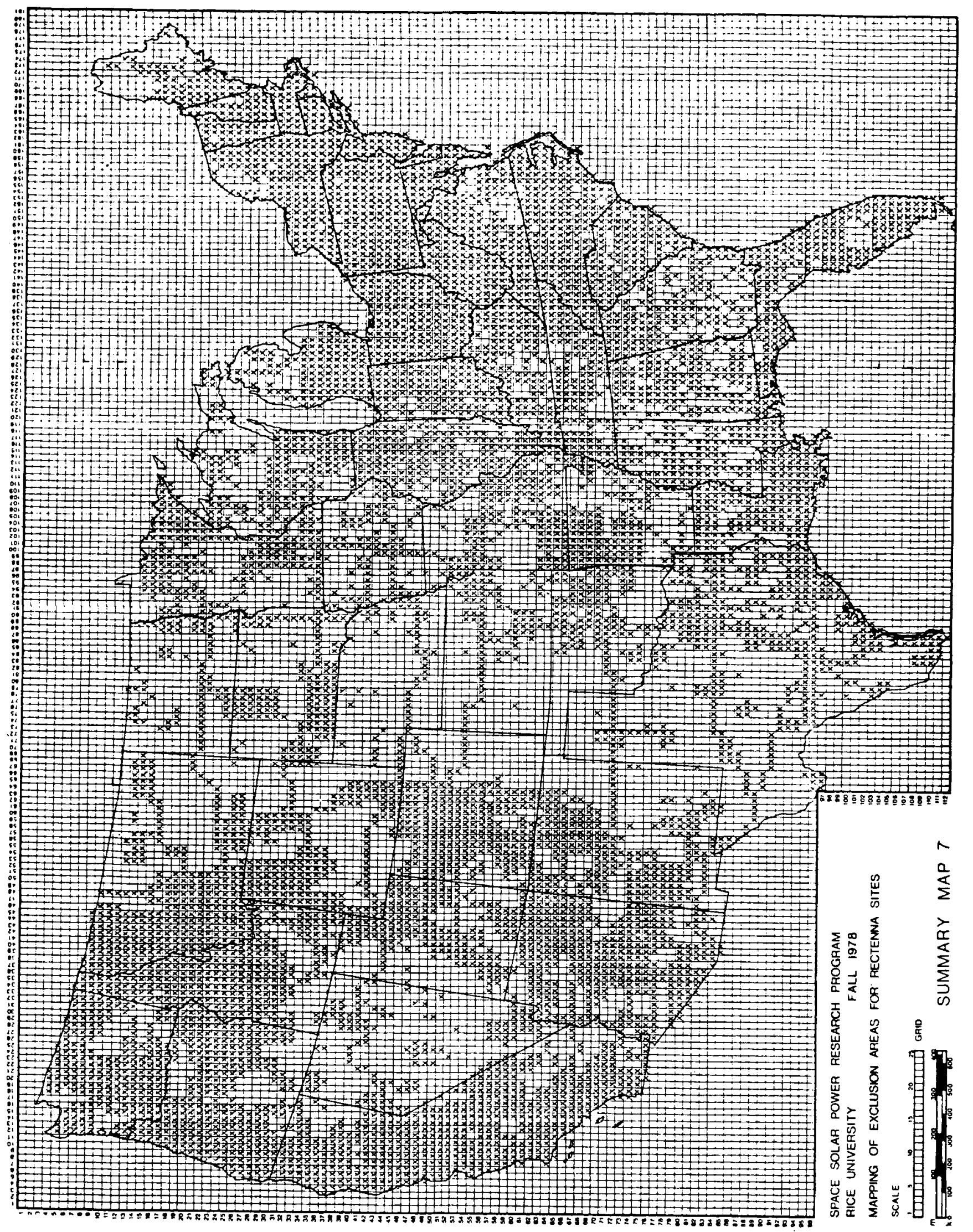




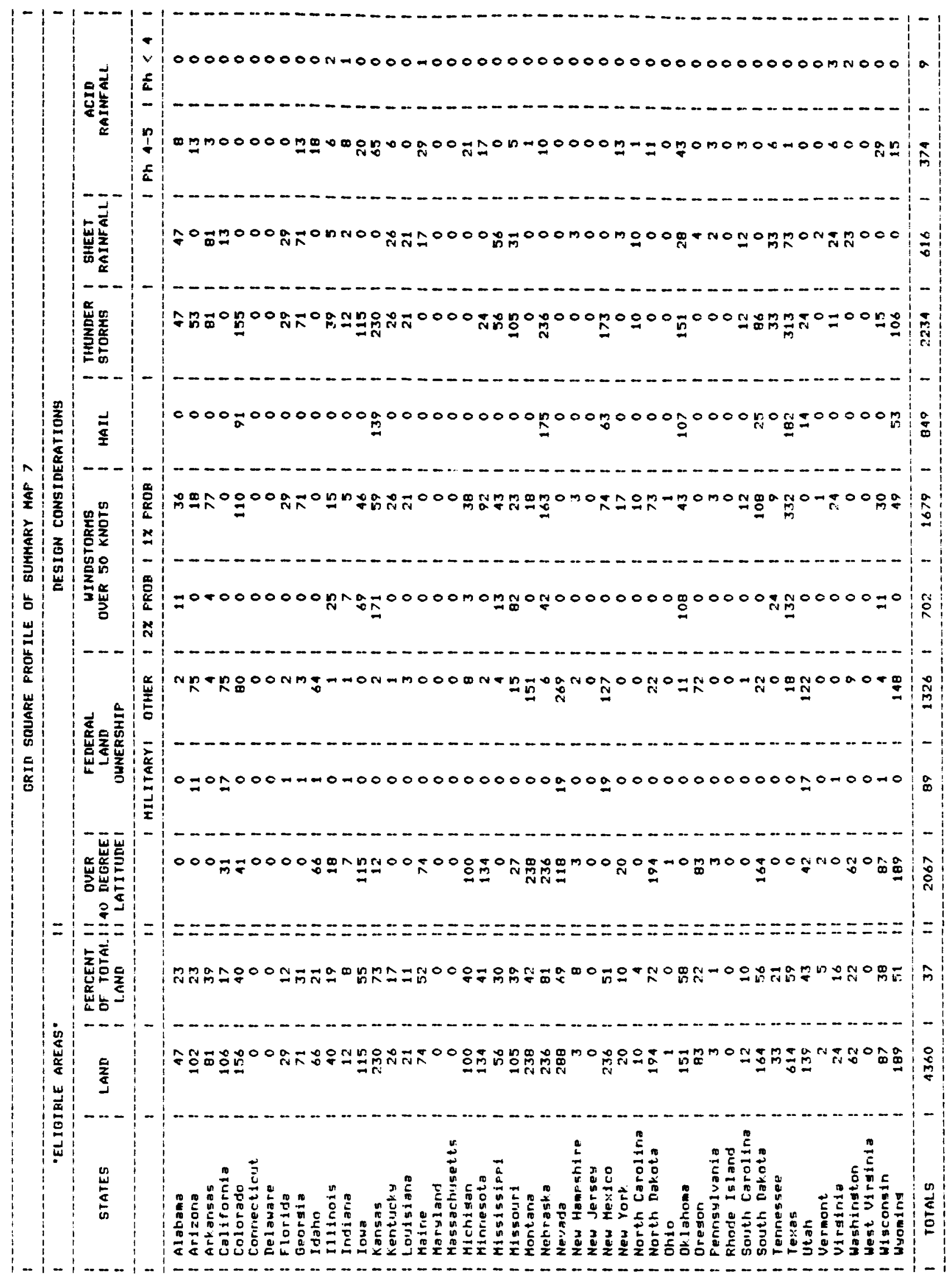


SUMMARY MAP 8

This map was assembled by adding Summary Map 7 with Land In Cultivation. 


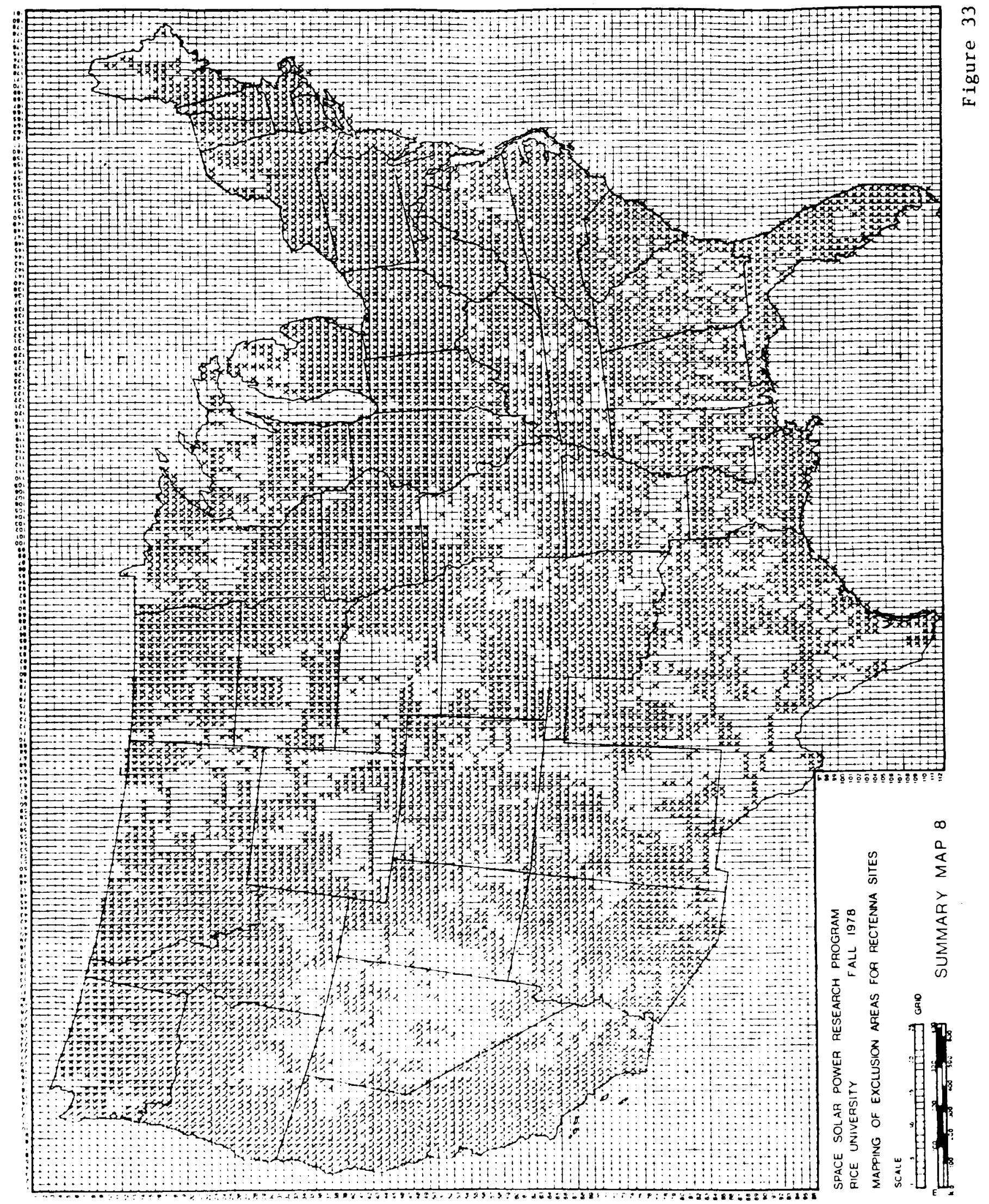




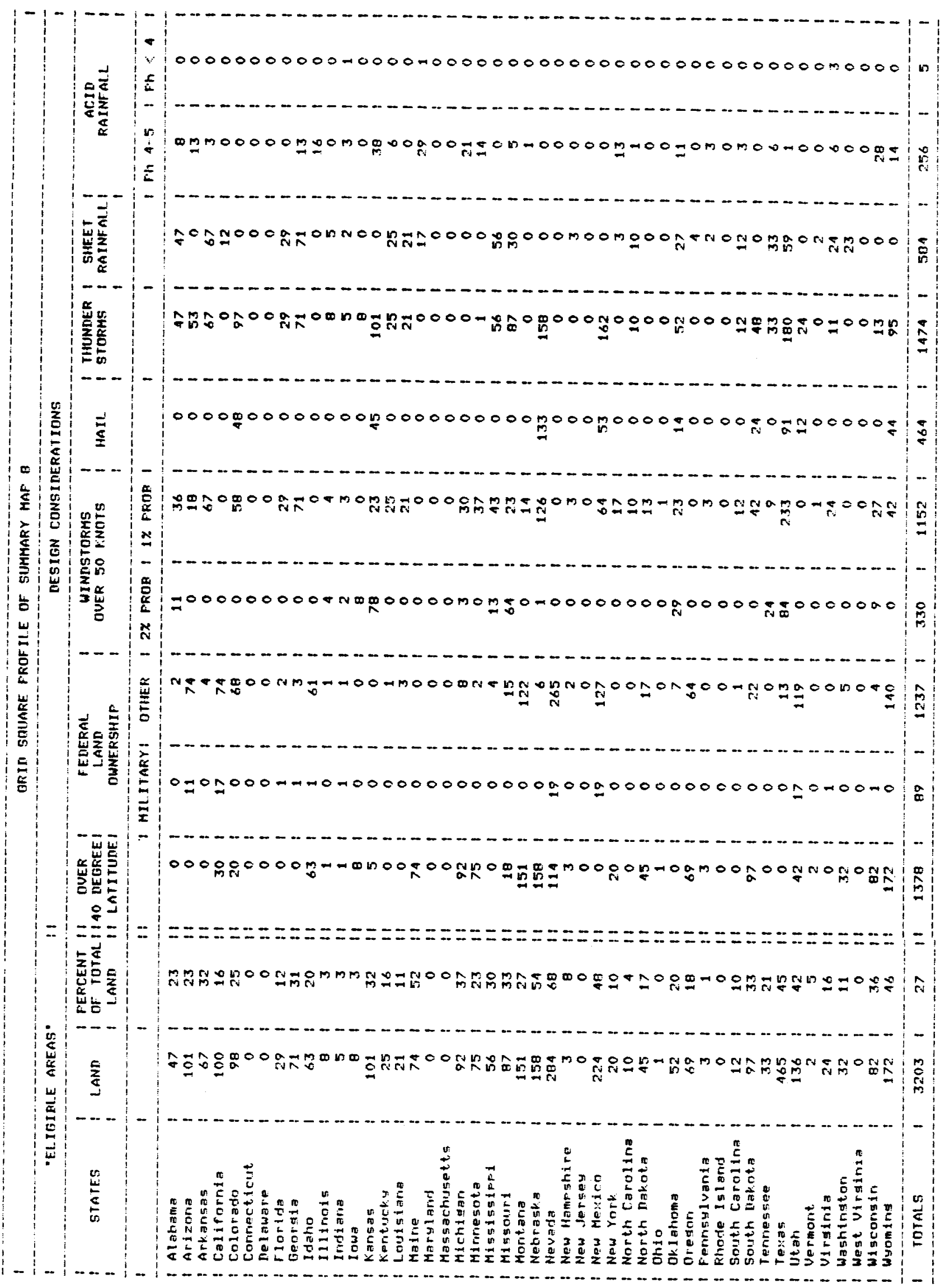


SUMMARY MAP 9

This map was assembled by adding Summary Map 8 with Land Suitable For Cultivation (both variables). 


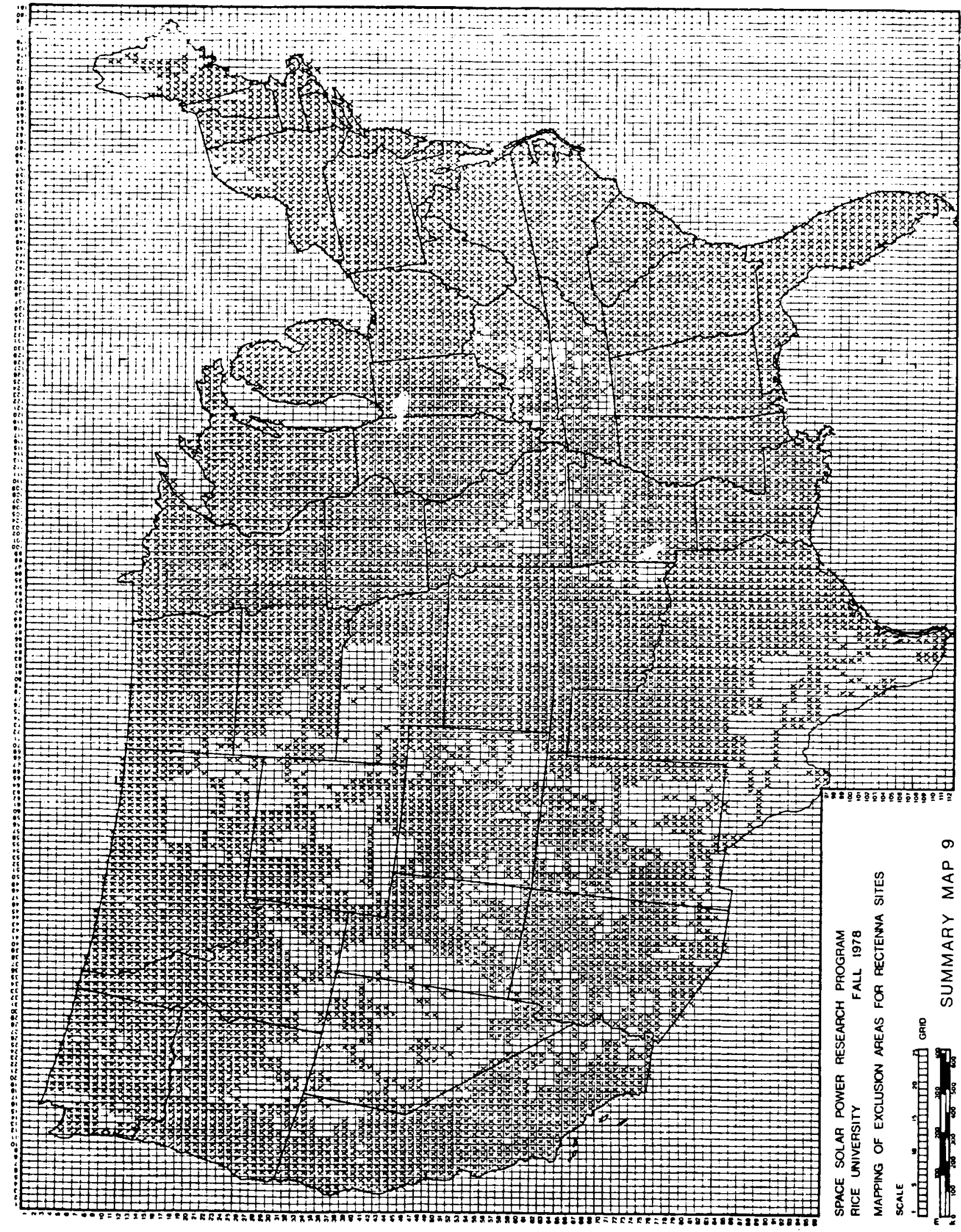




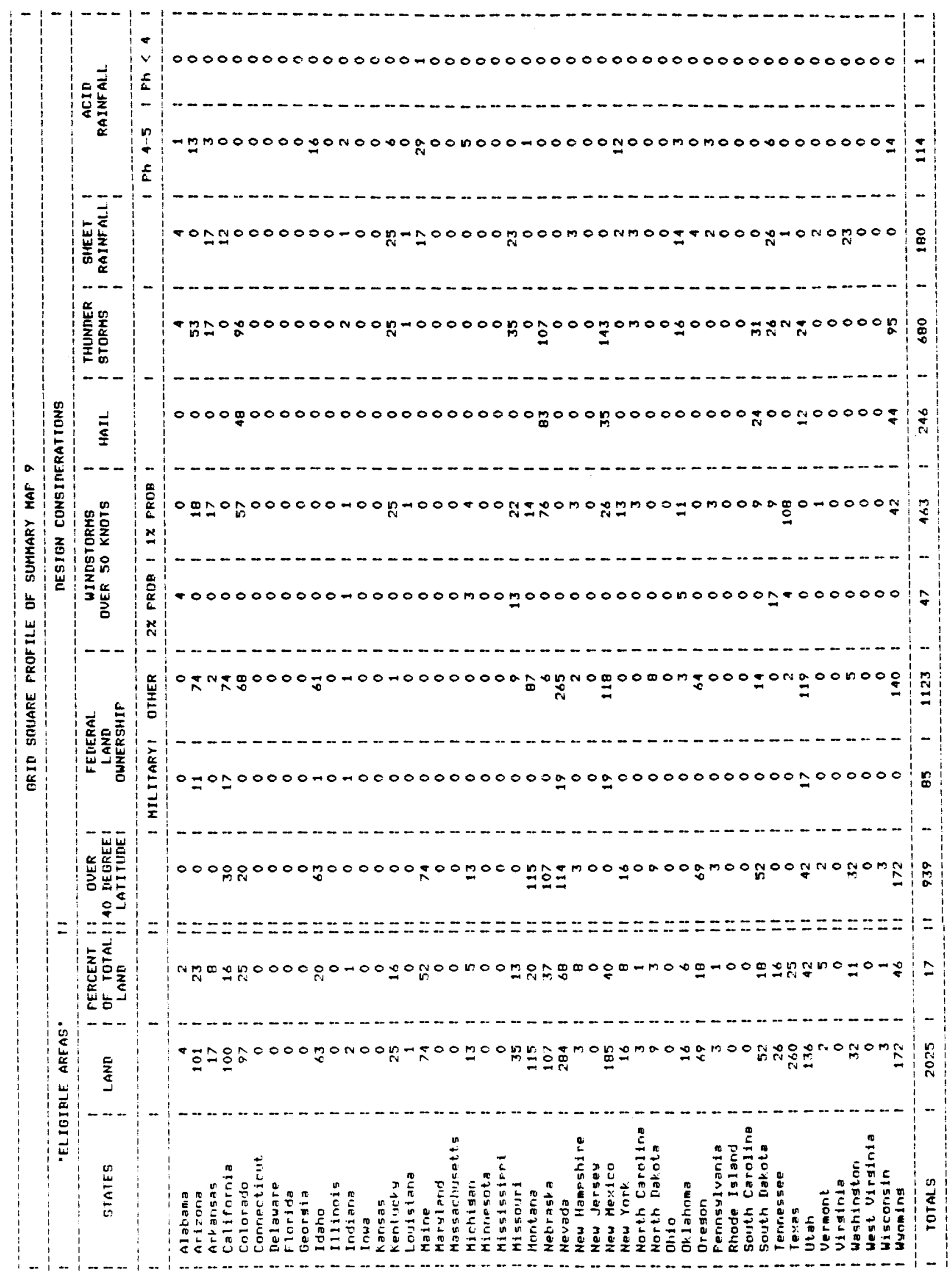


SUMMARY MAP 10

This map was assembled by adding Summary Map 7 with Flyways of Migratory Waterfowl. 


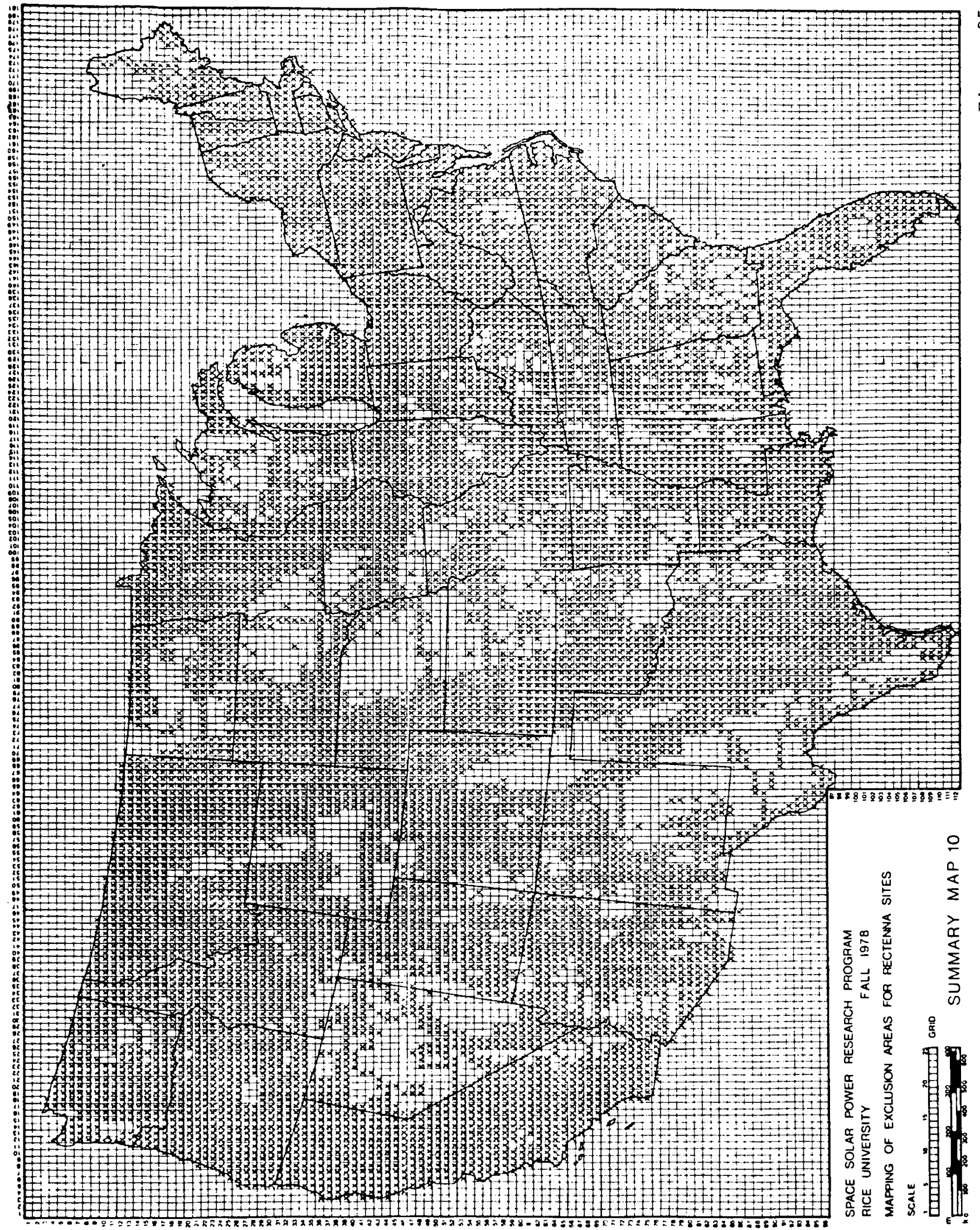




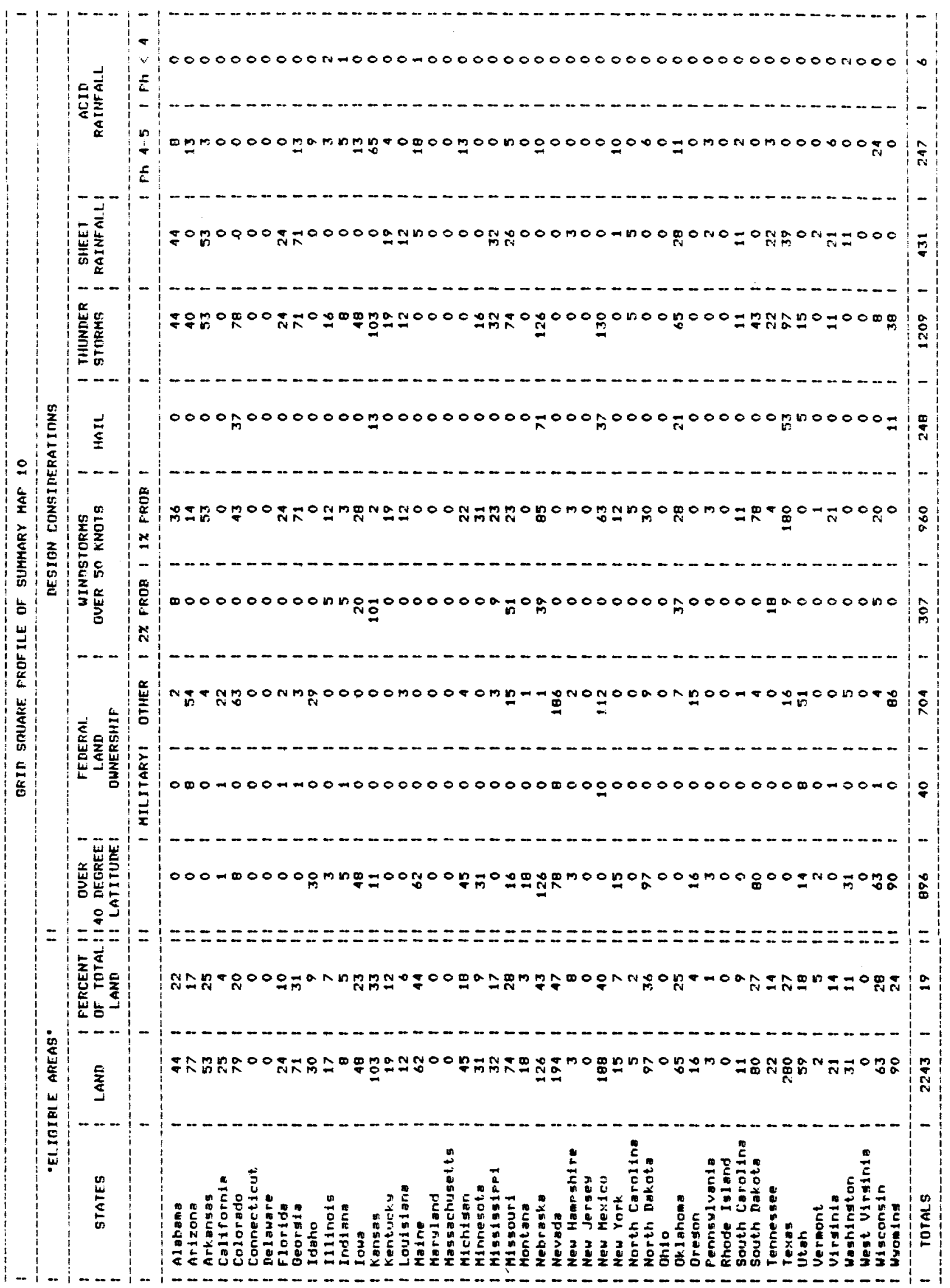


SUMMARY MAP 11

This map was assembled by adding Summary Map 7 with Seismic Hazards (both variables). 


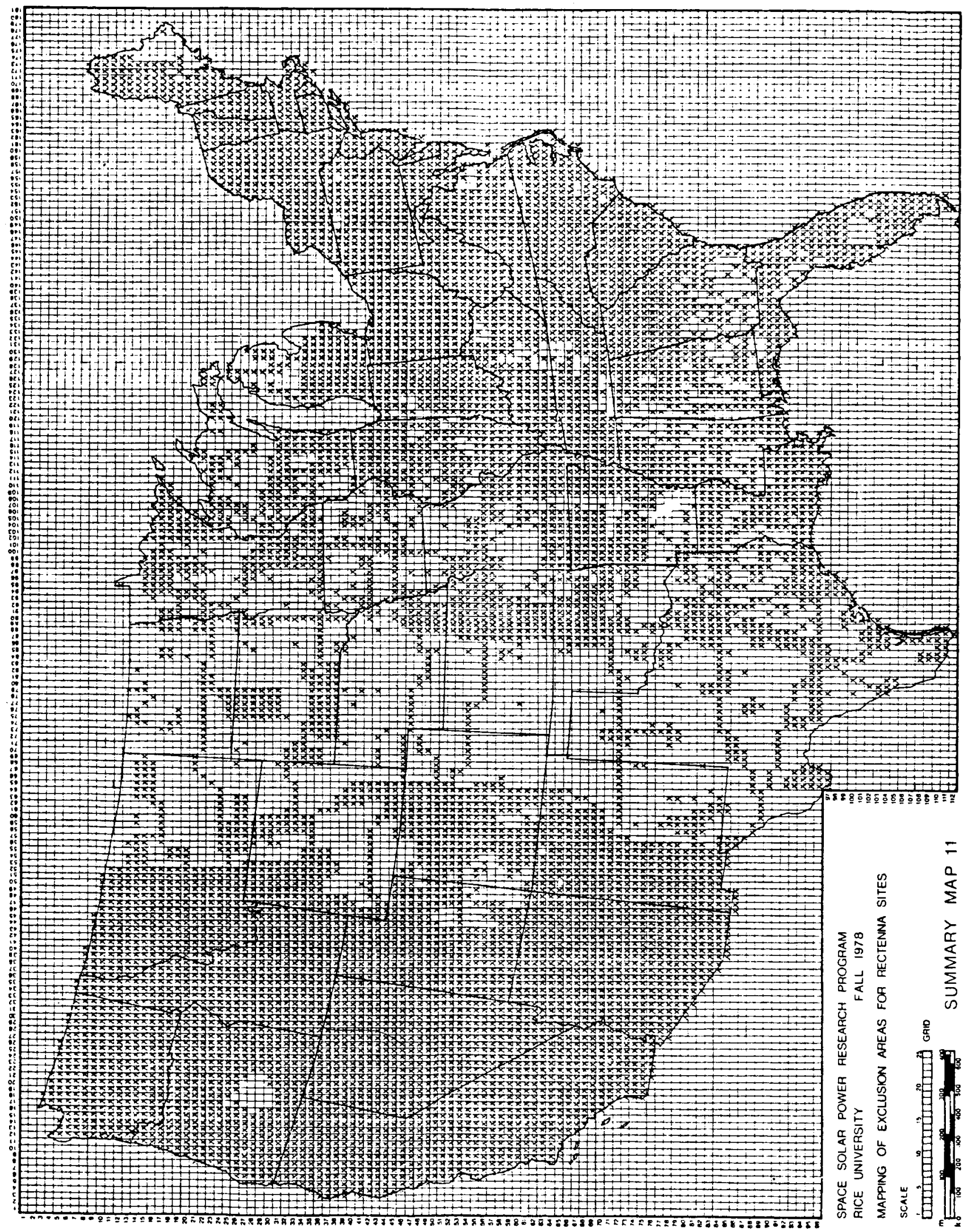




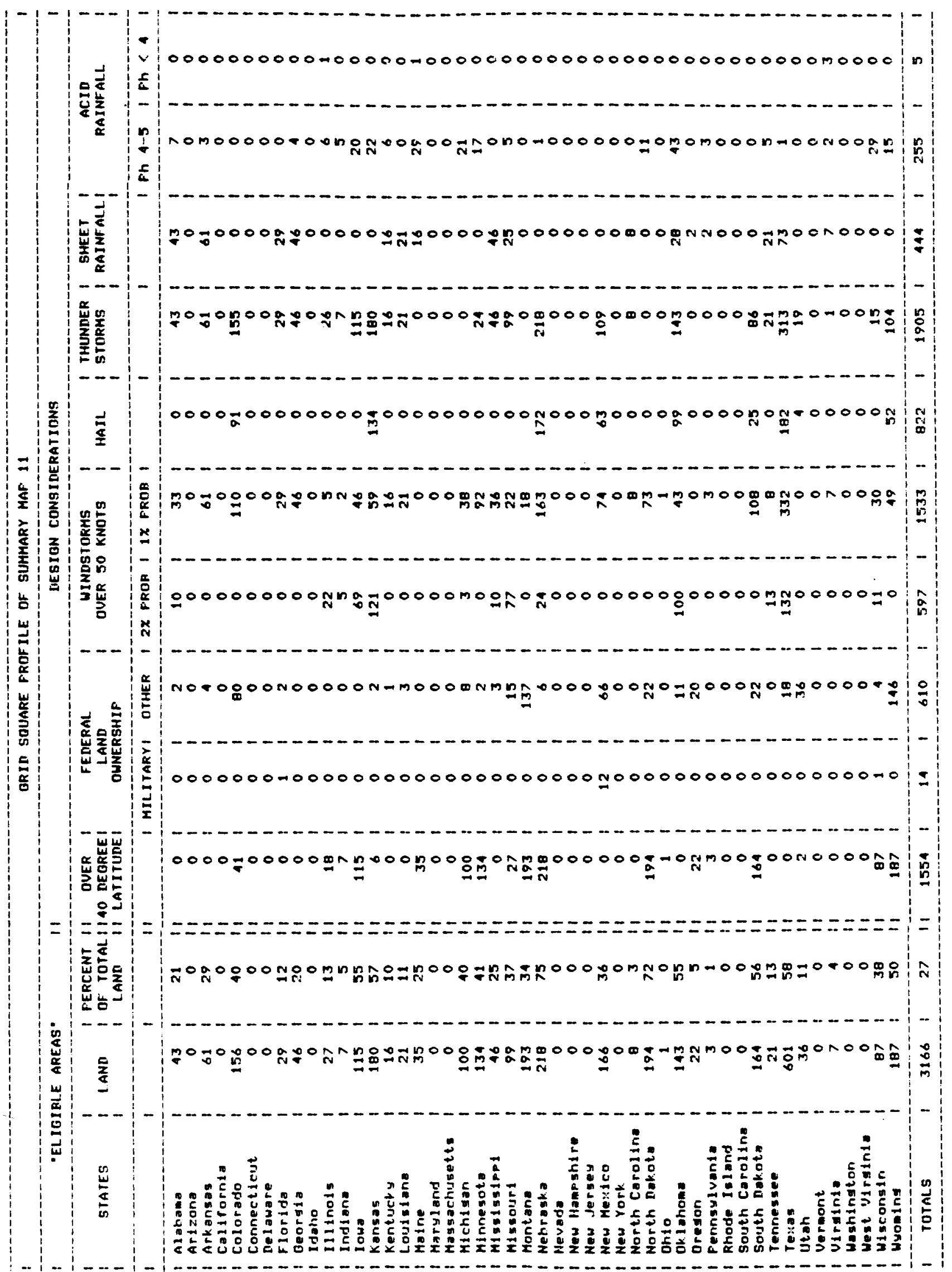


V. CONCLUSIONS AND SUGGESTIONS FOR FUTURE WORK

At this point in time, no firm conclusions are offered by the Rice University team regarding potential sites. There are several reasons for not making these conclusions. First, each of the synthesis maps needs to be considered in more detail to more adequately understand the spatial impacts of the variables and combinations of variables. Secondly, additional syntheses need to be performed to see the effects of certain other combinations of variables. However, Summary Maps 7, 8 and 10 appear to be most meaningful of the maps created under this contract.

It must be said that "eligible" areas do emerge under from the summary combinations of variables, but the need exists for more information about these "eligible" areas before specific sites may be suggested. The conclusion that a rectenna could be located in any of these "eligible" areas is clearly not warranted. A major concern of the research team is that these summary maps will be taken out of context and be set forth as identifying preferred sites without any accompanying information indicating the data collection methodology and limitations.

The approach taken does appear to be well adapted to these types of large scale, locational problems. The overall framework established in this study is highly adaptible, and both the scale and the number of variables considered can be altered.

With respect to the overall availability of 3 million acres of land, two distinct issues must be identified. First, there is the issue of whether or not 3 million available acres exist in the proper geographic region of the United States. Secondly, there is the issue of whether the United States is willing to dedicate such available land to receiving antennas. Although 3 million acres of land represents less than $0.2 \%$ of the total land area of the United States, it is important to note that in 1969, urban land uses were determined to utilize $35 \mathrm{million}$ acres. In other words, 60 rectenna sites would represent almost $9 \%$ of the total 
land area devoted to urban uses in 1969.

Finally, it should be noted that the entire project was completed in a very short time frame and that the project team has not had much time to carefully study the maps and data profiles. Therefore, our conclusions concerning future work may be more meaningful than our "conclusions" from the analytical exercise.

There are at least three types of future work that we feel should be pursued. The first involves refinement and enlargement of the data base at the United States level. The second involves research into identified "eligible" areas and the third involves the development of varying resolution data base that utilizes existing Federal government data management sys tems and Landsat imagery.

Initially, a number of the maps set forth in Section III need to be checked and perhaps altered. In particular, national grasslands need to be added to the national forests map, the topography unacceptable map needs to be considered in more detail, the windstorms map may be supplemented by other data, etc. In other words, while this initial effort collected some very good information in a very short time frame, additional information can be added to make this system more functional with respect to the rectenna siting requirements. Additionally, a more detailed description and analys is of the rectenna design should be required.

Second, detailed research should be conducted in the "eligible" areas so that siting recommendations could be made on a state by state or region by region basis. An initial decision at this stage would be to determine which "eligible" areas map should be used. Our recommendation would be to alter the national maps according to the first future work suggestion and to then rerun syntheses using this new information. At this time, Summary Maps 7 and 8 would seem to be prime candidates for determining "eligible" areas, but a decision should not be made at this time concerning which "eligible" areas map to consider. 
Third, the approach utilized in the analysis of the "eligible" areas would be the same as the approach utilized to study the United States. In other words, these areas would be analyzed in detail with respect to selected variables of concern and additional information would be gathered at this second level for certain variables not mapped at the national level. Of particular importance at this scale of analysis would be state and local recreational areas, wetlands, major non-interstate highways, "prime" agricultural lands and population concentrations, to mention a few. Then, the overlay or sieve analysis procedure would be performed on these "eligible" areas, thereby excluding certain portions of these areas from further consideration. In this manner, information that would be directly relevant to site determinations could be generated.

Inherent in this second level of sieve analvsis is the need for more detailed spatial data. While research will need to be undertaken to obtain spatial information for certain of these variables, a major option that should be pursued would be to identify the degree of compatibility between the Rice University data system and several ongoing data management efforts at the federal level. In particular, the Department of Energy is currently establishing the Energy-Environment Atlas which should be coded and ready to use in the near future. Additionally, the United States Geological Survey is also establishing high resolution computerized land use data base, with a substantial portion of the United States already having been mapped. This Soil Conservation Service is following the U.S.G.S. mapping effort with interpretative soils data and prime agricultural land designation. Finally, the U. S. Fish and Wildlife Service's Wetlands Inventory is also supposed to be established as a computer data system. With all of these data systems in existence, an obvious area of future research would be to determine how these systems could be integrated at the output level and to determine how a varying resolution spatial data base could be established. In short, computer-assisted analysis of existing computerized data should be pursued as a major aspect of future work. 
Several other alternatives should be considered in future work. First, no types of analysis besides overlay or sieve analysis have been perfoemed on the data presented in this report. At this time, it is difficult to state which additional types of analysis should be performed, if any, but the opportunity exists to more fully explore the information existing at this time. Second, those grid squares that are excluded on the basis of a single variable could be examined in more detail to determine which variable excludes that cell and to determine the limits of confidence ascribed to that variable. While this is not suggested throughout the United States, this procedure could be useful in certain regions with few sites.

A final alternative for future work would be to integrate the legal/ regulatory study with this exclusion mapping effort. There are several reasons why this combination could be useful. First, the analysis of "eligible" areas will directly raise issues regarding state and local environmental policies. Second, the work pursued in this siting study has somewhat of a legal orientation that could be expanded in a future phase. Therefore, while the combination of the legal/regulatory research is not essential, it would certainly be compatible and perhaps desirable. 
APPENDIX A 


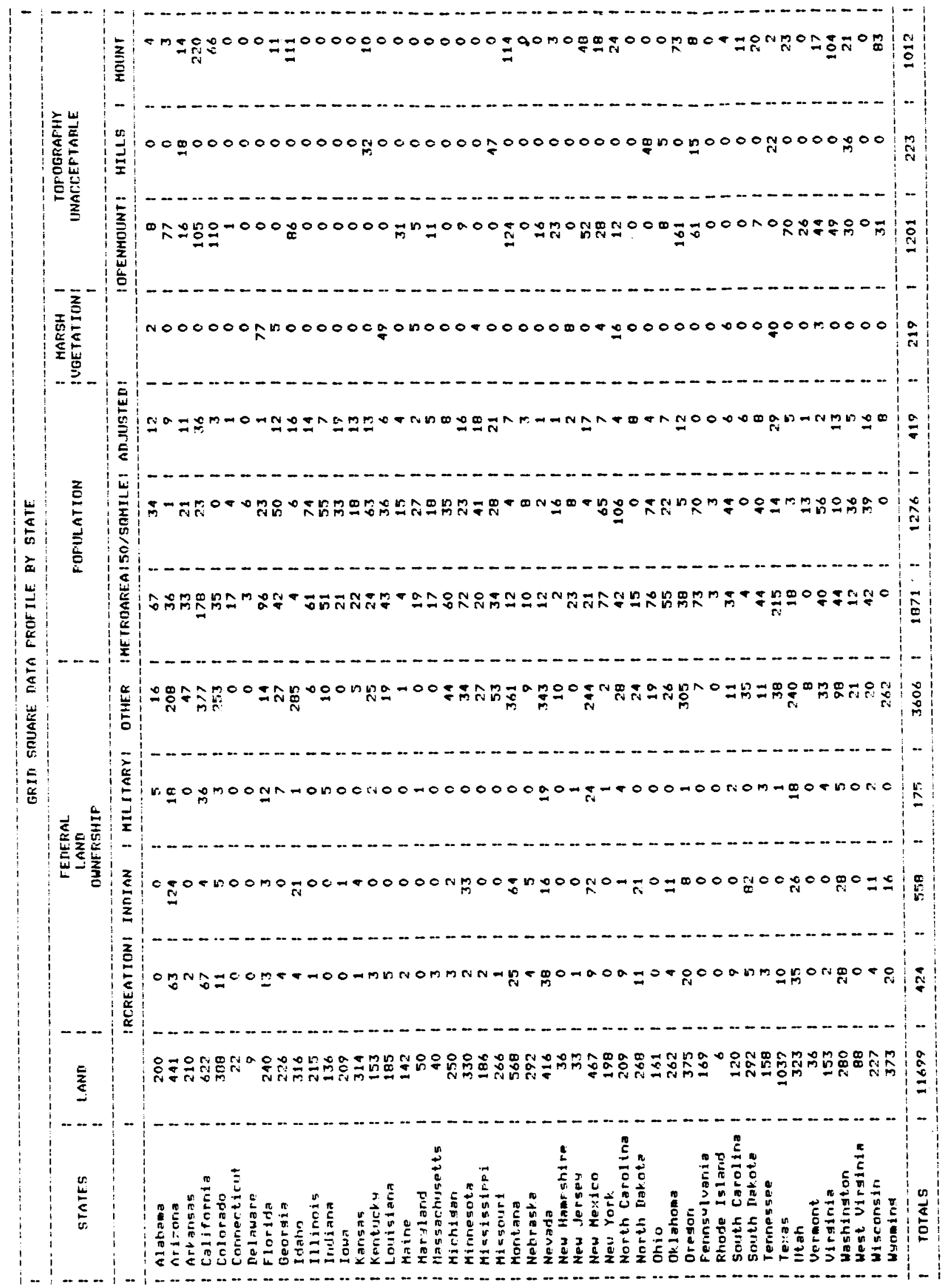




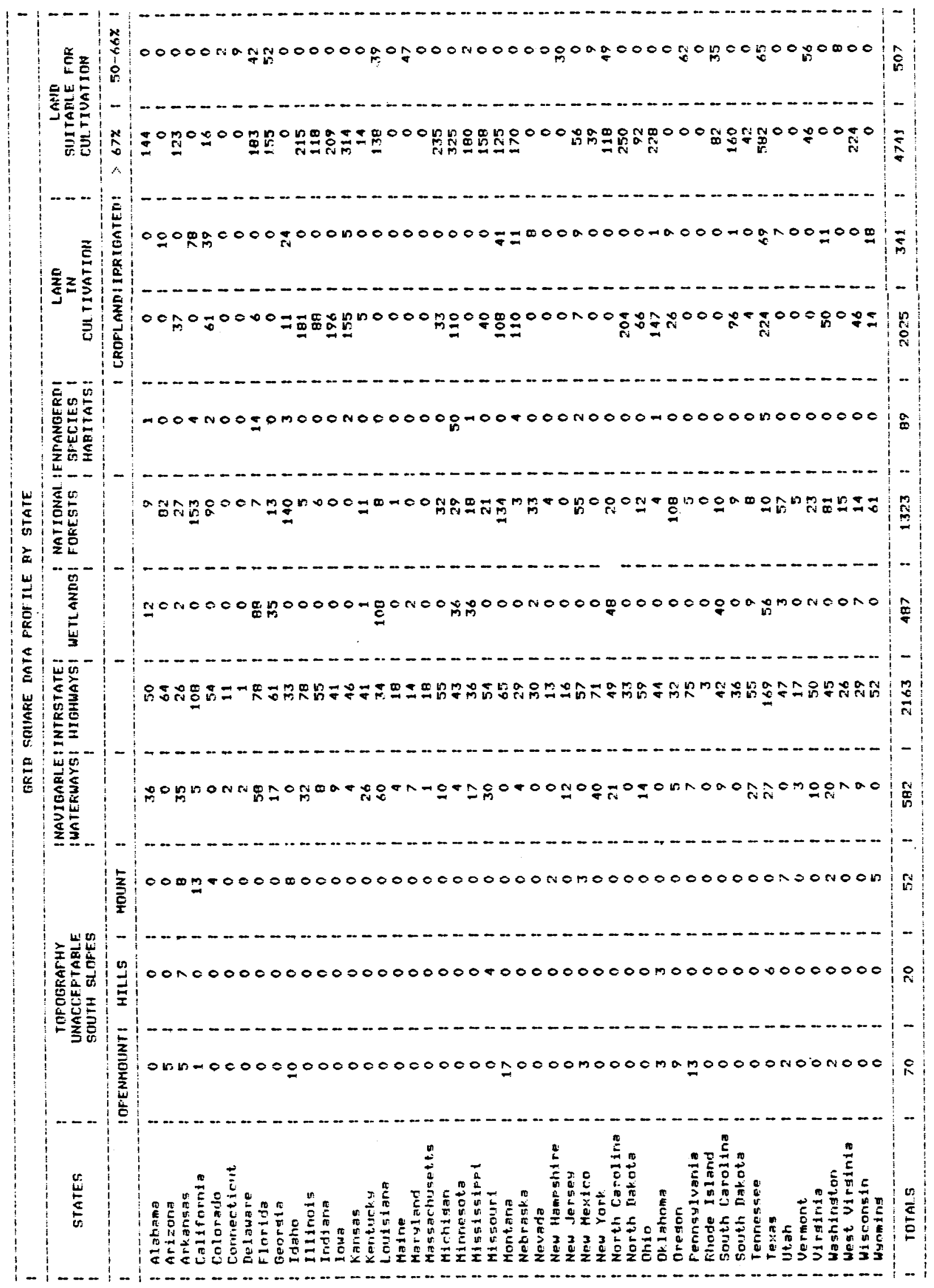




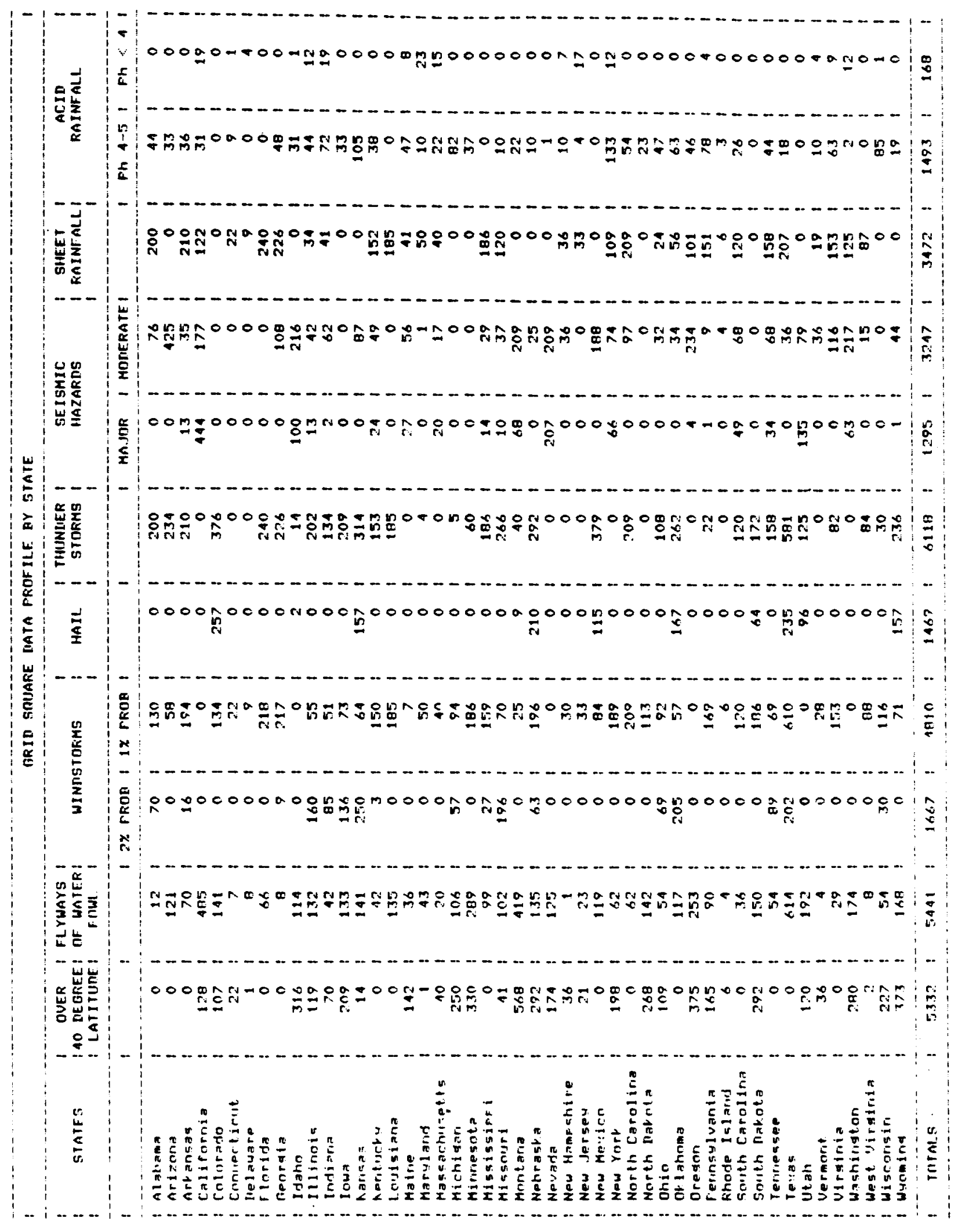


APPENDIX B

The two maps shown in this Appendix are Summary Maps with hand-drawn overlays showing the Interstate Highway System and the Power Distribution System of the United States. 


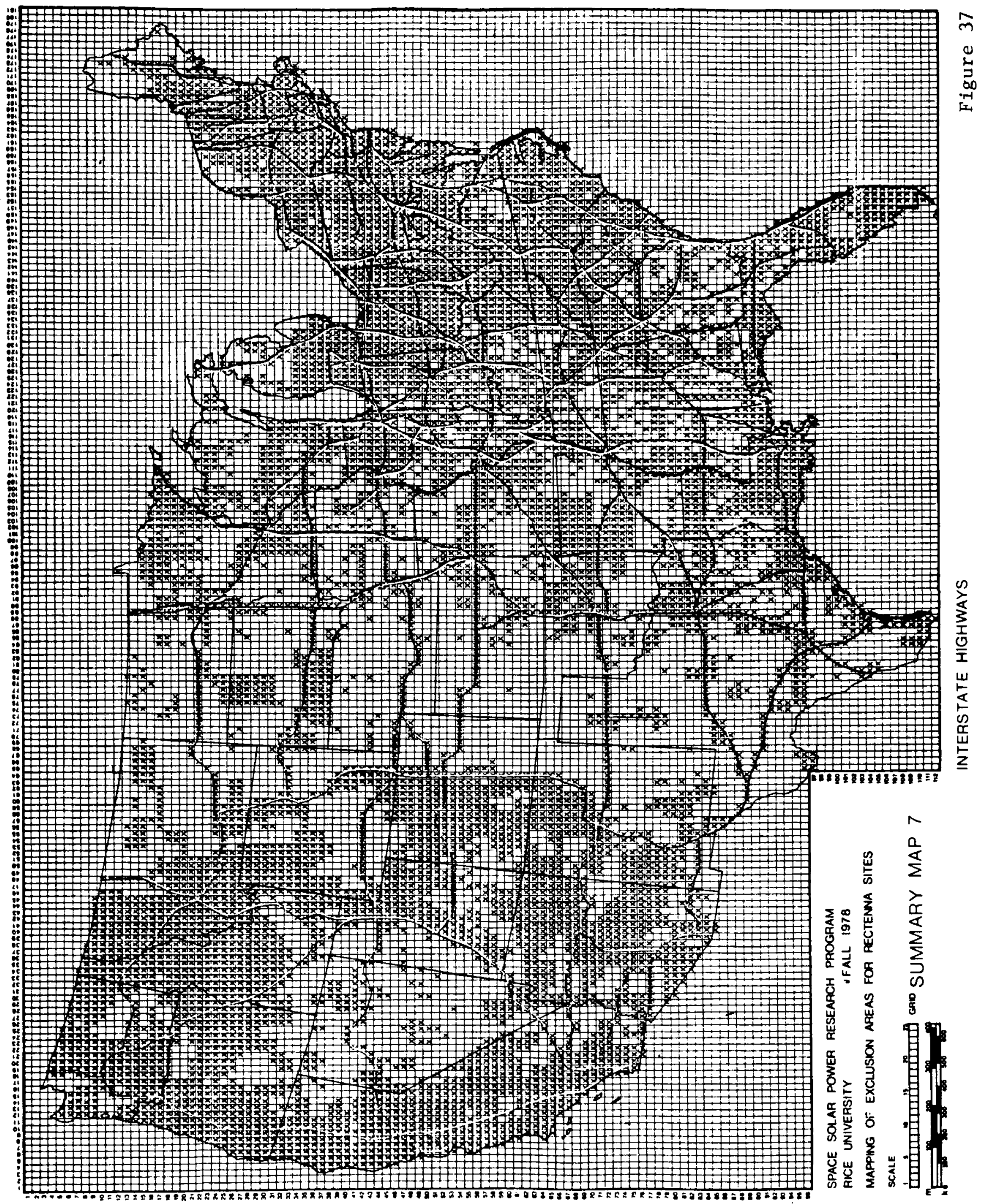




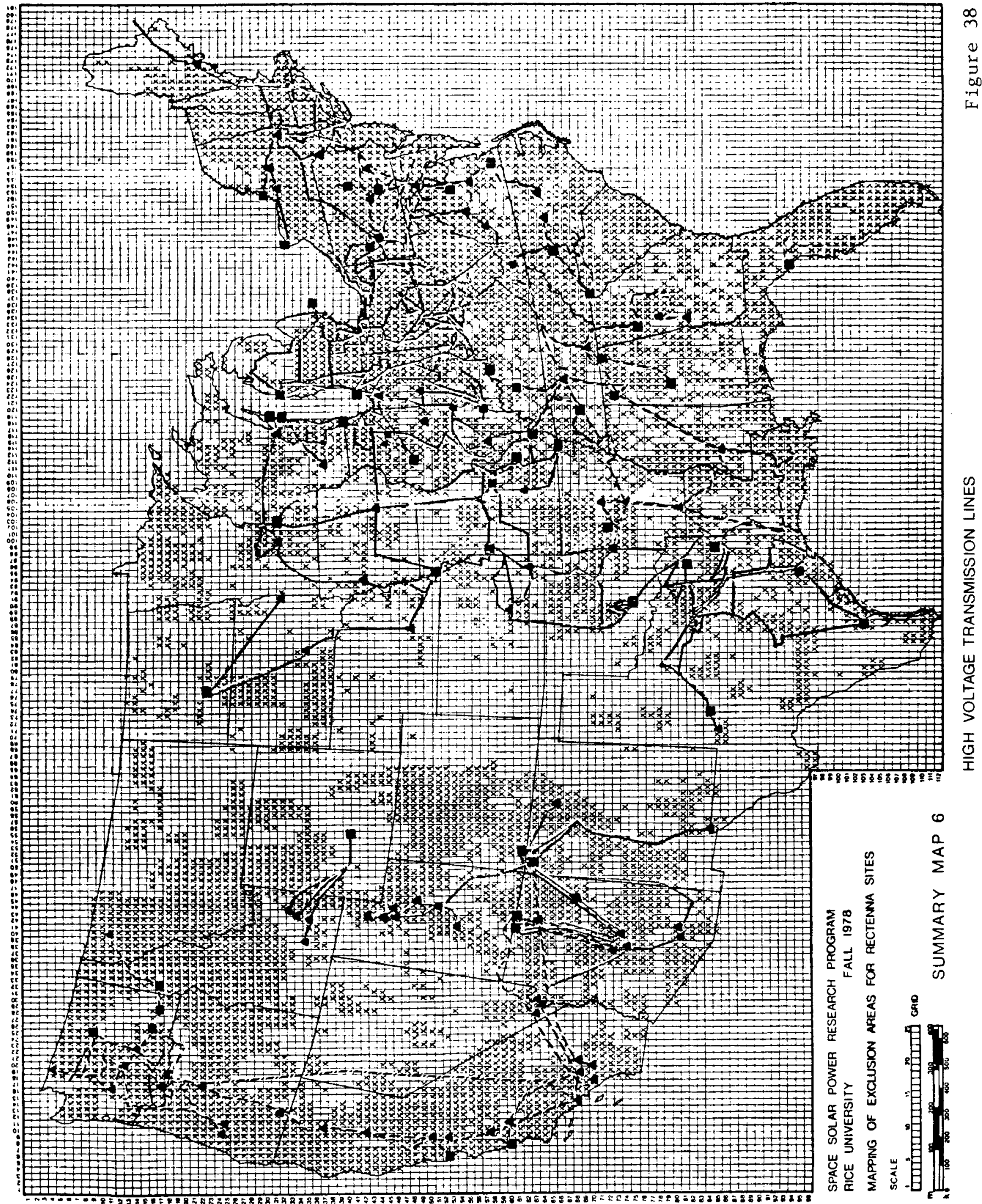


Selected References (Does not include Satellite Power System References See Kotin Report on Resources)

1. Alexander $C$. and M. Manheim. The Use of Diagrams in Highway Route Locations. Pub1. No. 61. Dept. of CiviT Eng. M.I.T., Cambridge, Mass. March, 1962.

2. Cargo, D. and B. Mallory. Man And His Geologic Environment. 2nd Ed. Addison Wesley Publ. Co. MenTo Park, Ca. 1977.

3. Clarendon Press. Oxford Regional Economic Atlas: United States and Canada. Clarendon Press. 0xford. T967.

4. Cohen, S. and S. C. Pieper. The Speakeasy - 3 Reference Manua 1-Level Mu. Report AHL-8000 Rev 2. Argonne Nat. Laboratories. Chicago, ITI. Augus $\bar{t}$ 1977.

5. Council on Environmental Quality. Environmental Quality: 1976 - The Seventh Annual Report of the Counc iT on Environmental Quality, Council on Environmental QuaTity. Washington, D. C. 1976.

6. Federal Register, Vol. 42. P. 47840. September ??, 1977.

7. Hopkins, L. D. "Methods of Generating Land Suitability Maps: A Comparative Evaluation". Amer. Inst. of Planners J., October, 1977.

8. Krauskopf, T. M. and D. C. Bunde. "Evaluation of Environmental Impacts Through Computer Modelling Process". in R. Ditton and T. Goodale, eds. Environmental Impact Analysis: Philosophy and Methods. Univ. of Wisconsin. Madison, Wisconsin. 1972 .

9. Lewis, P. H. Recreation In Wisconsin. State Department of Resource Development. Madison, Wisconsin 1962.

10. McHarg, I. Design With Nature. The Natural History Press. Garden City, New York. 1967.

11. Rowe, P. G. et al. Principles For Local Environmental Management. Ballinger Press. Cambridge, Mass. $\overline{1978 .}$

12. Rowe, P. G. and A. DeLeon-Fajardo. "LUFSAT-Land Use Feasibility Study Analysis Technique". DMG Journal. Vol. 6, No. 4. 1973.

13. Schlicting, R. D. "Data Base Manipulation In Speakeasy". Speakeasy Center. Argonne National Laboratories. Argonne Illinois. Unpublished, 1977.

14. Steinetz, C., et a]. "Hand-Drawn Overlays: Their History and Prospective Uses". Landscape Architecture. September, 1976.

15. "The Amateur Scientist". Scientific American 230:122-127 (June, 1974).

16. United States Department of Agriculture. "Perspectives On Prime Lands". Background Papers For Seminar On The Retention of Prime Lands. July, 1975. 
17. "Recommendations on Prime Lands". Prepared at the Seminar on the Retention of Prime Lands. July', 1975.

18. , "2/3 of Our Land: A National Inventory". Soil Conservation Service. Program Aid \#984. Washington, D. C. 1971.

19. United States Department of the Census, Geography Division. Assorted Maps. 1978.

20. United States Department of Commerce, Environmental Data Service. Climatic Atlas of the United States. Reprinted by the National Oceanic and Atmospheric Administration, Washington, D. C., 1977.

21. U. S. Department of Commerce, National Oceanic and Atmospheric Administration. Climates of The United States. National Oceanic and Atmospheric Administration. Washington, D. C.

22. United States Geological Survey. National Atlas of the United States of America. United States Department of the Interior. Geological Survey. Washington, D. C., 1970.

23. U. S. Department of the Interior, "Wetlands of the United States". U. S. Fish and Wildlife Service. Washington, D. C. 1955.

24. Ward, J. and D. Grant. "CASAT: Computer Assisted Space Allocation Technique". Proc. Kentucky Workshop On Computer Applications to Environmental Design. Lexington, Ky., 1970. 